\title{
Synthetic approaches toward sesterterpenoids
}

\author{
Daniel T. Hog, Robert Webster and Dirk Trauner* \\ Received 12th January 2012 \\ DOI: 10.1039/c2np20005h
}

Covering: up to December 2011

Sesterterpenoids account for many bioactive natural products, often with unusual and complex structural features, which makes them attractive targets for synthetic chemists. This review surveys efforts undertaken toward the synthesis of sesterterpenoids, focusing on completed total syntheses and covering $c a .50$ natural products in total.

1 Introduction

2 Linear sesterterpenoids

3 Monocarbocyclic sesterterpenoids

3.1 Manoalide

3.2 Diumycinol

3.3 Ceriferic acid derivatives

4 Bicarbocylic sesterterpenoids

4.1 Terpestacin

4.2 Dysidiolide

4.3 Miscellaneous bicarbocyclic sesterterpenoids

5 Tricarbocyclic sesterterpenoids

5.1 Gascardic acid

5.2 Ophiobolins

5.3 Ceroplastins

5.4 Miscellaneous tricarbocyclic sesterterpenoids

6 Tetracarbocyclic sesterterpenoids

6.1 Cerorubenic acid-III

6.2 Miscellaneous tetracarbocyclic sesterterpenoids

7 Pentacarbocyclic sesterterpenoids: Retigeranic acid

8 Conclusions

9 Acknowledgements

10 References and notes

\section{Introduction}

Ever since Komppa's pioneering work on camphor, ${ }^{1}$ terpenoids (i.e. regular terpenes and their partially degraded congeners) have played a prominent role in the development of organic synthesis. Many key concepts in organic chemistry, such as Wagner Meerwein rearrangements, Diels Alder reactions, or polyolefin cyclizations, were first explored with members of this large natural product class. As the power of organic synthesis

Fakultat fur Chemie und Pharmazie, Ludwig Maximilians Universitat Munchen, and Munich Center for Integrated Protein Science, Butenandtstr. 5 13,81377 Munchen, Germany.E mail: Dirk.Trauner@ lmu. de grew, increasingly complex terpenoids have been targeted and their successful total syntheses must now number in the hundreds.

Within the terpenoid family, sesterterpenoids probably form the smallest class, comprising less than a thousand known compounds. They consist of two and a half (sester in Latin) terpene units, which for historic reasons were defined as pieces made of ten carbons. As such, sesterterpenoids contain 25 (or slightly fewer) carbon atoms. They have been recovered from a variety of sources, including lichens, higher plants, fungi, insects and sponges, often showing significant biological activity e.g. as anti inflammatory or cytotoxic agents.

With their comparatively large size, structural complexity, and molecular diversity, sesterterpenoids represent highly attractive targets for total synthesis and they have spurred many elegant synthetic approaches. These are the subject of the present review, which focuses specifically on the synthesis of sesterterpenoids rather than their isolation, structure and biological evaluation. We refer to the review series sesterterpenoids ${ }^{2}$ in this journal and to similar accounts ${ }^{3}$ for details on these aspects. Furthermore, we will limit our discussion to members of the class that have attracted substantial attention from the synthetic community and will largely ignore compounds where little or no synthetic work has been reported.

\section{Linear sesterterpenoids}

The natural products of this subclass possess a linear carbon chain, which in most cases has been partially oxidized. Such an oxygenation often leads to cyclization, resulting in furans and/or lactones. In contrast to the other sesterterpenoid subclasses, no additional $\mathrm{C} \mathrm{C}$ bond is formed during biosynthesis. Although numerous linear sesterterpenoids have been reported, very few have been targeted by synthetic chemists to date.

In 1998, Romo and co workers reported the total synthesis of (+) okinonellin B (1) (Scheme 1) ${ }^{6,7}$ Retrosynthetic bifurcation of 


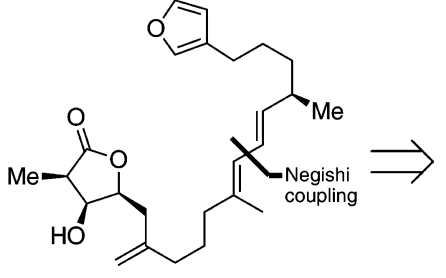

(+)-okinonellin B (1)

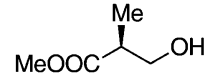

(S)-Roche ester (2)

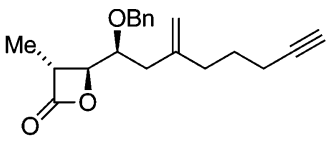

3
Scheme 1 Romo's disconnection of (+) okinonellin B. Bn benzyl.

the natural product via Negishi coupling allowed for its assembly in a convergent manner. A $\beta$ lactone $\mathbf{3}$ was employed to address the stereoselective synthesis of the highly substituted $\gamma$ butyro lactone within okinonellin B (1). The absolute configuration of the isolated allylic stereocenter bearing a methyl group origi nated from the commercially available $(S)$ Roche ester (2). In 2001, Norizuki and co workers ${ }^{8}$ synthesized ( ) idiadione (4) ${ }^{9}$ starting from $(S)$ citronellal, establishing the single stereogenic center to be $(S)$ configured (Fig. 1). Another linear fur anosesterterpenoid, (18S) variabilin $\mathbf{( 5 ) ^ { \mathbf { 1 0 } }}$ was prepared effi ciently by Yoda et al. in $2004,{ }^{11}$ utilizing a lipase catalyzed asymmetric desymmetrization to install the sole stereocenter. Recently, Goméz and Fall accomplished the enantioselective synthesis of $(+)$ palinurin (6), which was found to act as a non competitive inhibitor of GSK $3 \beta$, a kinase implicated in $\mathrm{Alz}$ heimer's desease. ${ }^{12,13}$ They achieved the synthesis via the chiral auxiliary controlled diastereoselective alkylation of a tetronic acid derivative and a series of standard olefinations to install the

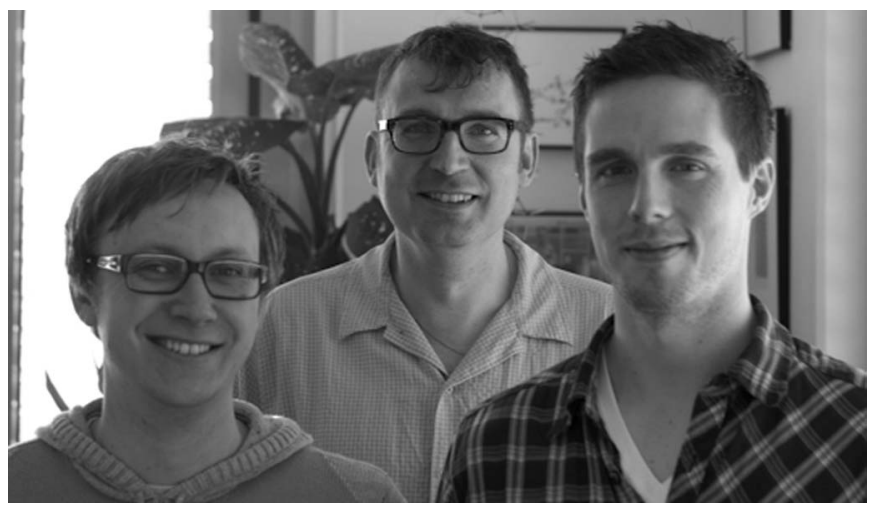

From left to right : Daniel T. Hog, Dirk Trauner and Robert Webster.

Robert Webster was born in Saskatoon, Saskatchewan, Canada (1981). In 2004, he graduated from the University of Saskatch ewan with a B.Sc. in chemistry (great distinction). Opting to continue his studies at the University of Toronto, where his work focused on terpenoid total synthesis and asymmetric rhodium catalyzed reactions, he earned his Ph.D. in 2010 under the super vision of Professor Mark Lautens. He is currently an Alexander von Humboldt postdoctoral fellow exploring biomimetic natural product total synthesis in the laboratories of Professor Dirk Trauner at the LMU München. double bonds with the required configurations. Similar to the synthesis of okonellin B (1), the isolated allylic stereogenic center bearing a methyl group was incorporated starting from the $(R)$ Roche ester ent (2).

Moenocinol (7) ${ }^{14}$ is an achiral sesterterpenoid alcohol isolated as a hydrolysis product of the antibiotic moenomycin A, which is produced by various Streptomyces strains (Fig. 1). ${ }^{15}$ Numerous attempts to synthesize moenomycin A and its components have been reported, ${ }^{16,17}$ including several syntheses of moenocinol (7) itself by the groups of Tschesche, ${ }^{18}$ Grieco, ${ }^{19}$ Kocienski, ${ }^{20}$ Coates, ${ }^{21}$ Welzel, ${ }^{22}$ Schmidt, ${ }^{23}$ Yang $^{24}$ and Hilt. ${ }^{25}$ This work has already been thoroughly reviewed elsewhere, ${ }^{17}$ and consequently will not be elaborated upon here.

\section{Monocarbocyclic sesterterpenoids}

\subsection{Manoalide}

The sesterterpenoid $(+)$ manoalide $(\mathbf{8})$ was first isolated, along with a number of structurally similar metabolites, in the early 1980s by de Silva and Schröder from the Pacific sponge Luffar iella variablis (Fig. 2). ${ }^{26}$ Although its structure is relatively simple, bearing only one defined stereogenic center, manoalide (8) has attracted substantial attention from synthetic chemists. This is likely due to the fact that manoalide (8) is a potent and irre versible inhibitor of phospholipase $\mathrm{A}_{2}$ : the enzyme that catalyzes arachidonic acid release from membrane bound phosphogly cerides, resulting in the formation of pro inflammtory factors. ${ }^{27}$ In 1985, Katsumara et al. reported the first racemic synthesis of manoalide (8), ${ }^{28}$ which was followed by six further syntheses of the racemate by the groups of Garst, ${ }^{29} \mathrm{Katsamura}^{30}{ }^{30} \mathrm{Kocienski}^{31}$

Daniel T. Hog was born (1984) and raised in Freiburg im Breis gau, Germany, before moving to Münster to study chemistry (2004). After a research internship with Professor Antonio M. Echavarren at ICIQ, Tarragona, Spain, he conducted his Diploma research under the supervision of Professor Martin Oestreich at WWU Münster. In 2009, he joined the laboratories of Professor Dirk Trauner at LMU München as a graduate student. He is currently pursuing natural product synthesis of sesterterpenoids, supported by a scholarship from the Fonds der Chemischen Industrie.

Dirk Trauner was born in Linz, Austria. After studying biology and then biochemistry at the University of Vienna, he joined the group of Professor Johann Mulzer at the Free University of Berlin to pursue natural product synthesis. In the late 1990s, he was a postdoctoral fellow with Professor Samuel J. Danishefsky at the Memorial Sloan Kettering Cancer Center in New York City. In 2000, he joined the University of California, Berkeley, where he rose through the ranks to become an Associate Professor of Chemistry. In 2008, he moved to the University of Munich, where he currently resides as a Professor for Chemical Biology and Genetics. 
and Hoffmann. ${ }^{32}$ However, only two enantioselective routes toward manoalide $(\mathbf{8})$ have been reported to date.

Almost twenty years after its isolation, Sodano and co workers succeeded in the first asymmetric synthesis of (+) manoalide (8) (Scheme 2). ${ }^{33}$ To this end, they prepared alkyl iodide $\mathbf{1 0}$ starting from $\beta$ ionone (9) and improved the yields of the sequence leading to this compound previously reported by Hoffmann. ${ }^{32}$ Sodano et al. envisaged utilizing an enantioselective aldol reaction to install the single stereogenic center. Thus, subjecting 3 furaldehyde (15) and silyloxydiene 11 to a mixture of $\mathrm{Ti}(\mathrm{O} i \mathrm{Pr})_{4}$ and $(R)$ BINOL (known as Sato's procedure) gave the corresponding aldol product $(88 \% e e)$, which was subse quently converted into ester $\mathbf{1 2}$ by microwave irradiation in $\mathrm{MeOH}$. This intermediate was then alkylated with homoallyl iodide 10, requiring the presence of tetrabutylammonium salt $\mathbf{1 6}$ as a phase transfer catalyst to furnish, after diastereoselective ketone reduction, furan 13. An ensuing three step protocol generated lactone $\mathbf{1 4}$ via ester hydrolysis, acetylation with concomitant lactonization and finally elimination of acetate in the presence of DBU. Having obtained the corresponding lactol by reduction with DIBAL $\mathrm{H}$, Sodano et al. finally accessed $(+)$ manoalide $(\mathbf{8})$ by photooxygenation of the furan moiety.

Several years later, in 2003, Kocienski et al. reported the second enantioselective synthesis of $(+)$ manaolide (8) (Scheme 3). ${ }^{34}$ In contrast to Sodano's work, the single stereogenic center was installed using a Sharpless kinetic resolution. However, Kocienski opted to utilize the same homoallyl iodide $\mathbf{1 0}$ featured in Sodano's synthesis, that was also prepared from $\beta$ ionone (9), but using a different eight step protocol. Their second building block was derived from furyl aldehyde 17, which was reacted with propargyl magnesium bromide to afford racemic prop argylic alcohol 18. Exposure of the alcohol to Sharpless asymmetric epoxidation conditions afforded the desired $(R)$ configured alcohol 18 in $41 \%$ yield. Successive Mo catalyzed cycloisomerisation in the presence of $\mathrm{Bu}_{3} \mathrm{SnOTf}$ led to vinyl stannane 19, the required intermediate for their second key step: a $\mathrm{Cu}$ mediated 1,2 metalate rearrangement. For this purpose,

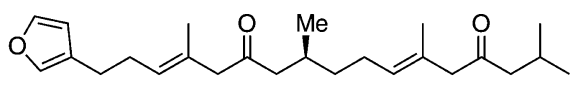

(-)-idiadione (4)
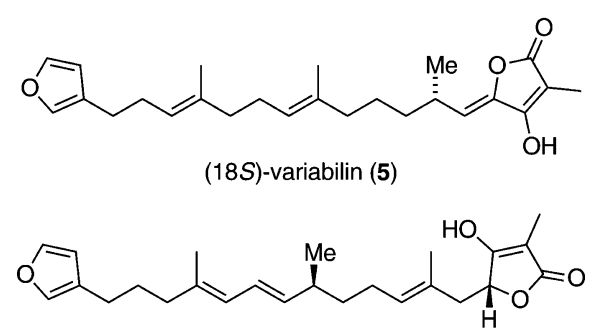

(+)-palinurin (6)

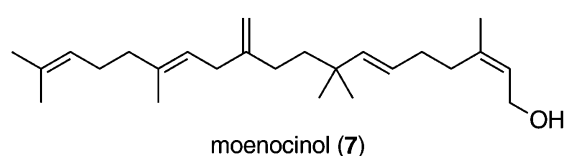

Fig. 1 Molecular structures of successfully synthesized linear sesterterpenoids.<smiles>CC1=C(CC/C(C)=C/CCC2=CC[C@@H]([C@H]3CC(=O)O[C@@H]3O)O[C@H]2O)C(C)(C)CCC1</smiles>

(+)-manoalide (8)

Fig. 2 The molecular structure of the sesterterpenoid (+) manoalide.

exposure of stannane $\mathbf{1 9}$ to $s \mathrm{BuLi}$ generated the corresponding vinyl lithium species, which was then added to mixed cuprate $\mathbf{2 1}$ previously prepared from homoallyl iodide 10, $t$ BuLi and 1 pentynylcopper. This procedure triggered the rearrangement to form an intermediate vinyl cuprate species that was quenched with $\mathrm{I}_{2}$ to generate vinyl iodide 20. With this compound in hand, only three steps remained to finish the synthesis: a Pd catalyzed carbonylation yielded a lactone that was subsequently reduced by DIBAL $\mathrm{H}$ to the corresponding lactol. Similar to Sodano's endgame, photooxidation of the furan moiety in the presence of Rose Bengal gave rise to $(+)$ manoalide (8).

Within the synthesis of $(+)$ manoalide (8) Kocienski and co workers took advantage of a 1,2 metalate rearrangement, a methodology, which had been applied earlier in the same<smiles>CC(=O)/C=C/C1=C(C)CCCC1(C)C</smiles>

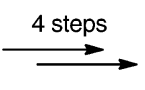<smiles>CC1=C(CC/C(C)=C/CCI)C(C)(C)CCC1</smiles>
9 10

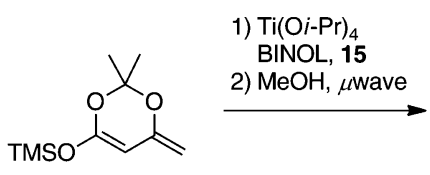

11

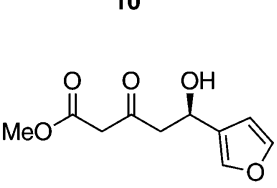

12

1) ester hydrolysis 2) $\mathrm{Ac}_{2} \mathrm{O}$, py 3) $\mathrm{DBU}$
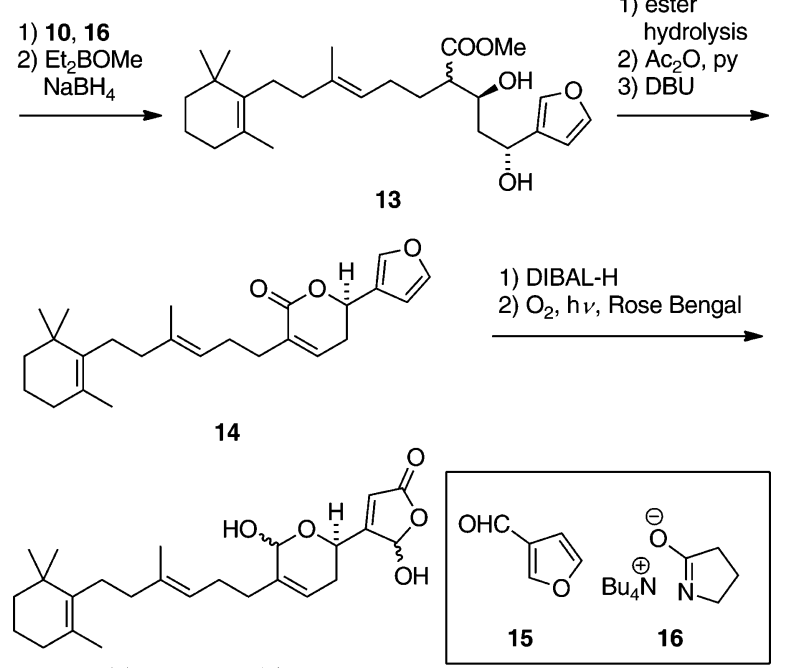

(+)-manoalide (8)

Scheme 2 Sodano's asymmetric synthesis of $(+)$ manoalide. TMS tri methylsilyl, BINOL 1,1' bi(2 naphtol), $\mathrm{Ac}_{2} \mathrm{O}$ acetic anhydride, py pyridine, DBU 1,8 diazabicyclo[5.4.0] undec 7 ene, DIBAL $\mathrm{H}$ diiso butylaluminum hydride. 
laboratories en route to the related natural product luffariolide $\mathrm{E}$ (26) (Scheme 4). ${ }^{35,36}$ The 1,2 metalate rearrangement, the same key step used in Kocienski's synthesis of manoalide (8), was carried out using vinyl stannane 22 and cuprate 27. Treating stannane 22 with $n$ BuLi generated the corresponding organo lithium species, which was then reacted with dialkyl cuprate 27 to form higher order cuprate 23. The latter rearranged with inver sion of the alkene geometry to yield alkenyl cuprate $\mathbf{2 4}$. In contrast to their synthesis of manoalide $(\mathbf{8})$, the sequence was not terminated by quenching with $\mathrm{I}_{2}$, but by direct carboxylation and subsequent esterification to give the $(Z)$ configured alkene $\mathbf{2 5}$ in an overall yield of $48 \%$. Three further transformations gave rise to $(3 R, 4 R)$ luffariolide $\mathrm{E}(\mathbf{2 6})$ in racemic form, but the NMR data did not match that of the isolated natural product. There fore, the authors concluded by chemical correlation to related natural products of known absolute configuration ${ }^{35}$ that natural luffariolide $\mathrm{E}$ (26) possesses the $(3 S, 4 R)$ configuration. More over, Kocienski et al. prepared racemic $(3 S, 4 R)$ luffariolide $\mathrm{E}$ later that year, verifying their conclusion. ${ }^{37}$

\subsection{Diumycinol}

Another compound targeted within this subclass of sesterterpe noids is diumycinol (28) (Fig. 3) ${ }^{38}$ In analogy to its acyclic isomer moenocinol (7) (Section 2), this sesterterpenoid alcohol is a hydrolysis product from moenomycin type antibiotics, more precisely from diumycin. While there was initially some contro versy concerning whether these alcohols truly arise from a terpenoid origin, it has been shown that they are indeed formed via the non mevalonate pathway from a $\mathrm{C}_{10}$ and a $\mathrm{C}_{15}$
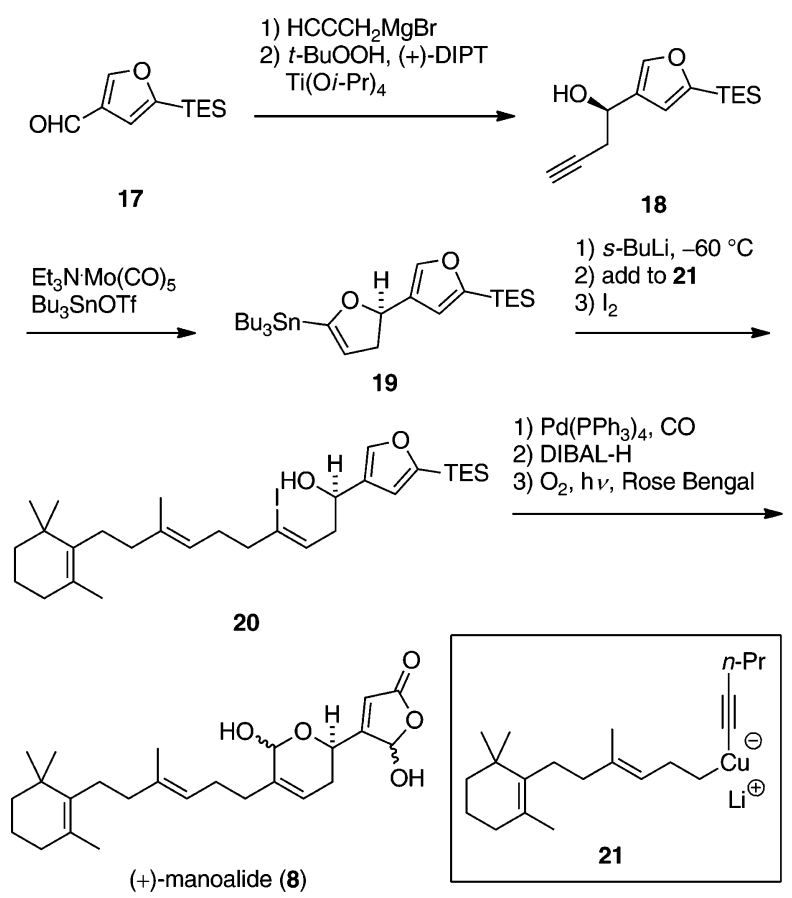

Scheme 3 Kocienski's asymmetric synthesis of (+) manoalide. TES triethylsilyl, DIPT diisopropyl tartrate, DIBAL H diisobutyl aluminium hydride, $\mathrm{Bu}_{3} \mathrm{SnOTf}$ tributylstannyl trifluoromethane sulfonate. precursor. ${ }^{39}$ In contrast to moenocinol (7), however, diumycinol (28) has attracted less attention from synthetic groups and only two racemic syntheses by the groups of Grieco $^{40}$ and Kocienski ${ }^{41}$ have been reported. These findings have recently been reviewed in detail by Wenzel in an overview of syntheses dealing with the transglycosylation step in peptidoglycan biosynthesis. ${ }^{17}$

\subsection{Ceriferic acid derivatives}

A series of macrocyclic sesterterpenoids, including ceriferic acid (29), its methyl ester 30 and ceriferic acid I (32), imbued with a cembrenoid 14 membered ring, were isolated in the late 1970 s from the wax secreted by the Japanese scale insect Cerplastes ceriferus (Fig. 4). ${ }^{42}$ Two groups, namely Kato's and Kodama's, were responsible for the synthesis of ceriferol (31), ${ }^{43}$ ceriferol I (34), ${ }^{44}$ methyl ceriferate I (33), ${ }^{44}$ and the deoxygenated analogue cericerene (35). ${ }^{45}$ None of the above syntheses were asymmetric, so the lone stereocenter (tentatively assigned as $(R)$ by $\mathrm{Naya}^{42 d}$ based on analogy to the optical rotation of related hydrocar bons) has not been unambiguously assigned.

Kato's synthetic work ${ }^{43,45}$ in the early 1980 s was instrumental for elucidating the structures of this sesterterpenoid subclass. Both ceriferol (31) and ceriferol I (34), isomers differing by the position of a double bond, were synthesized starting from ger anylgeranyl acetone (36) (Scheme 5). The key step, a surprisingly efficient and selective Friedel Crafts type macrocyclization of acid chloride 37, was mediated by $\mathrm{SnCl}_{4}$ to close the 14 membered ring and produce $\beta$ chloro ketone 38 in $97 \%$ yield. Elimination of chloride from the side chain of ketone $\mathbf{3 8}$ was unselective, giving a $1: 1$ mixture alkenes that were then
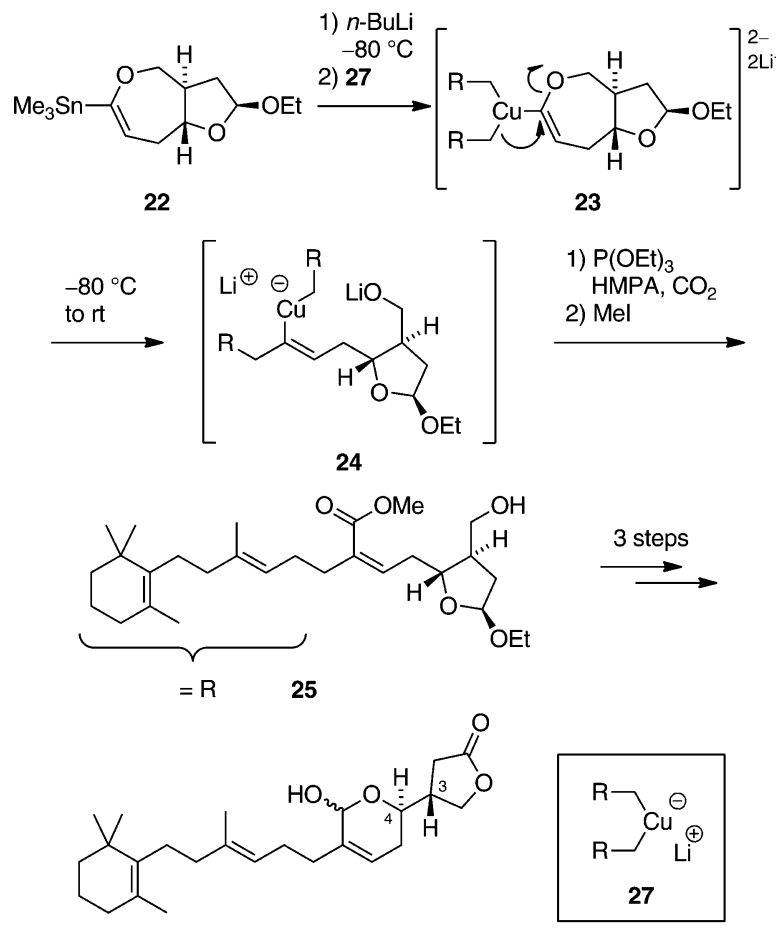

(3R,4R)-luffariolide $\mathrm{E}(26)$

Scheme 4 Mechanistic details of the 1,2 metalate rearrangement: the key step from Kocienski's syntheses of luffariolide E and (+) manoalide. rt room temperature, HMPA hexamethylphosphoramide. 
separated, and each was carried through a sequence of synthetic manipulations to afford racemic ceriferol (31) and ceriferol I (34), respectively.

In 1986, Kodama reported a racemic synthesis of methyl cer iferate I (33) (Scheme 6). ${ }^{44}$ The coupling of allyl bromide 39 and geraniol derived sulfide $\mathbf{4 3}$ under basic conditions furnished dioxolane $\mathbf{4 0}$ that was later desulfurized and deprotected to give aldehyde 41. The side chain was appended using ester 44, and after an eleven step protocol, including a Claisen rearrangement, the cyclization precursor, phosphonate 42, was obtained. Treatment of phosphonate $\mathbf{4 2}$ with $\mathrm{NaH}$ in DME succeeded in Horner Wadsworth Emmons macro cyclization, but gave methyl ceriferate I (33) as the minor double bond isomer along with the undesired cis isomer as the major product (not shown).

\section{Bicarbocylic sesterterpenoids}

\subsection{Terpestacin}

The fungal metabolite terpestacin (45) was first isolated by Oki and co workers in 1993 and its relative configuration was unambiguously confirmed by $\mathrm{X}$ ray crystallography (Fig. 5). ${ }^{46}$ Terpestacin (45) was shown to inhibit the formation of syncytia, i.e. multinuclear cell bodies, which are part of the pathology of HIV infection. This property, in addition to its interesting structural features, which include a 15 membered carbomacro cycle with three trisubstituted olefins and four stereogenic centers, was due cause for capturing the attention of several synthetic groups. ${ }^{47}$ Successful approaches to this target prior to 2007 have been reviewed in some detail by Maimone and Baran. ${ }^{48}$ Nevertheless, this section will present an overview of the topic that includes the additional material published since 2007.

In 1998 Tatsuta et al. reported a racemic synthesis, ${ }^{49}$ and later that year the first enantioselective route to terpestacin (45). ${ }^{50}$ They followed an ex chiral pool strategy, using tri $O$ acetyl D galactal as a starting material (38 linear steps, not shown). Tatsuta's successful syntheses not only verified the structure of terpestacin, but also confirmed its absolute configuration. Since then, four additional syntheses have appeared in literature by the groups of Myers, ${ }^{51}$ Jamison, ${ }^{52}$ Trost $^{53}$ and Tius. ${ }^{54}$

The Myers group successfully completed the asymmetric total synthesis of terpestacin (45) in 2002 in 19 steps and an overall yield of $5.8 \%{ }^{51}$ Their route employed a sequence of diastereo selective enolate alkylations, starting from optically pure amide 47 that was obtained via allylation of $(R, R)$ pseudoephedrine propionamide, exploiting a methodology previously developed in the same laboratories (Scheme 7). Subsequent diaster eoselective iodolactonization led to $\delta$ lactone $\mathbf{4 8}$ with concomi tant cleavage of the chiral auxiliary. The resulting alkyl iodide was transformed into an alcohol, followed by TIPS protection to give lactone 49, thus setting the stage for a second

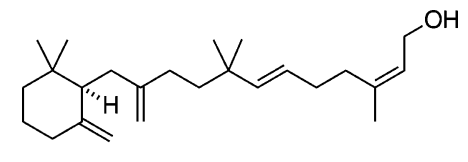

diumycinol (28)

Fig. 3 The structure of the sesterterpenoid alcohol diumycinol.
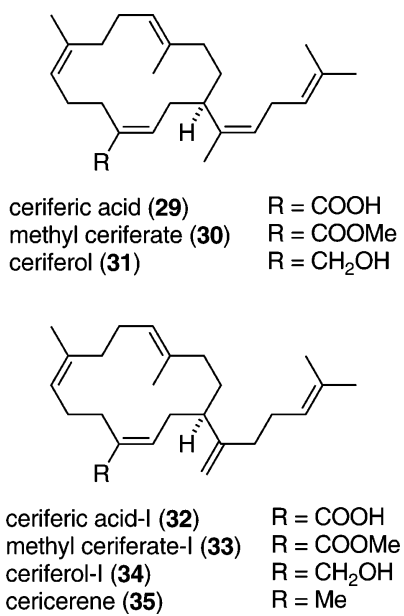

Fig. 4 Molecular structures of ceriferic acid and related sesterterpenoids.

diastereoselective enolate alkylation. The bulky TIPS ether was postulated to direct si face attack from the allylic bromide $\mathbf{5 6}$ to generate the desired quaternary stereocenter in lactone $\mathbf{5 0}$ with good fidelity (dr $8.8: 1)$. Installation of the allylic iodide and cyclopentenone moiety in compound $\mathbf{5 1}$ required four steps and generated the requisite functionality for a third enolate alkyl ation to close the macrocycle. This reaction took place smoothly using Masamune's base in high dilution $(0.002 \mathrm{M})$ and con structed the desired trans fused [13.3.0] bicycle $\mathbf{5 2}$ with accept able stereocontrol (trans: cis $=4.8: 1$ ). An aldol reaction with the (Z) ketene acetal 57, derived from tert butyl propionate, intro duced the desired three carbon chain selectively from the $\beta$ face, giving rise to alcohol 53. Subsequent two step reduction of the ester functionality was accompanied by cleavage of the silyl enol ether and produced a hemiketal that was chemoselectively dehydrated using Martin's sulfurane. Epoxidation of the result ing cyclic enol ether 54 with DMDO and ring opening under acidic conditions yielded the presumed triol $\mathbf{5 5}$ as an interme diate, which collapsed via isomerisation and dehydration when treated with methanolic $\mathrm{K}_{2} \mathrm{CO}_{3}$. Finally, cleavage of the TBS group with $1 \mathrm{~N} \mathrm{HCl}$ in THF gave rise to ( ) terpestacin (45).
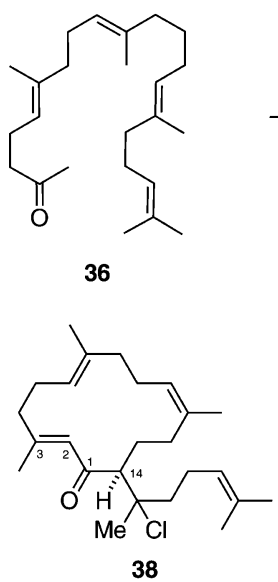
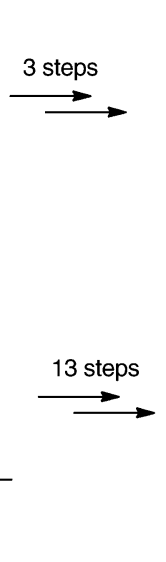
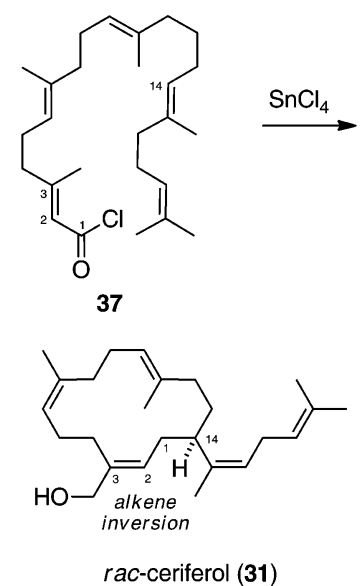

Scheme 5 Kato's acylative macrocyclization approach to ceriferol. 


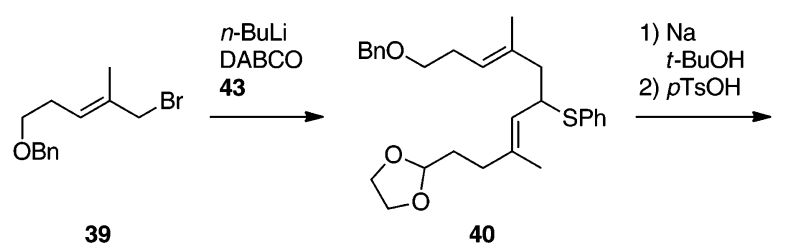

39
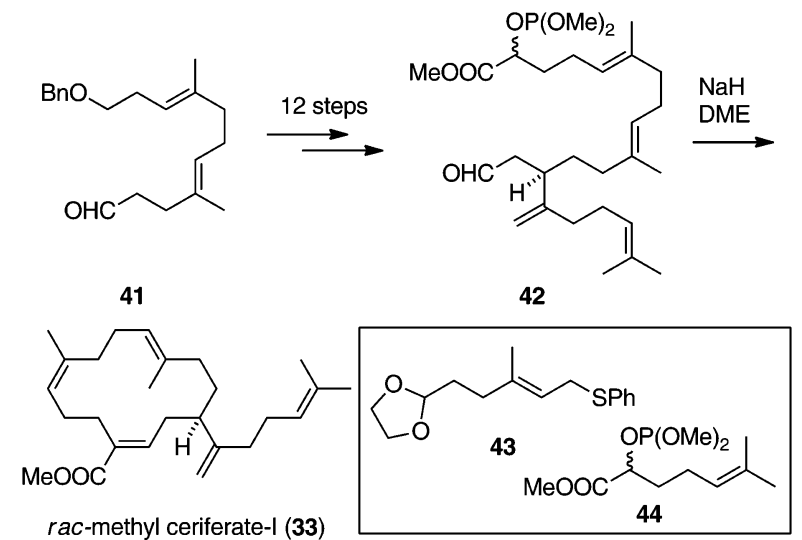

Scheme 6 Kodama's racemic synthesis of methyl cerifate I. DABCO 1,4 diazabicyclo[2.2.2]octane, DME 1,2 dimethoxyethane, $p$ TsOH $p$ toluenesulfonic acid.

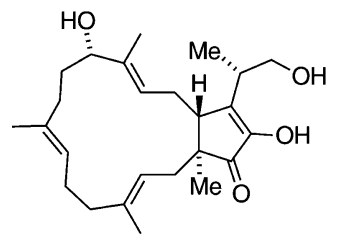

(-)-terpestacin (45)

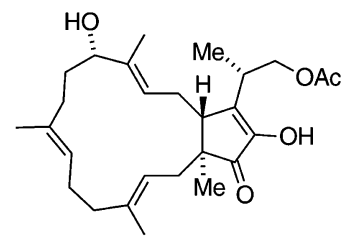

(-)-fusaproliferin (46)
Fig. 5 Molecular structures of ( ) terpestacin and ( ) fusaproliferin. Ac acetyl.

Interestingly, despite the absolute configuration of Myers' synthetic ( ) terpestacin (45) matching the configuration assigned by Tatsuta in 1998, Myers' optical rotation measure ment was in disagreement with the previously reported values from both Tatsuta (synthesis) and Oki (isolation), who reported terpestacin (45) to be dextrorotary. Upon careful investigation, Myers et al. concluded that the earlier reports contained arte factually erroneous measurements caused by chloroetherification of terpestacin (45) initiated by $\mathrm{CHCl}_{3}$, the solvent used for the optical rotation measurement. They found that prolonged exposure of ( ) terpestacin (45) to $\mathrm{CHCl}_{3}$ formed a chlorinated product (not shown) that was dextrorotary with a larger magnitude than ( ) terpestacin (45) itself. Myers et al. dispelled the ambiguity of the stereochemical assignment and successfully synthesized ( ) fusaproliferin (46) ${ }^{55}$ from ( ) terpestacin (45) in two additional steps by bisacetylation and mono deacetylation, verifying the assignment of its absolute configuration as well.

The following year, the third enantioselective synthesis of ( ) terpestacin (45) was disclosed by Jamison's group, ${ }^{52}$ utilizing a stereoselective intermolecular reductive coupling between an alkyne and an aldehyde, a methodology that was conceived in their laboratories. In contrast to Myers' strategy, Jamison installed the three carbon side chain at the beginning of the synthesis using an NMO promoted Pauson Khand reaction between dicobalt complex $\mathbf{5 8}$ and enantiomerically pure dihy drofuran 59, yielding bicycle $\mathbf{6 0}$ with complete control of regio and diastereoselectivity (Scheme 8). The latter was transformed into the desired alkyne $\mathbf{6 1}$ over a five step sequence via cuprate addition, reduction (both occurring from the convex face), desilylation, alkyne isomerisation and finally TMS protection of the resulting alcohol. The aldehyde fragment 63 was prepared in a straightforward manner from diol 62, that was in turn obtained from $(E, E)$ farnesyl acetate by chemo and enantioselective dihydroxylation. When the key aldehyde/alkyne coupling step was attempted using $\mathrm{Ni}(\operatorname{cod})_{2}$ with $\mathrm{Et}_{3} \mathrm{~B}$ and $\mathrm{Bu}_{3} \mathrm{P}$, the reaction exhibited low regioselectivty $(1.5: 1)$ and no diastereoselectivity $(1: 1)$. Fortunately, replacing $\mathrm{Bu}_{3} \mathrm{P}$ with a $P$ chiral phosphine ligand 64 enabled the formation of the desired alcohol 65 with enhanced regioselectivity $(2: 1)$ and modest, but synthetically useful diastereoselectivity $(3: 1)$. Following functional group manipulation, the macrocycle was closed by intramolecular alkylation, similar to Myers' synthesis, using a cyclopentanone enolate generated from LiHMDS to give tricycle 66. The next challenge the team was confronted with was the installation of the quaternary stereogenic center at $\mathrm{C} 1$. Notably, they discov ered that the presence of $\mathrm{H}_{2} \mathrm{O}$ was crucial to achieve a successful $\alpha$ alkylation with $\mathrm{NaH} / \mathrm{MeI}$ in toluene, which was attributed to producing finely dispersed $\mathrm{NaOH}$ in situ. Three further trans formations, namely deprotection, $\alpha$ hydroxylation via a potas sium enolate and ring opening of the resulting hemiketal followed by enolization led to the completion of the synthesis of ( ) terpestacin (45).

Later, in 2007, Trost and co workers published the fourth enantioselective total synthesis of ( ) terpestacin (45), exploiting the unusual reactivity of the diosphenol moiety (a cyclic 1,2 diketone with one ketone existing as an enol). ${ }^{53}$ They planned to introduce chirality using the $\mathrm{Pd}$ catalyzed asymmetric allylic alkylation (AAA) methodology previously developed in their laboratories. The crucial macrocyclic ring closure was envisaged to proceed by means of a ring closing metathesis (RCM). Stereo convergent $O$ alkylation of commercially available diosphenol 67 with racemic isoprene monoepoxide (76), employing AAA reaction conditions in the presence of $\mathrm{Pd}_{2} \mathrm{dba}_{3}$ and ligand $(R, R)$ 74, provided (after subsequent TIPS protection) allyl vinyl ether 68 in high yield $(95 \%)$ and enantioselectivity $(88$ 96\% ee) (Scheme 9). A Claisen rearrangement was used to install the quaternary center, followed by a Saegusa Ito oxidation to form an $\alpha$ keto enone (not shown). The latter underwent a diastereo selective 1,4 Sakurai allylation to furnish cyclopentenone $\mathbf{6 9}$, which in turn was converted into allylic bromide $\mathbf{7 0}$ over a simple three step sequence. This newly formed bromide $\mathbf{7 0}$ was then coupled to the dianion of sulfone $\mathbf{7 5}$ via alkylation, followed by a Pd catalyzed reductive desulfurization to cleanly afford RCM precursor 71. Optimal results were observed with Grubbs' second generation catalyst, delivering the desired $(E)$ configured mac rocycle 72, albeit in moderate yield (35 44\%). The final task remaining was to install the three carbon side chain. This problem was solved with a second AAA/Claisen rearrangement sequence. After PMB deprotection, allylic carbonate 77 was exposed to AAA conditions to facilitate $O$ alkylation of the macrocycle's diosphenol moiety, immediately followed by a Claisen rearrangement under microwave irradiation. 


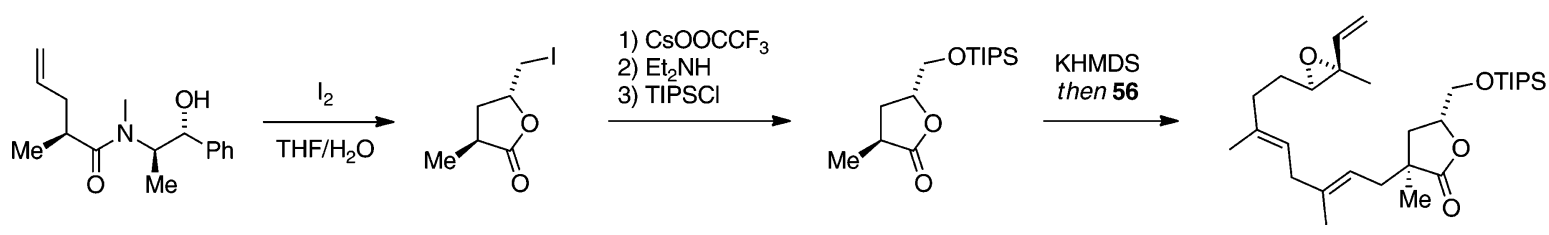

47

48

49

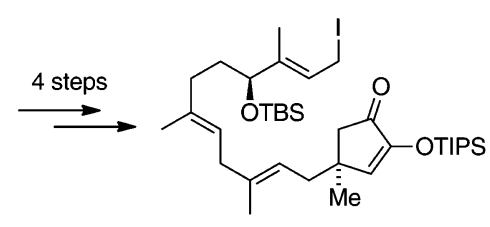

51

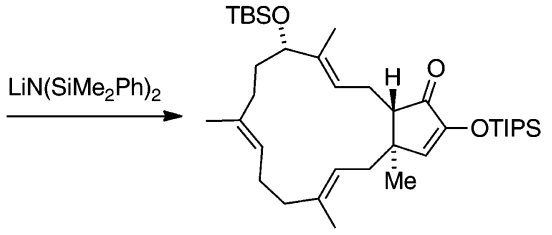

52

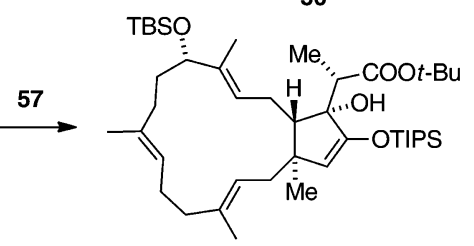

53

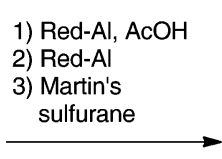

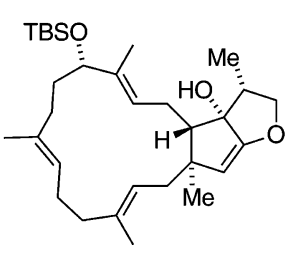

54

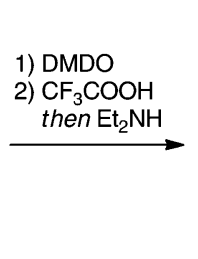

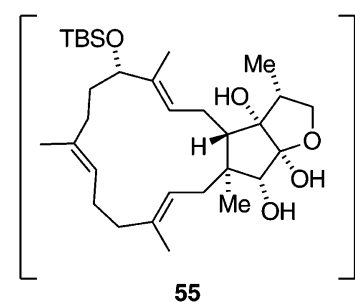

1) $\mathrm{K}_{2} \mathrm{CO}_{3}$

2) $\mathrm{HCl}$

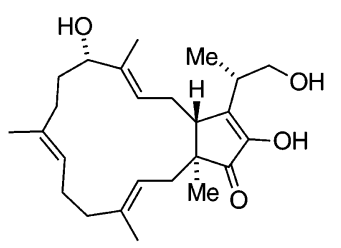

(-)-terpestacin (45)
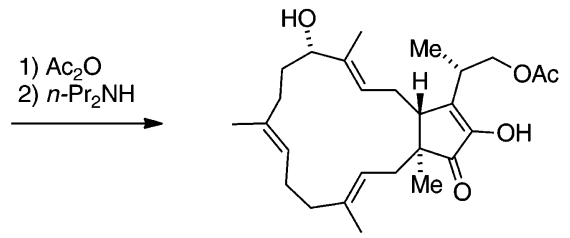

(-)-fusaproliferin (46)

55

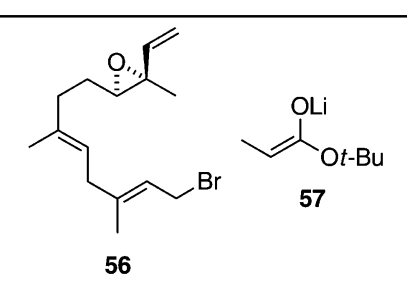

Scheme 7 Myers' enantioselective synthesis of ( ) terpestacin and ( ) fusaproliferin employing a series of three diastereoselective enolate alkylations. TIPS triisopropylsilyl, KHMDS potassium hexamethyldisilazide, Red Al sodium bis(2 methoxyethoxy)aluminum hydride, Martin's sulfurane bis[ $\alpha, \alpha$ bis(trifluoromethyl)benzyloxy]diphenylsulfur, DMDO $3,3^{\prime}$ dimethyldioxirane, $\operatorname{Ac}_{2} \mathrm{O}$ acetic anhydride, Ac acetyl.

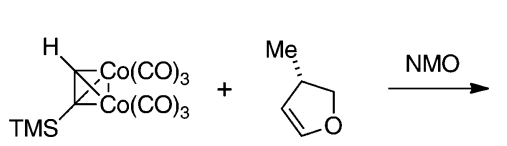

58

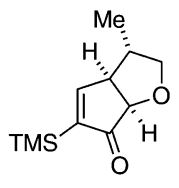

60

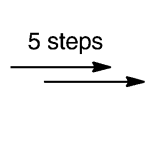

61<smiles>CC#CCC1CC(O)C2OCC(O)C12</smiles><smiles>CC(=O)OCC=C(C)CCC=C(C)CCC=O</smiles>

63

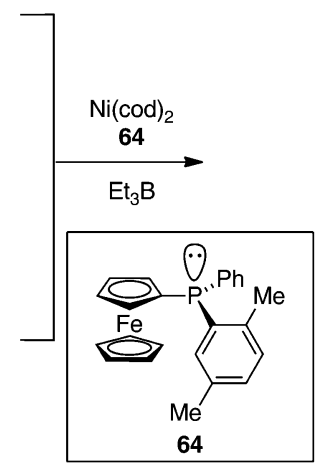

1) $\mathrm{NaH}, \mathrm{Mel}, \mathrm{H}_{2} \mathrm{O}$ 2) TBAF 3) KHMDS, $\mathrm{O}_{2}, \mathrm{P}(\mathrm{OEt})_{3}$ 4) $\mathrm{K}_{2} \mathrm{CO}_{3}$

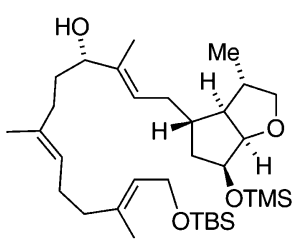

65
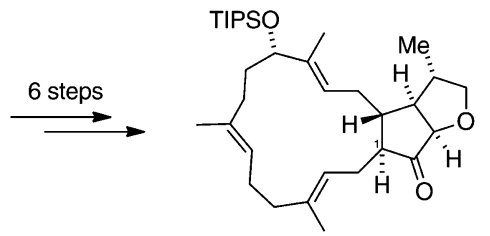

66

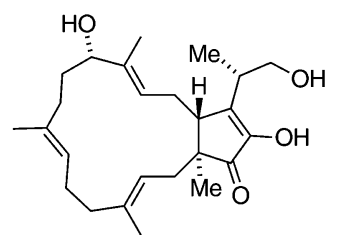

(-)-terpestacin (45)

Scheme 8 Jamison's asymmetric synthesis of ( ) terpestacin utilizing a Ni catalyzed intermolecular aldehyde/alkyne coupling. NMO $N$ methyl morpholine $N$ oxide, cod 1,5 cyclooctadiene, TMS trimethylsilyl, TBSOTf tert butyldimethylsilyl trifluoromethanesulfonate, TIPS triiso propylsilyl, TBAF tetrabutylammonium fluoride, KHMDS potassium hexamethyldisilazide. 
Reprotection of the diosphenol gave PMB ether 73 as a virtually single diastereomer $(>15: 1)$ emerging from the overall reaction sequence. Only a short series of transformations remained necessary to complete the synthesis, including a reagent controlled Sharpless asymmetric dihydroxylation with AD mix $\alpha$ to oxidize the disubstituted side chain alkene chemoselectively in the presence of three trisubstituted alkenes. Following deprotection, Trost's group successfully synthesized ( ) terpes tacin (45) in a total of 21 steps (longest linear sequence).

In the same year, Tius reported a 15 step synthesis of terpes tacin (45) with an overall yield of $6.4 \%$, albeit in a racemic fashion. ${ }^{54}$ They envisaged the core $\alpha$ hydroxy enone structure originating from an allene ether Nazarov cyclization as a key step, forming one stereogenic center, which in turn would set all other stereogenic centers in the target. To this end, $\gamma$ butyro lactone (78) was subjected to an one pot aldol/dehydration process with aldehyde $\mathbf{8 5}$, then a subsequent isomerization protocol yielded the $(E)$ configured lactone 79 in $66 \%$ yield (Scheme 10). ${ }^{54 b}$ After the addition of allenic lithium species 86 to lactone 79, generating a hemiacetal (not shown), treatment with acid triggered the desired Nazarov cyclization and MOM deprotection to yield cyclopentenone 80. This was followed by a two step sequence involving acetonide formation and diastereoselective hydrogenation to furnish enone 81. Having installed the quaternary stereogenic center in cyclopentenone $\mathbf{8 2}$, by alkylating the lithium enolate from ketone $\mathbf{8 1}$ with allylic bromide 87, Tius' group turned their attention to closing the macrocyclic ring. In contrast to the previously discussed syntheses (but in analogy to the synthesis of Tatsuta), they planed to achieve this goal using a Horner Wadsworth Emmons reaction. Liberation of the free alcohol functionalities in phos phonate 82 by treatment with $\mathrm{Et}_{3} \mathrm{~N} \cdot \mathrm{HF}$, followed by DMP oxidation of both the primary and the secondary alcohols afforded the keto aldehyde macrocyclization precursor, which smoothly underwent macrocyclization in the presence of Hünig's base and $\mathrm{LiCl}$, giving rise to tricycle $\mathbf{8 3}$. Subsequently, a chemo and diasteroselective ( $\mathrm{dr} 4: 1)$ reduction of enone 83 was attained by exposure to a $1: 1$ mixture of tert $\mathrm{BuLi} / \mathrm{DIBAL} \mathrm{H}$, and the resulting alcohol was protected as its TES silyl ether. Tius installed the last remaining methyl group in the side chain using a vinylogous enolate alkylation, leading to TES ether $\mathbf{8 4}$. Despite the stereochemical outcome being the opposite required for ter pestacin (45), it proved possible to invert the methyl group by formation of the corresponding TBS dienol ether and reproto nation with $\mathrm{Cl}_{3} \mathrm{CCOOH}$ at low temperature. Finally, simulta neously cleavage of the TES ether and acetonide protecting groups with $1 \mathrm{~N} \mathrm{HCl}$ gave rise to racemic terpestacin (45).

\subsection{Dysidiolide}

The bicarbocyclic sesterterpenoid ( ) dysidiolide (88) was iso lated in 1996 and its relative configuration was established unambiguously by $\mathrm{X}$ ray crystallography (Fig. 6). ${ }^{56}$ The hydroxybutenolide moiety undergoes rapid exchange at $\mathrm{C} 25$, resulting in a diastereomeric mixture. However, upon crystalli zation, this carbon exclusively assumes the configuration diagrammed below. A further remarkable feature of its geometry is that the large side chains each occupy axial and pseudoaxial positions on the same face of its decalin system.

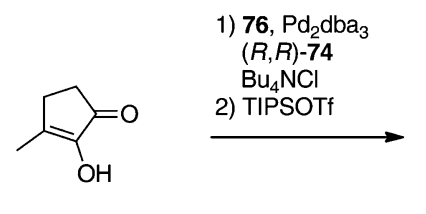

67

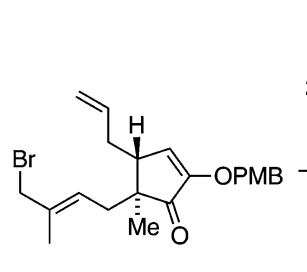

70

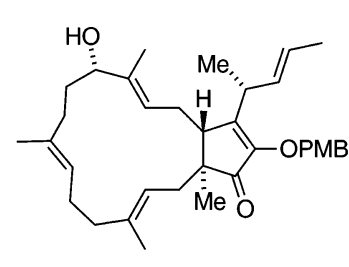

73

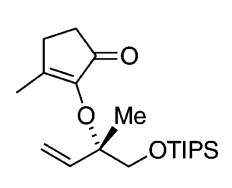

68

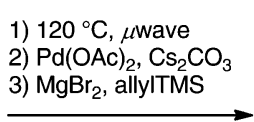

3) $\mathrm{MgBr}_{2}$, allyITMS

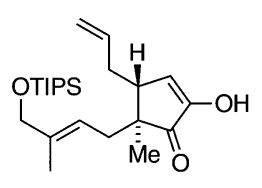

69

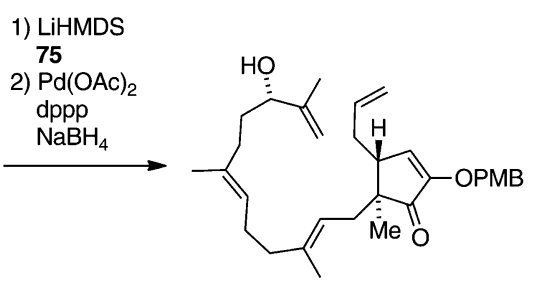

71

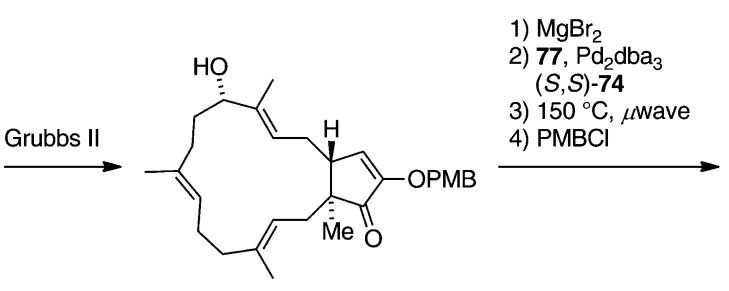

72

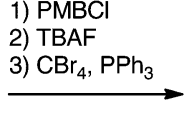

2) $T B A$ 
In addition to its novel carbon skeleton at the time of its discovery, dysidiolide (88) was the first natural product reported to inhibit protein phosphatase cde25a, an enzyme involved in dephosphorylation of cyclin dependent kinases, which have been proposed as potential anti cancer targets. Early results showed that dysidiolide (88) inhibits growth of A 549 human lung carcinoma and P388 leukemia cell lines. ${ }^{57}$ Not surprisingly, a large number of synthetic chemists were drawn to dysidiolide (88) as a target, which culminated in several total and formal total syntheses. As a detailed discussion of all these approaches would exceed the range of this review, we will focus in the following on three successful syntheses by Corey, ${ }^{58}$ Dani shefsky ${ }^{59}$ and Forsyth. ${ }^{60}$

Just one year after its isolation, Corey's group presented the first route to ( ) dysidiolide $(\mathbf{8 8}){ }^{58}$ They commenced their synthesis from the Wieland Miescher ketone analogue 89, that was readily available in enantiomerically pure form (Scheme 11). A second quaternary stereogenic center was incorporated by Birch reduction and trapping of the resulting lithium enolate with allyl bromide, after which an enone was introduced by means of a sulfoxide elimination. This was followed by a Michael addition of TMS Li to generate $\beta$ silyl ketone 90 , the purpose of which will be explained below. In a series of ten transformations, Corey converted ketone 90 into alcohol 91 by means of standard reactions as e.g. dihydroxylation, $\mathrm{NaIO}_{4}$ cleavage, Wittig methylenation and a diastereoselective hydrogenation using Wilkinson's catalyst. Having obtained alcohol 91, the stage was set for a biosynthetically inspired key step to construct the fully substituted bicyclic core of dysidiolide (88). Thus, treatment of tertiary alcohol 91 with gaseous $\mathrm{BF}_{3}$ initiated the formation of a tertiary carbocation, triggering a methyl shift to form the desired quaternary stereogenic center, facilitated by the neigh boring TMS group due to hyperconjugation. The reaction was terminated by an elimination, extruding the TMS group and generating alkene 92 with the desired double bond regiochem istry. To extend the northern side chain, it was first necessary to cleave the primary TBS ether with PPTS and substitute the resulting alcohol for an iodide (not shown) prior to displacement with iso propenyl cuprate 95. An additional two steps, namely deprotection of the primary alcohol and DMP oxidation yielded aldehyde 93. One drawback late in the synthesis, however, was that addition of furan 3 yl lithium (96) to aldehyde 93 formed alcohol 94 as a mixture of diastereomers $(1: 1)$. To solve this problem, the $(S)$ configured alcohol 94 was oxidized to the

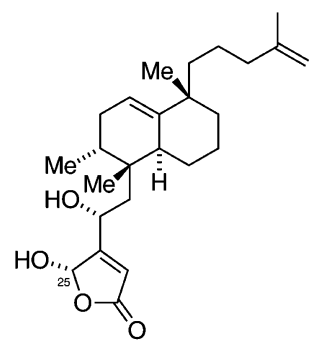

(-)-dysidiolide (88)

Fig. 6 The molecular structure of the bicarbocyclic sesterterpenoid ( ) dysidiolide.

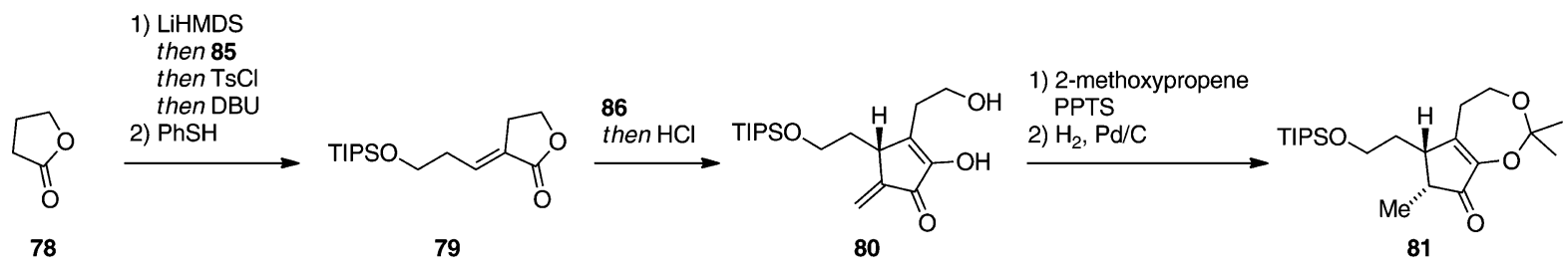

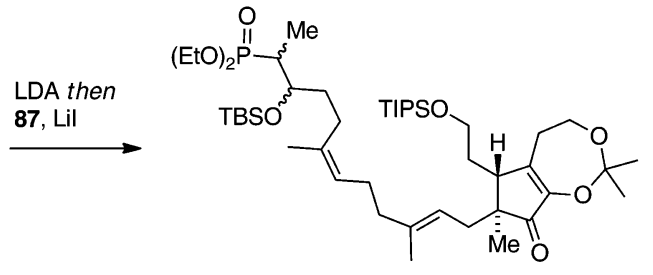

82

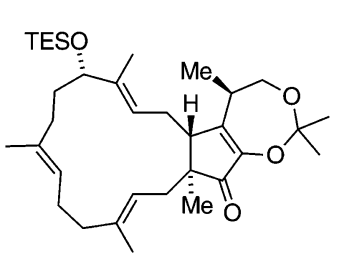

84

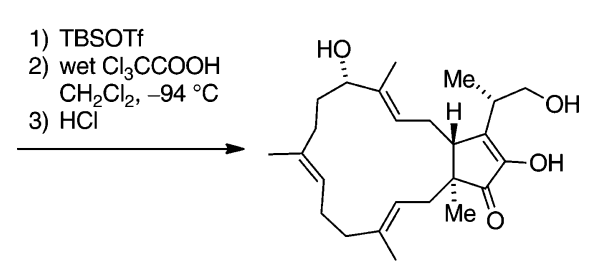

rac-terpestacin (45)

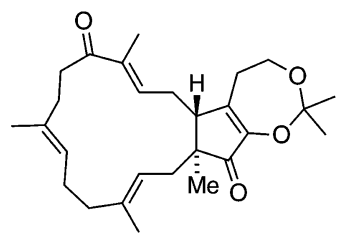

1) $t$-BuLi/DIBAL-H

2) $\mathrm{TESCl}$

3) LDA then Mel/HMPA

83

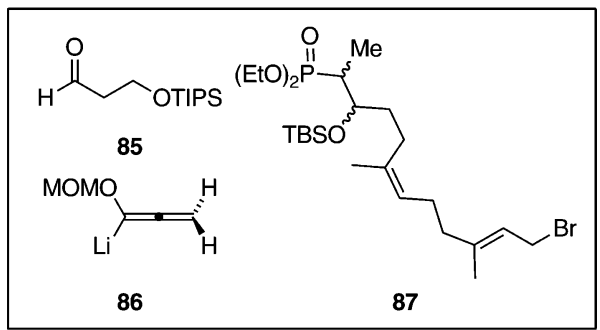

Scheme 10 Tius's racemic synthesis of terpestacin via an allene Nazarov cyclization. TIPS triisopropylsilyl, LiHMDS lithium hexamethyldisil azide, TsCl $p$ toluenesulfonyl chloride, DBU 1,8 diazabicyclo[5.4.0]undec 7 ene, PPTS pyidinium $p$ toluenesulfonate, LDA lithium diiso

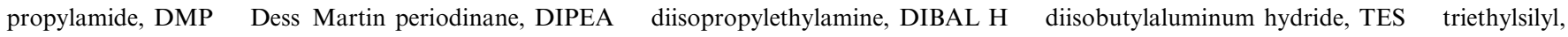
HMPA hexamethylphosphoramide, TBSOTf tert butyldimethylsilyl trifluoromethanesulfonate, MOM methoxymethyl. 
corresponding ketone, followed by a diastereoselective CBS reduction to give almost exclusively the $(R)$ configured alcohol 94. Ultimately, the photooxygenation of a furan utilizing Rose Bengal (Section 3.1 on manoalide) gave rise to ( ) dysidiolide (88) and thus established its absolute configuration.

The straightforward, but nevertheless linear synthesis by Corey started with the bicarbocyclic core of dysidiolide (88) already in place. In contrast, the convergent approach of Dani shefsky and co workers involved generating a more highly functionalized bicycle via an intermolecular Diels Alder reac tion. ${ }^{59}$ Their syntheses were reported almost contemporaneously, although Danishefsky's route was not enantioselective. At the beginning of the synthesis, Danishefsky et al. subjected dioxolane 97 to dimethyl cuprate followed by trapping of the resulting anion with ethyl iodoacetate (102) (Scheme 12). A subsequent reduction and silylation sequence furnished compound $\mathbf{9 8}$, which served as a masked dioxolenium dienophile. The other cycload dition partner, diene 100, was assembled from lithium enolate 99 and alkyl iodide 103, by successive enol triflate formation and Stille coupling to vinyl stannane 104. The key Gassman Diels Alder reaction was carried out using TMSOTf as an acid catalyst (to activate dioxolane 98, proceeding through the dioxolenium cation intermediate), in good yield with the desired regio and diastereoselectivity. As the bicycle 101 possessed the six stereo genic centers of dysidiolide (88) with the correct relative stereo chemistry, as well as the complete northern side chain, all that remained necessary were minor functional group interconver sions and elaboration of the southern appendage. This was accomplished first by a Wolff Kishner reduction that was accompanied by desilylation, and TPAP/NMO oxidation to yield aldehyde 93, the same intermediate as in Corey's synthesis. Danishefsky completed the synthesis in a similar fashion to Corey, by nucleophilic attack of 3 furyllithium (96) and a pho tooxgenation in the presence of Rose Bengal (Scheme 11). The same diasteroselectivity problem from nucleophilic attack of the furyllithium species 96 onto aldehyde 93 was faced, but Dani shefsky's solution was to separate the isomeric products and invert the stereochemistry of the undesired alcohol 94 using Mitsunobu conditions.

Most of the other published syntheses of dysidiolide (88) are based on intermolecular Diels Alder reactions. A number of groups have employed the useful building block 106 that is readily available in enantiomerically pure form starting from racemic 2 methylcyclohexanone (105) using a method from d'Angelo (Scheme 13). ${ }^{61}$ Among these groups are Boukouvalas, ${ }^{62}$ Shirai ${ }^{63}$ and Jung ${ }^{64}$ who accomplished enantioselective total or formal total syntheses of ( ) dysidiolide (88) using similar Diels Alder approaches. Furthermore, Waldmann et al. prepared a model system containing the decalin core, ${ }^{65}$ which was accompanied by the solid phase synthesis of analogues to carry out SAR studies. ${ }^{66}$ Additionally, the group of Yamada reported both a racemic ${ }^{67}$ and an asymmetric ${ }^{68}$ total synthesis of ( ) dysidiolide (88), also utilizing an intramolecular Diels Alder reaction. Recently, Kaliappan and Gowrisankar reported a racemic formal total synthesis of dysidiolide (88) based on a dienyne metathesis to construct the dienophile portion. ${ }^{69}$

In 2000, however, Forsyth presented a conceptually different approach to racemic dysidiolide (88) featuring a diastereo selective sequential chirality transfer to install the stereogenic centers on its core. ${ }^{60}$ His synthesis commenced with a diastereo selective anti alkylation of racemic keto ester 107, which was followed by vinylogous ester formation and reductive 1,3 carbonyl transposition to yield enone 108 (Scheme 14). After protecting the primary alcohol as its TMS ether, the resulting enone was reacted with the higher order cyanocuprate generated from bromide 112, $t \mathrm{BuLi}$ and $\mathrm{CuCN}$ to afford, after silyl ether cleavage, diol 109. Having conducted a double oxidation with Jones' reagent and subsequent esterification of the resulting free

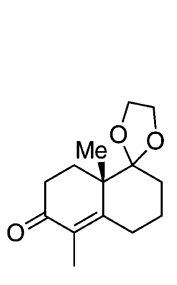

1) $\mathrm{Li} / \mathrm{NH}_{3}$

2) allyl bromide

3) LDA, PhSSPh

4) $m \mathrm{CPBA}$

5) $(\mathrm{MeO})_{3} \mathrm{P}$

6) TMSLi, HMPA

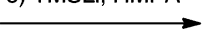

89

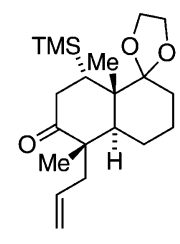

90

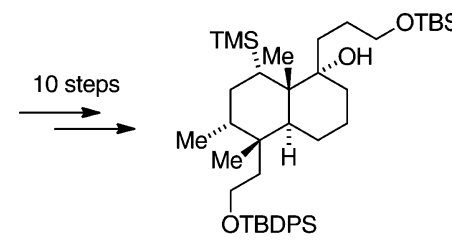

91

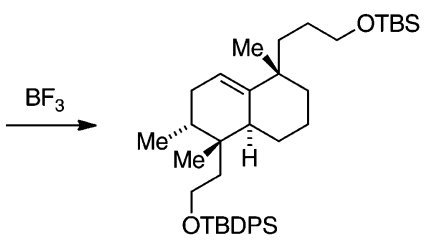

92

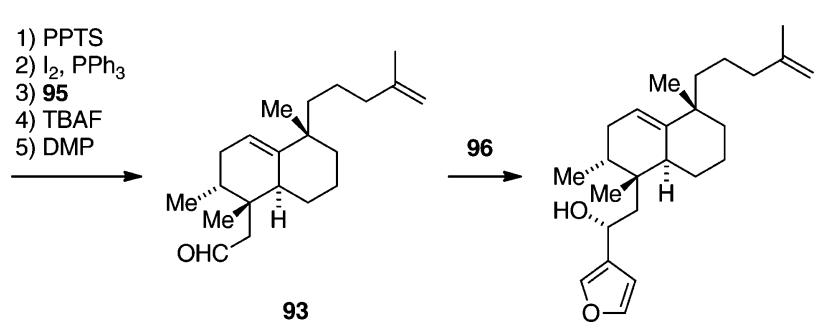

94

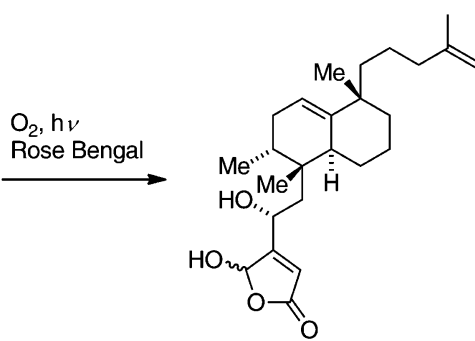

(-)-dysidiolide (88)

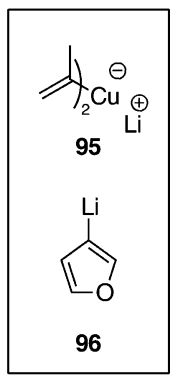

Scheme 11 Corey's asymmetric synthesis of ( ) dysidiolide. LDA lithium diisopropylamide, $m$ CPBA $m$ chloroperbenzoic acid, TMS trime thylsilyl, HMPA hexamethylphosphoramide, TBS tert butyldimethylsilyl, TBDPS tert butyldiphenylsilyl, PPTS pyridinium $p$ toluenesulfo nate, TBAF tetrabutylammonium fluoride, DMP Dess Martin periodinane. 


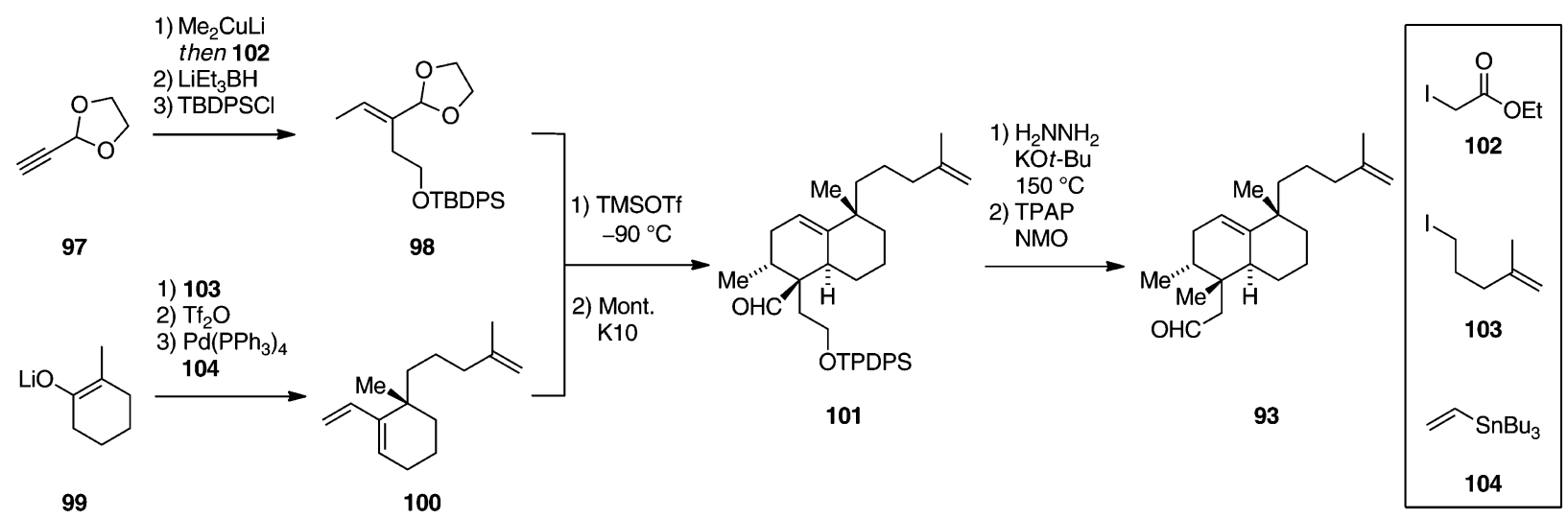

Scheme 12 Danishefsky's racemic synthesis of dysidiolide, TBDPS tert butyldiphenylsilyl, $\mathrm{Tf}_{2} \mathrm{O}$ trifluoromethanesulfonic anhydride, TMSOTf trimethylsilyl trifluoromethanesulfonate, Mont. K10 montmorillonite K10, TPAP tetrapropylammonium perruthenate, NMO $N$ methyl morpholine $N$ oxide.

acid, Forsyth closed the six membered ring by means of an intramolecular aldol condensation in the presence of $\mathrm{KO} t \mathrm{Bu}$, yielding decalin 110. The latter was treated with a cuprate prepared from bromide 113, $t \mathrm{BuLi}, \mathrm{CuI}, \mathrm{PBu}_{3}$ and $\mathrm{BF}_{3}$ etherate to produce exclusively the 1,4 adduct $\mathbf{1 1 1}$ as a single diaste reomer with respect to the newly formed quaternary stereogenic center (the stereochemistry at the ring junction was not assigned). The authors commented that other cuprate reagents, such as those first described by Yamamoto, and other additives such as TMSCl offered no improved reactivity. Finally, a six step protocol led to aldehyde $\mathbf{9 3}$, the common intermediate from the Corey and Danishefsky syntheses, that was converted to racemic dysidiolide (88) as previously described (Scheme 11). Other racemic formal syntheses by the groups of Piers ${ }^{70}$ and Maier ${ }^{71}$ were published in the same year, also opting to close the decalin system utilizing an intramolecular aldol condensation.

\subsection{Miscellaneous bicarbocyclic sesterterpenoids}

Apart from the two natural products discussed in the sections above, various other bicarbocyclic sesterterpenoids have been successfully synthesized during the past 20 years. The natural products $(+)$ cladocoran A (114) $)^{72}$ and $(+)$ cladocoran B $(\mathbf{1 1 5})^{72}$ closely resemble dysidiolide (88), differing only by location of the alkene present in the decalin system. Their structures were originally misassigned after isolation, but total syntheses by the groups of Marcos ${ }^{73}$ and Yamada ${ }^{74}$ allowed for structural revision as depicted in Fig. 7. The synthesis of another structurally related natural product, $(+)$ dysideapalaunic acid (116) ${ }^{75}$ was disclosed in 1991 by Hagawira and Uda. ${ }^{76}$ The authors chose to build around the decalin core, starting from a readily available enan tiomerically pure Wieland Mischer ketone analogue. In 1987, Piers and $\mathrm{Waij}^{77}$ had reported a racemic synthesis of the

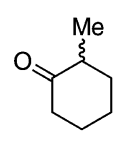

105
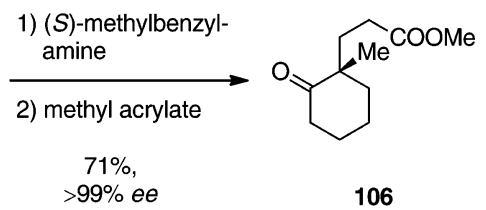

Scheme 13 d'Angelo's asymmetric synthesis of $\delta$ ketoester 106. antimicrobial sesterterpenoid (+) palauolide $(\mathbf{1 1 7})^{\mathbf{7 8}}$ in 17 steps. Starting from 3,6 dimethylcyclohex 2 enone, they successfully installed the four contiguous stereogenic centers in the first four steps of their synthesis, while the remaining 13 steps adjusted the oxidation states and elaborated the side chain (not shown).

Two decades later, in 2002, Cheung and Snapper ${ }^{79}$ published the total synthesis of the potent anti inflammotory marine metabolite $(+)$ cacospongionolide B (118) ${ }^{80}$ Within the short twelve step sequence, Snapper utilized an RCM to close the
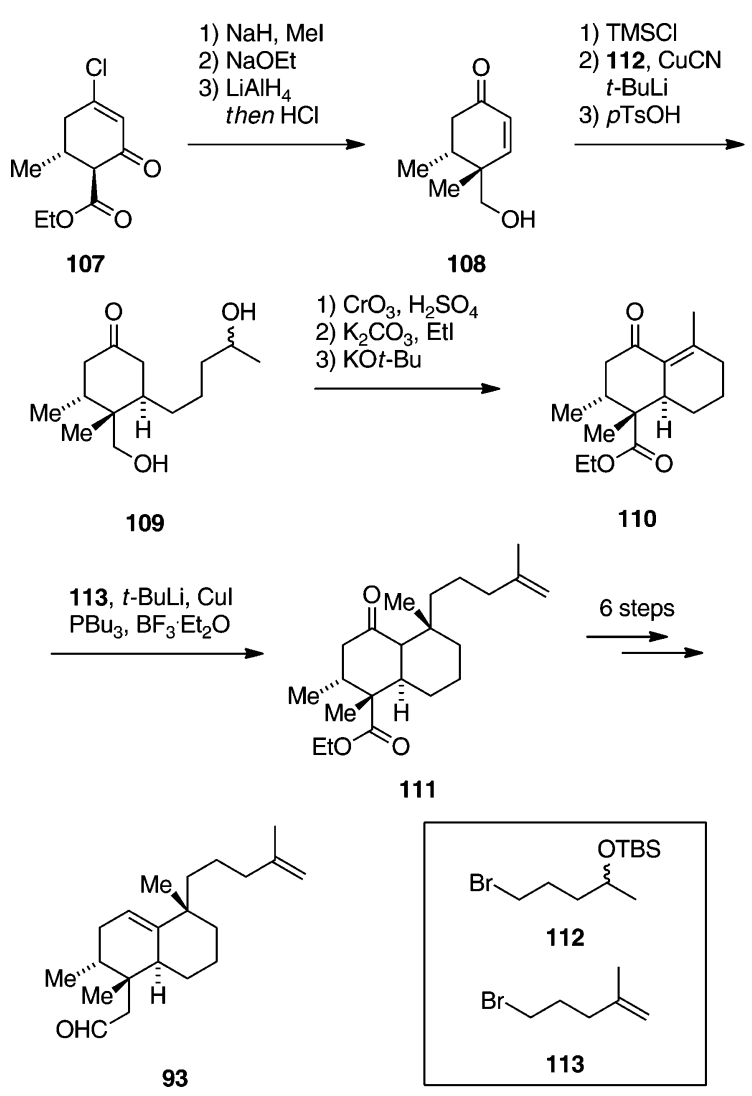

Scheme 14 Forsyth's racemic synthesis of dysidiolide. TMS trime thylsilyl, $p$ TsOH $p$ toluenesulfonic acid, TBS tert butyl dimethylsilyl. 
dihydrofuran moiety. Recently, the laboratories of Basabe ${ }^{81}$ published an enantioselective route to the marine metabolite (+) luffalactone (119) ${ }^{82}$ relying on a Yamaguchi lactonization and a photochemical oxidation of a furan as key steps.

Two other marine natural products, ( ) ircinianin $(\mathbf{1 2 0})^{\mathbf{8 3}}$ and its cyclic isomer $(+)$ wistarin $(\mathbf{1 2 1})^{84}$ have been the target of several synthetic studies (Scheme 15). ${ }^{85}$ While Yoshii and Takeda $^{86}$ achieved an elegant biomimetic racemic synthesis of ircianinin (120), inspired by a biogenetic hypothesis put forward by Hofheinz, ${ }^{83}$ Uenishi and co workes re examined this route eleven years later, completing an enantioselective synthesis in $1997 .{ }^{87}$ They synthesized aldehyde 122 starting from the $(R)$ Roche ester ent (2) (Section 2), which in turn underwent a Nozaki Hiyama Kishi (NHK) reaction with vinyl iodide 123, followed by an intramolecular Diels Alder reaction to furnish the tricyclic adduct $\mathbf{1 2 4}$ in $60 \%$ yield. It is worth noting, the epimeric alcohol also formed in the NHK coupling did not cyclize spontaneously at room temperature, and could be iso lated from the reaction mixture (not shown). Further deoxy genation and demethylation led to ( ) ircinianin (120), which was converted to $(+)$ wistarin (121) by iodoetherification and subsequent reductive deiodination. Interestingly, wistarin (121) was the first example of a sesterterpenoid that occurs naturally in both enantiomeric forms. ${ }^{88}$

Another family of bicarbocyclic sesterterpenoids, the leuco sceptroids, ${ }^{89}$ represented by $(+)$ leucosceptroid A $(\mathbf{1 2 5})^{89 a}$ and (+) leucosceptroid D (126) ${ }^{89 b}$ has recently attracted the attention of Horne and co workers (Scheme 16). ${ }^{90}$ Isolated in 2010 and 2011 from the small tree Leucosceptrum canum, these natural products possess anti feedant and anti fungal properties, provoking the authors to give them the moniker 'harbor defen sive sesterterpenoids.' Horne planned to use an intramolecular Diels Alder reaction to close the central six membered ring, and in their 2011 report, they described the synthesis of the Diels Alder precursor, triene 127, in an enantioselective fashion. Exposing the latter to heat, in the presence of BHT, provided access to aldehyde 128, efficaciously building up the tricyclic core of the leucosceptroids. Unfortunately, their attempts to intro duce the C6 methyl group, by alkene epoxidation and ring opening with an appropriate organometallic reagent, have not yet been successful.

\section{Tricarbocyclic sesterterpenoids}

\subsection{Gascardic acid}

The group of Boeckman Jr. has demonstrated a longstanding interest in sesterterpenoid synthesis, producing a number of important contributions in this field. Among these contributions was their successful total synthesis of gascardic acid (136) in $1979,{ }^{91}$ the first truly structurally complex sesterterpenoid to have been made synthetically. Gascardic acid (136) was isolated in $1960,{ }^{92}$ and despite the careful investigation shortly following its isolation, ${ }^{93}$ the relative configurations of the two side chain ster eocenters were not unambigously proven. ${ }^{94}$ Thus, the synthesis by Boeckman et al. not only explored and pioneered new chemistry, but their work also clarified the structure of the natural product's unique molecular structure consisting of a [ $\left.\begin{array}{lll}5 & 6 & 7\end{array}\right]$ ring system and two adjacent quaternary stereogenic centers.

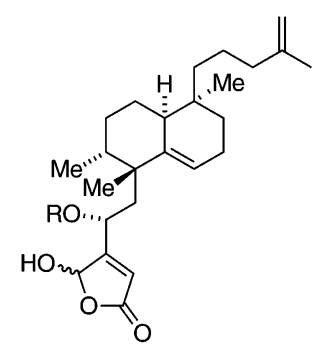

(+)-cladocoran $A(114) \mathrm{R}=\mathrm{H}$

(+)-cladocoran $B(115) R=A c$

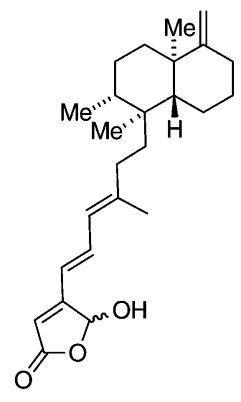

(+)-palauolide (117)

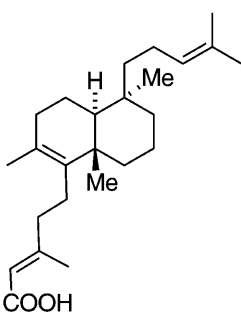

(+)-dysideapalaunic acid (116)

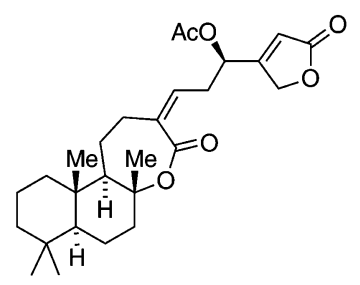

(+)-luffalactone (119)

Fig. 7 Molecular structures of successfully synthesized bicarbocyclic sesterterpenoids. Ac acetyl.

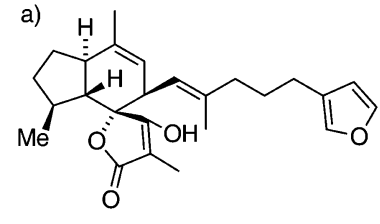

(-)-ircinianin (120)

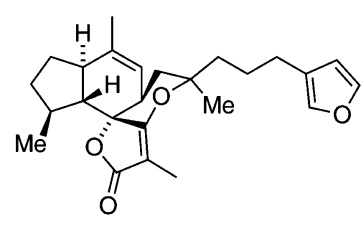

(+)-wistarin (121)

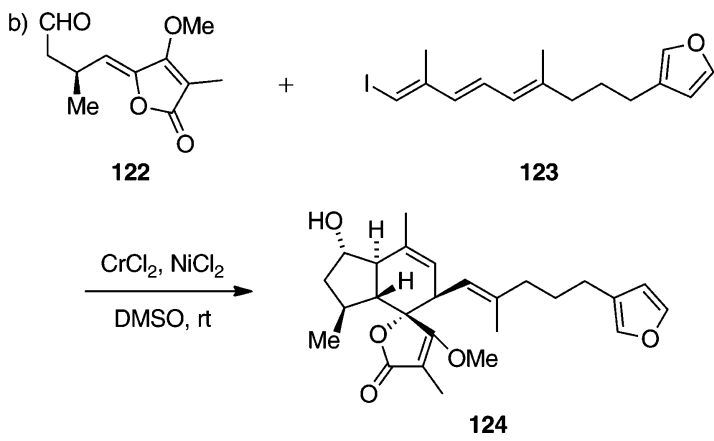

Scheme 15 (a) Molecular structures of ( ) ircinianin and (+) wistarin, (b) Uenishi's asymmetric synthesis: the key NHK/Diels Alder sequence to construct the tricyclic core structure. $\mathrm{rt}$ room temperature. 
The Boeckman synthesis of gascardic acid (136) was initiated by a conjugate addition/annulation process: Michael addition to cyclopentenone 129, employing mixed cuprate 137 , followed by trapping the resulting copper enolate with $\alpha$ trimethylsilylvinyl ketone 138, succinctly provided (after workup and base medi ated cyclization) the key hydrindenone 130 (Scheme 17). It was expected that such a cyclization would result in a cis relationship between the angular methyl group and the orientation of the side chain, based on earlier work in the same laboratories. The stereochemical outcome followed their prediction, unfortu nately, however, the stereogenic center present in the side chain was formed as a mixture of epimers $(1: 1)$ and was carried forward without separation. The next task facing the authors was to install a second quaternary stereogenic center in a sterically congested position. Since strategies based on organo cuprate reagents were not successful, the group resorted to a $[3,3]$ sig matropic rearrangement to achieve the desired functionalization. Vinyl ether 131, available in five steps from ketone 130, was heated $\left(160{ }^{\circ} \mathrm{C}\right)$ to affect a Claisen rearrangement, giving the desired aldehyde $\mathbf{1 3 2}$ as a single isomer in good yield (65\%). After oxidation of the aldehyde to the corresponding acid, an iodo lactonization was performed and the resulting intermediate lactone was directly converted to epoxide $\mathbf{1 3 3}$ by solvolysis with $\mathrm{NaOMe}$ and base mediated oxirane ring closure. Elaboration of this compound to exo methyene hydrindane $\mathbf{1 3 4}$ proved prob lematic, but could be accomplished in four steps. Lewis acid promoted rearrangement of the epoxide in $\mathbf{1 3 3}$ gave the ther modynamically more stable ketone. This was followed by saponification and an unusual olefination via adding lithium species 139 and subsequent reductive elimination. Finally, treatment with $\mathrm{CH}_{2} \mathrm{~N}_{2}$ gave diester 134 in good overall yield. Closure of the final ring via a regioselective Dieckmann reaction was affected by treatment with LiTMP. The synthesis was then completed as follows: chemoselective reduction of the ketone, mesylation and elimination yielded the racemic methyl ester $\mathbf{1 3 5}$. At that point, Boeckman et al. separated the mixture of epimers by means of liquid chromatography. Comparison of the spectral data revealed that their synthetic material was identical to an a)

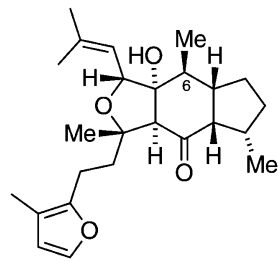

(+)-leucosceptroid A (125)

b)

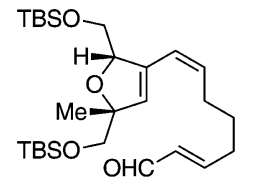

127

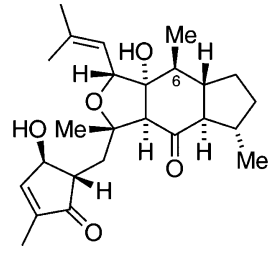

(+)-leucosceptroid D (126)
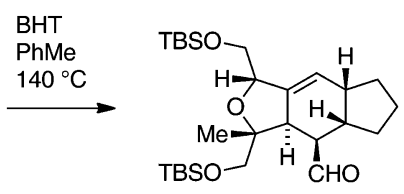

128
Scheme 16 (a) Molecular structure of the sesterterpenoids (+) leuco screptroid A and D, (b) Horne's intramolecular Diels Alder approach. TBS tert butyldimethylsilyl, BHT 2,6 di tert butyl 4 hydroxytoluene. authentic sample of natural methyl gascardate. At last, saponi fication of methyl ester $\mathbf{1 3 5}$ delivered racemic gascardic acid (136). Later that year, Boeckman and Clardy verified the struc ture of gascardic acid (136) by $\mathrm{X}$ ray analysis of its dicyclohexylammonium salt. ${ }^{95}$ However, the absolute configu ration of this natural product has not been clarified to date.

\subsection{Ophiobolins}

The fungal metabolite $(+)$ ophiobolin A (140) ${ }^{96}$ was the first naturally occurring sesterterpenoid identified. Since its isolation in 1958, several congeners have been isolated showing the same carbon skeleton A (Fig. 8). In addition to their complex and structurally daunting [ $\left.\begin{array}{lll}5 & 8 & 5\end{array}\right]$ tricarbocyclic ring system, this class of natural products shows potent anti bacterial and anti fungal properties, as well as cytotoxicity in different cancer cell lines. ${ }^{97}$ These characteristics have made the ophiobolins attractive targets for synthetic studies. ${ }^{98}$ However, despite the considerable effort expended in such endeavours, only one synthesis of (+) ophiobolin C $(\mathbf{1 4 1})^{99}$ has been reported by the laboratories of Kishi in $1989,{ }^{100}$ and very recently, more than 50 years after its isolation, Nakada reported the total synthesis of $(+)$ ophiobolin A (140) in 2011. ${ }^{101}$

Kishi et al. pointed out that one major challenge in the synthesis of the ophiobolin family rested on the difficulties associated with constructing the ring system, in particular the eight membered ring. ${ }^{100,102}$ This problem was addressed by taking advantage of an intramolecular NHK reaction. At the beginning of their lengthy, but ultimately successful enantiose lective route, Kishi et al. transformed 3 endo bromocamphor 142 over a series of six steps into alcohol 143, setting two stereogenic centers of the natural product (Scheme 18). ${ }^{103}$ After ozonolysis of the exocyclic double bond, protection of the primary alcohol and Saegusa Ito oxidation, then reduction of the enone under Luche conditions, allylic alcohol 144 was obtained (3:1 mixture in favor of the desired $\beta$ isomer). The latter was coupled with acid chloride 152 under basic conditions, setting the stage for a domino Brook/Claisen rearrangement to install the pendant side chain of $(+)$ ophiobolin $C$ (141). The desired cascade took place upon heating the ester 145 at $230{ }^{\circ} \mathrm{C}$ in xylenes to yield (after hydrolysis of the intermediate silyl ester) acid 146 in high yield $(72 \%)$ and good diastereoselectivity $(6: 1)$. With this important intermediate in hand, the functional groups were manipulated in a straightforward fashion over a nine step sequence, giving rise to aldehyde 147 . This product was treated with vinyl lithium reagent 153 (prepared asymmetrically starting from ( ) tartaric acid), ${ }^{104}$ followed by re pivaloylation of the partially deacylated product to furnish the vinylogous hemiacetal 148, which in turn underwent hydrolysis to the enone (not shown). Another three step sequence consisting of iododesilyla tion, selective deprotection of the THP ether and Swern oxida tion finally provided aldehyde $\mathbf{1 4 9}$ as the key intermediate for the NHK reaction. In this event, subjecting aldehyde 149 to a large excess of $\mathrm{CrCl}_{2}$ and a catalytic amount of $\mathrm{NiCl}_{2}$ led to the desired

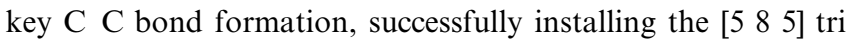
carbocyclic framework in alcohol 150. The product was obtained as a single isomer with its relative stereochemistry assigned according to model studies, without being unambiguously proven. ${ }^{104}$ To complete the remaining functional group 


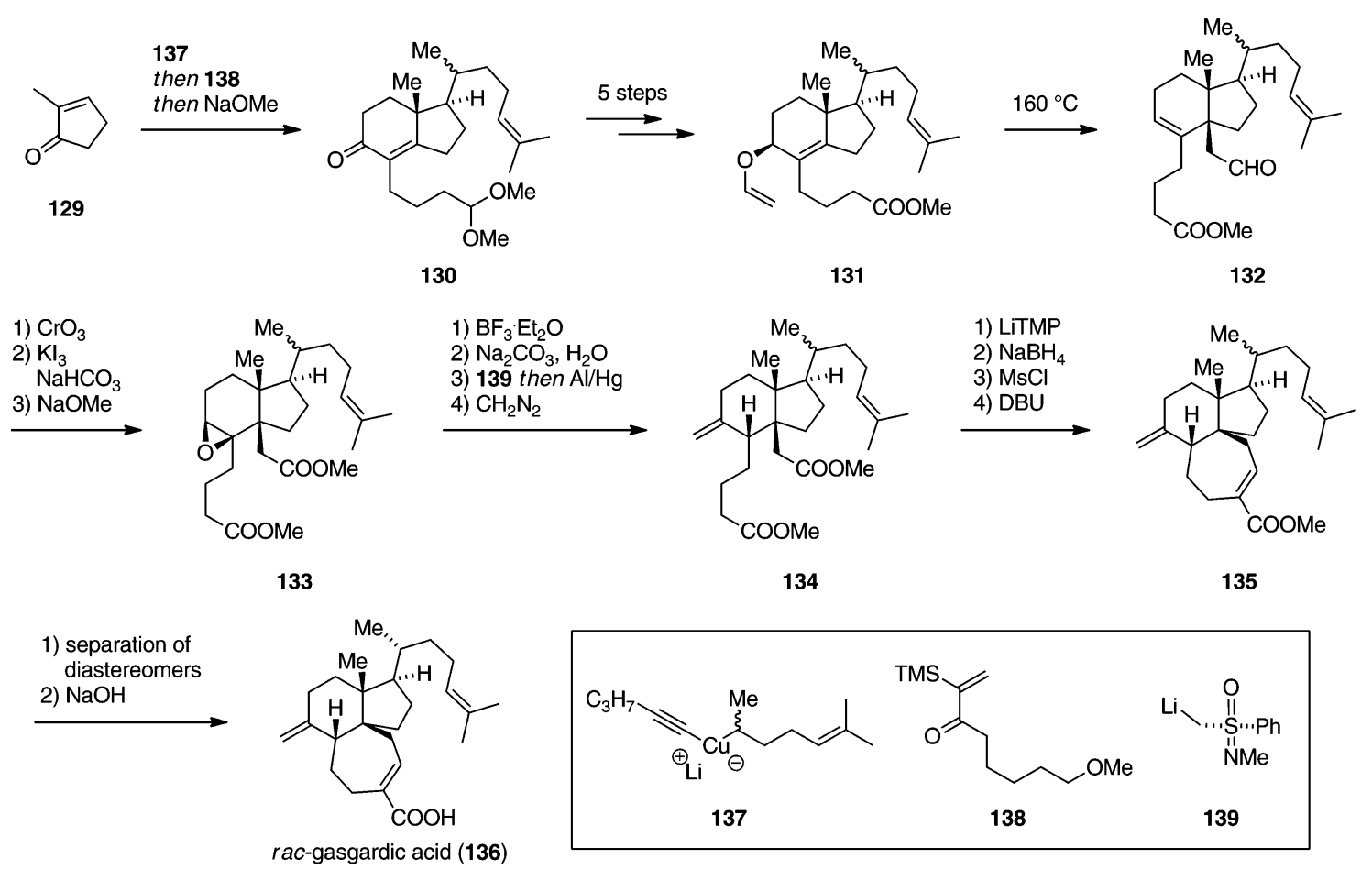

Scheme 17 Boeckman's racemic synthesis of gascardic acid showcasing the utility of $[3,3]$ sigmatropic rearrangements to install quaternary stereogenic centers in congested positions. LiTMP 2,2',6,6 tetramethylpiperidinyl lithium, Ms methanesulfonyl, DBU 1,8 diazabicyclo[5.4.0]undec 7 ene, TMS trimethylsilyl.

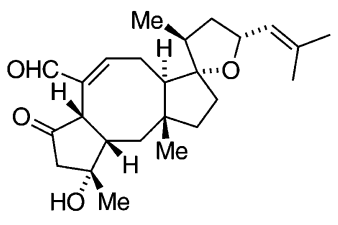

(+)-ophiobolin A (140)

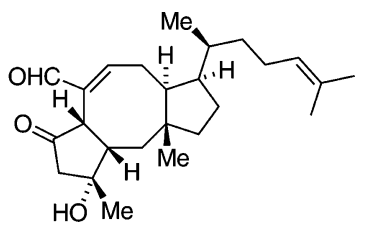

(+)-ophiobolin C (141)

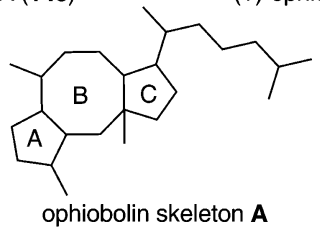

Fig. 8 Molecular structures of (+) ophiobolin A, (+) ophiobolin C and the ophiobolin skeleton.

manipulations needed, Kishi et al. transposed the allylic alcohol via epoxidation of the exocyclic double bond, then thiocarbonate formation and $\mathrm{Sn}$ mediated radical reductive ring opening, that was accompanied by diastereoselective conjugate reduction of the enone, to yield alcohol 151. An additional six steps finally provided (+) ophiobolin C (141) with analytical data in agree ment with that obtained from an authentic sample.

30 years after Kishi's synthesis of ophiobolin C (141), Nakada and co workers presented their successful route toward (+) ophiobolin A (140). ${ }^{101}$ Within that time range, powerful synthetic tools were developed that provided new opportunities to address complex synthetic targets. Hence, Nakada et al. envisaged to close the B ring of ophiobolin A (140) by means of an $\mathrm{RCM}$ reaction. The authors stated that such a reaction to install a tri substituted double bond in an eight membered ring is highly challenging and not well precedented in the literature. Moreover, they planned to generate the spirocyclic tetrahydro furan moiety via a Lewis acid promoted cyclization. Their route was initiated by an enzymatic desymmetrization, giving rise to acid 154, containing one quaternary stereogenic center, in $96 \%$ ee (Scheme 19). Following that, a 15 step sequence was required to prepare alkyl iodide 155. Subsequent treatment with $t \mathrm{BuLi}$ generated the corresponding organo lithium species, which was trapped by enantiomerically pure lactone 163 (prepared via diastereoselective $\alpha$ allylation chemistry employing an Evans' auxiliary) to provide hemiketal 156. After which, the above mentioned cyclization was explored, discovering that exposure of lactol 156 to $\mathrm{BF}_{3}$ etherate resulted in the formation of spirocycle 157, albeit in a modest yield of $45 \% .{ }^{105,106}$ Nakada et al. then shifted their focus toward closing the eight membered ring. To this end, the terminal alkene $\mathbf{1 5 7}$ was hydroborated and the resulting primary alcohol protected as its pivaloyl ester. Cleavage of the MOM ether and Dess Martin oxidation gave rise to aldehyde 158, that was subjected together with cyclopentanone 164 to Reformatsky type reaction conditions, using $\mathrm{Ph}_{3} \mathrm{SnH}$ and $\mathrm{Et}_{3} \mathrm{~B}$. The boron enolate generated in situ reacted smoothly with aldehyde 158 to furnish the aldol product as a single isomer $(90 \%$ yield, not shown), which was subsequently dehydrated with Burgess reagent to give enone $\mathbf{1 5 9}$ as a single diastereomer.

Next, the authors set the last two stereogenic centers in ophiobolin A (140) by taking advantage of substrate control: hydrogenation in the presence of RANEY ${ }^{\circledR} \mathrm{Ni}$ followed by exposure to MeLi yielded diol $\mathbf{1 6 0}$ with excellent diastereo selectivity, cleaving the pivaloyl ester in the process. A rather long, 15 step sequence was needed to arrive at the RCM precursor, diene 161, mainly due to protecting group 

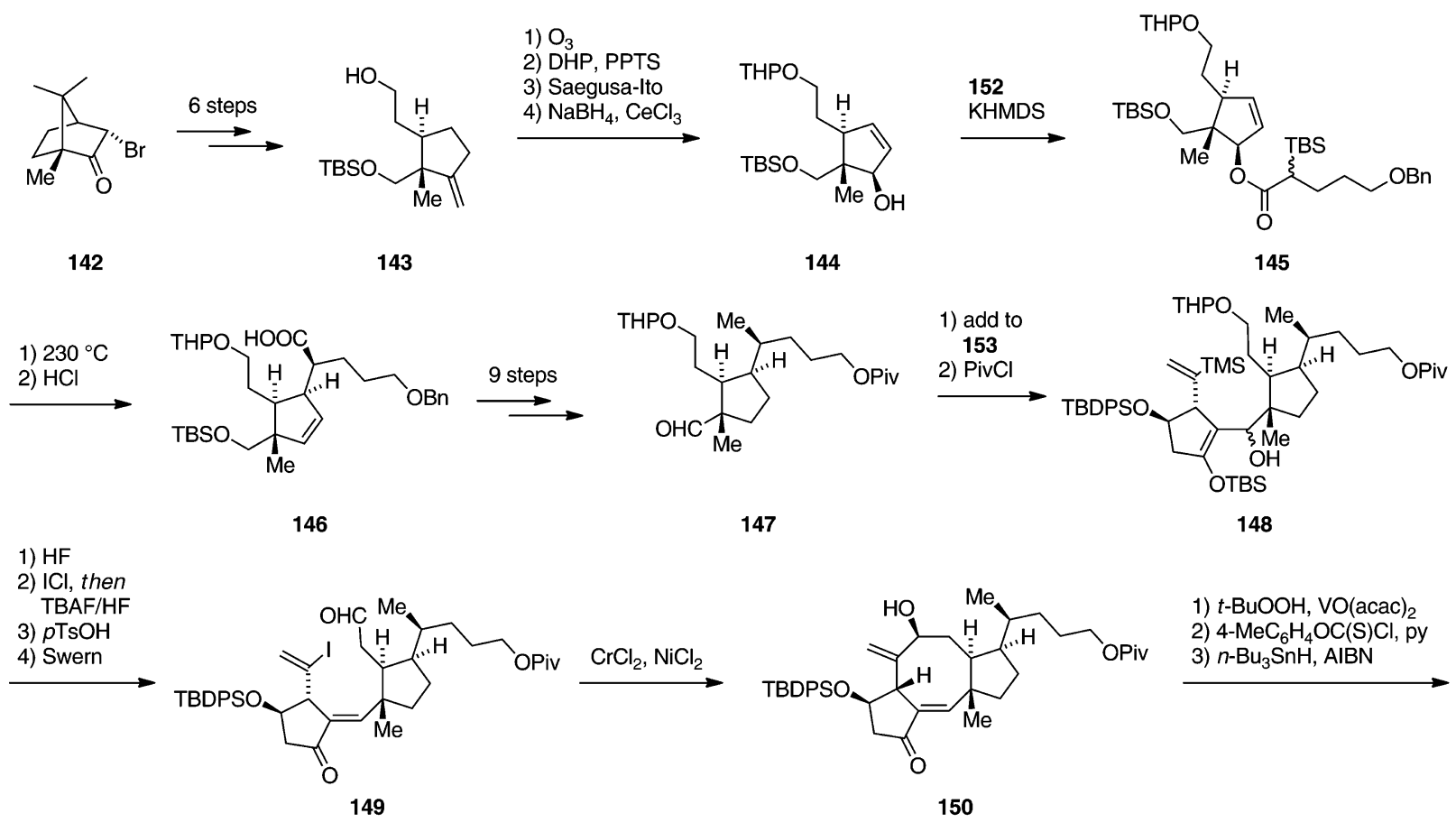

1) $t-\mathrm{BuOOH}, \mathrm{VO}(\mathrm{acac})_{2}$ 2) $4-\mathrm{MeC}_{6} \mathrm{H}_{4} \mathrm{OC}(\mathrm{S}) \mathrm{Cl}$, py 3) $n-\mathrm{Bu}_{3} \mathrm{SnH}$, AIBN

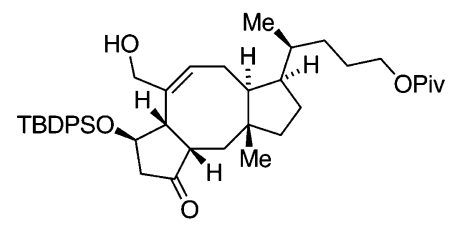

151

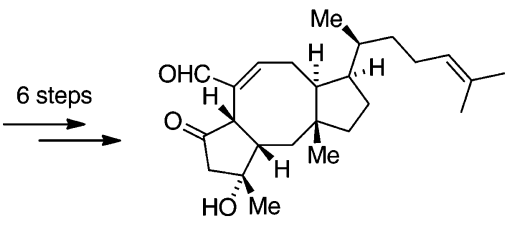

(+)-ophiobolin C (141)

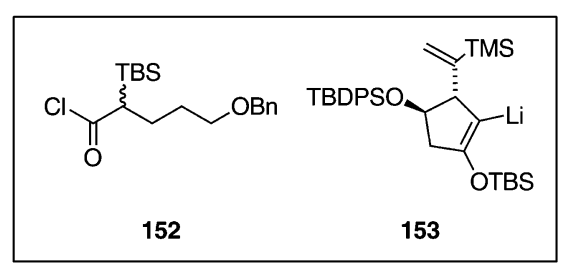

Scheme 18 Kishi's asymmetric synthesis of (+) ophiobolin C using an intramolecular NHK reaction. DHP 3,4 dihydro $2 H$ pyran, PPTS pyr idinium $p$ toluenesulfonate, Saegusa Ito TMS enol ether formation, then $\mathrm{Pd}(\mathrm{OAc})_{2}$, THP 2 tetrahydropyranyl, KHMDS potassium hexame thyldisilazide, Piv pivaloyl, TMS trimethysilyl, TBAF tetrabutylammonium fluoride, $p$ TsOH $p$ toluenesulfonic acid, Swern $\mathrm{Me}_{2} \mathrm{SO}$, $(\mathrm{COCl})_{2}$, then $\mathrm{Et}_{3} \mathrm{~N}$, TBDPS tert butyldiphenylsilyl, py pyridine, acac acetylacetone, AIBN $2,2^{\prime}$ azobis(2 methylpropionitrile), TBS tert butyldimethylsilyl, Bn benzyl.

manipulations, owing to the RCM reaction's sensitivity toward steric congestion. They were ultimately successful, however, as subjecting diene $\mathbf{1 6 1}$ to the Grubbs Hoveyda II catalyst in the presence of 1,4 benzoquinone at $110{ }^{\circ} \mathrm{C}$ closed the eight membered ring, yielding diol 162. Having correctly set all ster eogenic centers and established the tetracyclic framework, Nakada et al. finished the synthesis employing a straightforward six step protocol to give, at long last, the first successful total synthesis of $(+)$ ophiobolin A (140).

\subsection{Ceroplastins}

Shortly following the identification of the ophiobolins, was the discovery of other di and sesterterpenoids bearing a [ $\left[\begin{array}{lll}5 & 8 & 5\end{array}\right]$ tri carbocyclic core. As mentioned earlier, synthesis of such a carbon skeleton was considered challenging, especially the central eight membered ring, thus these natural products provided a platform to develop new synthetic methods for the generation of medium sized rings. ${ }^{98,102}$ One class of such sesterterpenoids possessing a $\left[\begin{array}{lll}5 & 8 & 5\end{array}\right]$ system includes the ceroplastins, represented by $(+)$ ceroplastol I $(\mathbf{1 6 5}),{ }^{107}(+)$ cer oplastol II (166) ${ }^{108}$ and $(+)$ albolic acid (167), ${ }^{109}$ as shown in
Fig. 9. The carbon skeleton of the ceroplastins bears a likeness to that of the ophiobolins, and the first synthesis of rac ceroplastol I (165) was reported by Boeckman et al. as a back to back publication in the same issue as Kishi's total synthesis of (+) ophiobolin C (141). ${ }^{110}$

Contrary to Kishi's strategy (forming the eight membered ring using a NHK reaction), Boeckman constructed the eight membered ring via the fragmentation of an appropriately func tionalized [3.3.1] nonanone system. To achieve this goal, they quickly built up a tricyclic system, starting from racemic bis carbonyl compound 168, by conjugate addition to Michael acceptor $\mathbf{1 7 7}$, followed by $p \mathrm{TsOH}$ mediated aldol condensation to yield tricyclic enone $\mathbf{1 6 9}$ as a $4.9: 1$ mixture of epimers (Scheme 20). Exploiting the bias of the tricyclic system, the group installed the quaternary stereogenic center in lactone $\mathbf{1 7 0}$ with complete stereocontrol during a five step sequence, involving three carbon chain extension and cyclization. A diaster eoselective Michael addition to enone $\mathbf{1 7 0}$ was accomplished using mixed cuprate 178, and the resulting lactone was sol volyzed with LiOMe to furnish ester 171. The [3.3.1] nonane scaffold was then built using a series of redox reactions. Although the authors did not specify the precise identity of the 


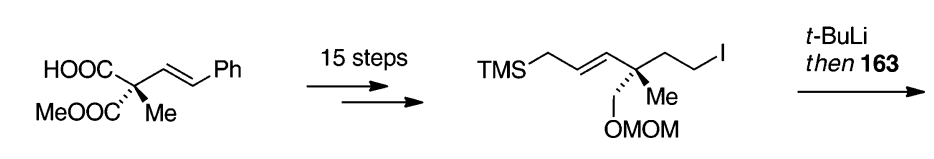

154

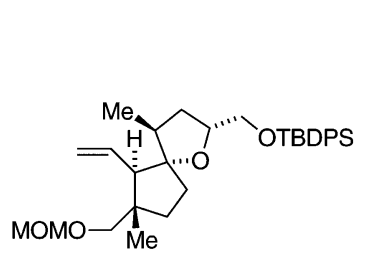

157

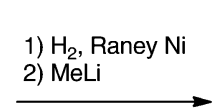

155

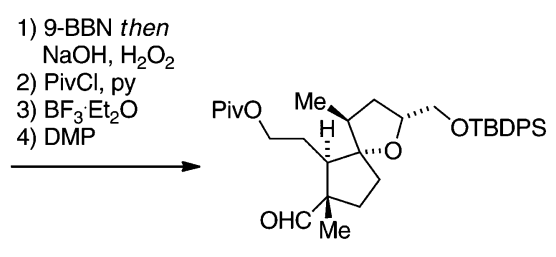

158

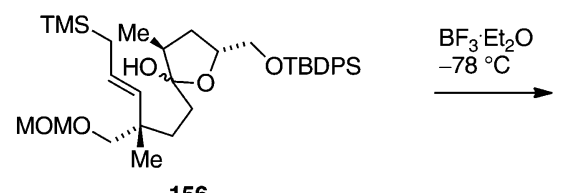

156

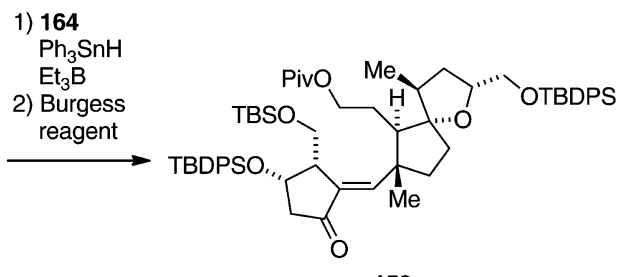

159

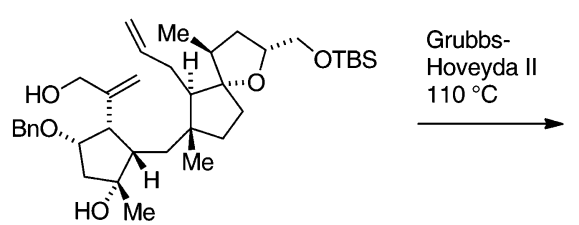

161

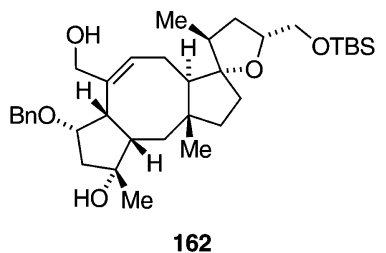

162

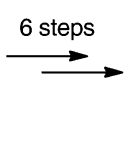

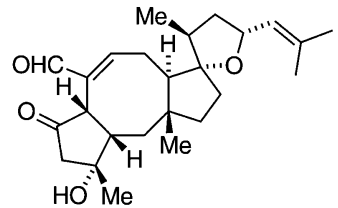

(+)-ophiobolin A (140)

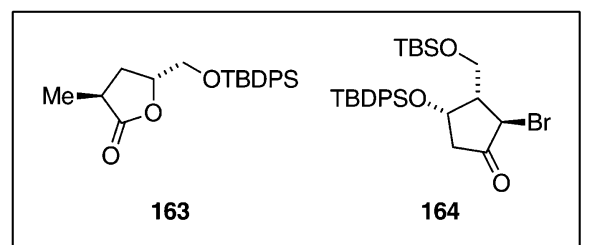

Scheme 19 Nakada's enantioselective synthesis of (+) ophiobolin A employing an RCM to construct the eight membered ring. Ph phenyl, TMS trimethylsilyl, MOM methoxymethyl, TBDPS tert butyldiphenylsilyl, 9 BBN 9 borabicylo[3.3.1]nonane, Piv pivaloyl, DMP Dess Martin periodinane, Burgess reagent (methoxycarbonylsulfamoyl)triethylammonium hydroxide, inner salt, TBS tert butyldimethylsilyl, Bn benzyl.

intermediates in this sequence, it involved a Dieckmann cycli zation that ultimately gave rise to tricyclic ketone 172. An additional four step protocol, including a regio and diaster eoselective reduction of the diketone with $\mathrm{LiAl}(\mathrm{O} t \mathrm{Bu})_{3} \mathrm{H}$, eventually leading to mesylate $\mathbf{1 7 3}$, the substrate for the key Grob fragmentation reaction. As expected, treating ketone $\mathbf{1 7 3}$ with $\mathrm{NaOMe}$ in boiling $\mathrm{MeOH}$ resulted in the formation of diester 174, bearing a suitably functionalized eight membered ring. After establishing the [ [ 58 5] tricarbocyclic framework via another Dieckmann condensation followed by Krapcho decar boxylation, the authors converted the resulting cyclopentanone under Saegusa Ito conditions into enone 175. In order to install the side chain, Michael acceptor $\mathbf{1 7 5}$ was reacted with cuprate 179 to yield ketone $\mathbf{1 7 6}$ as an inseparable $1: 1$ mixture of epimers. The next task at hand was to deoxygenate, and Boeckman et al. were pleased that the transformation of ketone 176 to the corresponding tosylhydrazone not only cleaved the TBS ether as well, but also allowed for separation of the epimers (from the cuprate addition) by preparative TLC. Finally, reduction under quite forcing conditions using $\mathrm{ZnCl}_{2} / \mathrm{NaCNBH}_{3}$ in $\mathrm{MeOH}\left(90{ }^{\circ} \mathrm{C}\right)$ afforded racemic ceroplastol I (165).

In 1993, Paquette and co workers presented an enantiose lective route to $(+)$ ceroplastol I (165). ${ }^{111}$ They began by utilizing the readily available asymmetric building block: acetal protected ketone 180, and converted it into lactone $\mathbf{1 8 1}$ over ten steps (Scheme 21). The latter underwent a sequential Tebbe olefina tion/Claisen rearrangement, generating (via diene 182) the eight membered ring with a cis junction that could be equilibrated with methanolic $\mathrm{K}_{2} \mathrm{CO}_{3}$ to yield the trans fused bicycle $\mathbf{1 8 3}$. After 1,3 carbonyl transposition, requiring five steps, Paquette et al. obtained enone $\mathbf{1 8 4}$ and used cuprate 186 to introduce the last ring, employing a Michael addition/annulation protocol developed earlier by Piers. ${ }^{112}$ Prior to finishing the synthesis with an endgame similar to that reported by Boeckman, Paquette transformed the resulting ketone in tricycle $\mathbf{1 8 5}$ into a trisubsti tuted alkene via formation of the corresponding enol triflate and subsequent methyl cuprate addition.

In comparison to (+) ceroplastol I (165), its double bond isomer $(+)$ ceroplastol II (166) is lacking one stereocenter, as the exocyclic double bond present in the former is shifted one carbon over in the latter, situating it at the ring junction. Nevertheless, this sesterterpenoid 166, as well as its oxidized form (+) albolic acid (167), resisted synthetic attempts until Kato et al. reported its first, and thus far only, total synthesis in $1988 .{ }^{113,114}$ Over the course of this endeavor, the group planned to construct the crucial eight membered ring using a number of interesting

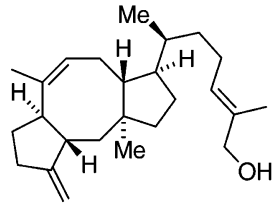

(+)-ceroplastol I (165)

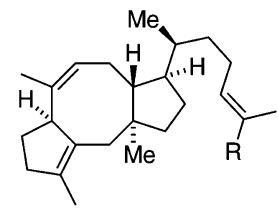

(+)-ceroplastol II (166) $\mathrm{R}=\mathrm{CH}_{2} \mathrm{OH}$ (+)-albolic acid (167) $\mathrm{R}=\mathrm{COOH}$
Fig. 9 Molecular structures of the ceroplastins. 


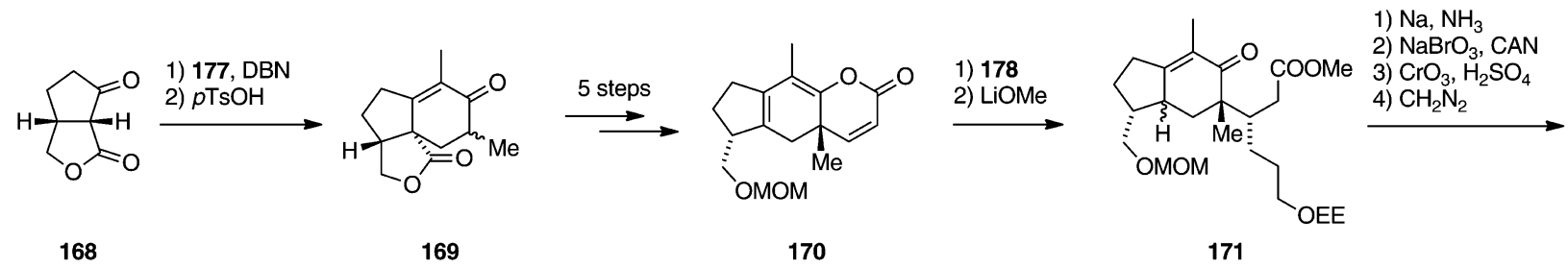

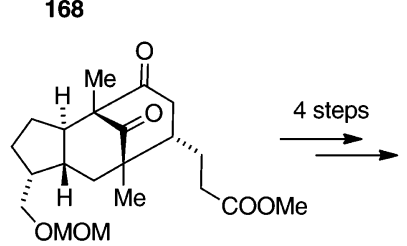

172

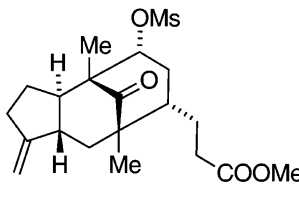

173

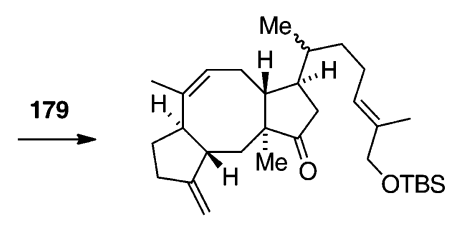

176

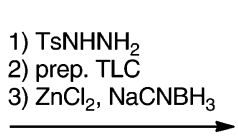

$\stackrel{\mathrm{ZnCl}_{2}, \mathrm{NaCNBH}_{3}}{\longrightarrow}$

$\mathrm{NaOMe}$
$\mathrm{MeOH}, \Delta$ $\mathrm{MeOH}, \Delta$<smiles>C=C1CC[C@H]2/C(C)=C/C[C@@H](CCC(C)=O)[C@H](C(C)=O)C[C@H]12</smiles>

1) KHMDS then

Lil, $155^{\circ} \mathrm{C}$ 2) Saegusa-Ito
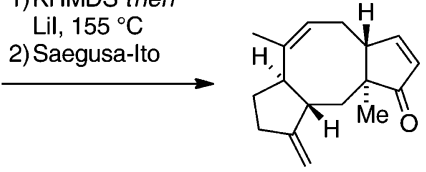

174

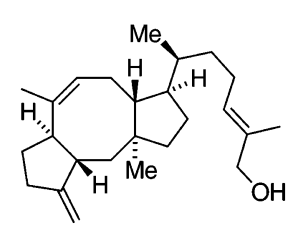

rac-ceroplastol I (165)

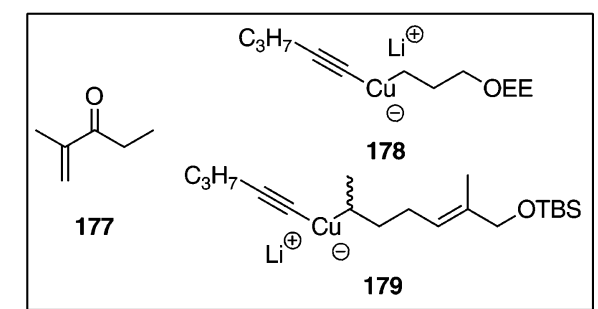

Scheme 20 Boeckman's racemic synthesis of ceroplastol I constructing the eight membered ring via a Grob type fragmentation. DBN 1,5 di azabicyclo[4.3.0]non 5ene, $p \mathrm{TsOH} \quad p$ toluenesulfonic acid, MOM methoxymethyl, EE ethoxyethyl, CAN ammonium cerium(Iv) nitrate, OMs methanesulfonyl, Saegusa Ito lithium diisopropylamide, then $\mathrm{Pd}(\mathrm{OAc})_{2}$, KHMDS potassium hexamethyldisilazide, TBS tert butyldi methylsilyl, $\mathrm{TsNHNH}_{2} \quad p$ toluenesulfonyl hydrazide, prep. TLC preparative thin layer chromatography.

transformations: a $\mathrm{CrCl}_{2}$ mediated coupling, a [3,3] sigmatropic rearrangement and a pinacol coupling/cyclization. Their synthetic program initiated with racemic ester 187, which underwent a $\mathrm{TiCl}_{2}$ mediated reductive cyclization to yield diol $\mathbf{1 8 8}$ as the major product (Scheme 22). To render their synthesis asymmetric, the authors conducted an optical resolution of the corresponding acid. Further transformations delivered both enantiomers of aldehyde $\mathbf{1 8 9}$ over a total of eight steps each. ${ }^{1{ }^{14 c} \mathrm{It}}$ is noteworthy that this classical resolution cannot be considered wasteful, since both enantiomers were eventually used in the synthesis. The aldehyde $(S) \mathbf{1 8 9}$ was transformed over six steps into allylic chloride 190, which in turn was subjected to a $\mathrm{CrCl}_{2}$ promoted reductive coupling with aldehyde $(R) \mathbf{1 8 9}$ in the pres ence of iso PrOH, providing alcohol 191 in $88 \%$ yield. The coupling product was converted over a sequence of six steps to TMS protected lactol 192, which served as a substrate for an unusual oxy Cope rearrangement. The expected chair like tran sition state of such a rearrangement would have resulted in the wrong stereochemical outcome at the quaternary stereogenic center, so Kato et al. biased the system to adapt a normally disfavored boat like transition state, by sequestering the hydroxy group in a six membered silyl lactol. Upon heating this lactol 192 to $190{ }^{\circ} \mathrm{C}$, the rearranged dihydropyran 193 was obtained in good yield. Next, the authors employed a series of chemical transformations to access bisaldehyde 194, the precursor for the key reductive cyclization. Once again employing $\mathrm{TiCl}_{2}$, dicar bonyl compound 194 cleanly underwent pinacol coupling to give diol 195 as a single diastereomer (the relative stereochemistry at one stereocenter could not be assigned unambiguously). A subsequent Birch reduction of the corresponding diacetate with concomitant cleavage of the pivaloyl ester gave rise to alcohol 196, possessing the tricarbocyclic core of $(+)$ ceroplastol II (166).
Extension of the side chain required seven additional steps, giving ester 197, that was used to complete the total synthesis of two sesterterpenoids in a divergent manner: saponification of the ester with $\mathrm{NaOH}$ provided the corresponding acid, (+) albolic

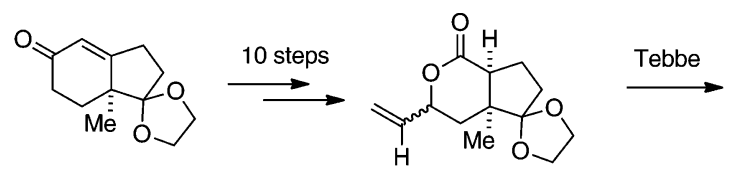

180<smiles>C=C1OC(=CC)C23OCCC2(CCCCC)OC13OCC</smiles>

181
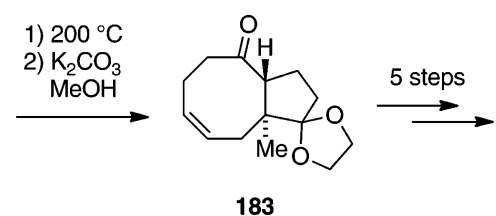

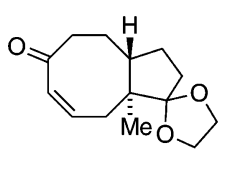

184

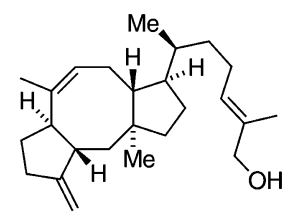

(+)-ceroplastol I (165)
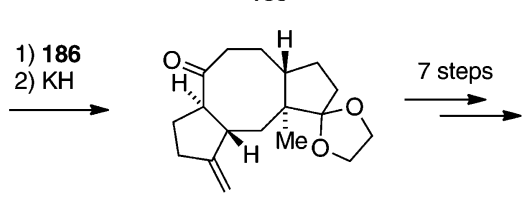

185

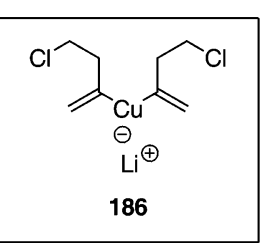

Scheme 21 Paquette's asymmetric synthesis of (+) ceroplastol I exploiting a Tebbe olefination/Claisen rearrangement sequence. Tebbe $\mathrm{Cp}_{2} \mathrm{TiCl}_{2}, \mathrm{AlMe}_{3}$ premixed. 
acid (167), whereas treatment with $\mathrm{LiAlH}_{4}$ resulted in the synthesis of $(+)$ ceroplastol II (166).

\subsection{Miscellaneous tricarbocyclic sesterterpenoids}

In addition to the ophiobolanes, ceroplastols and gascardic acid, a few other tricarbocyclic sesterterpenoids have captured the attention of synthetic chemists. Most of this attention has been directed at natural products possessing the cheilanthane skeleton B (Fig. 10). This topic however, has been reviewed in detail by Ungur and Kulciţki in 2009, ${ }^{115}$ and their account covers the completed syntheses of ( ) hyrthiosal (198), ${ }^{116,117}$ which features a rearranged carbon skeleton. Since then, Fekih et al. ${ }^{118}$ reported the semisynthesis of the cheilanthane sesterterpenoid ( ) petro saspongianolide R (199). ${ }^{119}$

The synthesis of another tricarbocyclic sesterterpenoid, ( ) nitiol (200) (Fig. 11), ${ }^{120}$ a potent enhancer of IL 2 gene expression in human $\mathrm{T}$ cell lines, was attempted, and almost achieved, by Dake and co workers. ${ }^{121}$ In their enantioselective approach, they constructed the carbon framework utilizing a Norrish Type I fragmentation (not shown), and successfully installed the cis relationship between the A ring methyl and iso propyl groups. However, due to a problematic deoxygenation, their attempts to convert dihydroxynitiane 201 into ( ) nitiol (200) have so far been unfruitful. ${ }^{121 b}$

\section{Tetracarbocyclic sesterterpenoids}

\subsection{Cerorubenic acid-III}

( ) Cerorubenic acid III (202) was first isolated in 1983 by Naya et al., and plays a role in insect communication (Fig. 12). ${ }^{122}$ From a series of detailed NMR experiments, the authors assigned its structure as consisting of a unique tetracyclo[8.4.1.0.0]pentade cane skeleton with a pendant side chain, seven contiguous stereogenic centers and an embedded vinylcyclopropane motif, its alkene moiety residing at a bridgehead site.

A campaign that spanned more than a decade in the Paquette group has spawned several published approaches to ( ) ceror ubenic acid III (202), ${ }^{123}$ culminating in a report of its total synthesis in 1998 that confirmed both the original structural assignment and its absolute configuration. ${ }^{124}$ Their successful approach started from cyclohexenone 203, by Michael addition of diethyl malonate, then saponification and decarboxylation to assemble 1,5 keto acid 204 (Scheme 23). An acid catalyzed Claisen condensation, followed by an intramolecular oxidative coupling that proceeded through a dienolate intermediate, gave access to $\mathrm{C}_{S}$ symmetric diketone 205. Subsequent mono methylenation gave unsymmetrical ketone rac 206, that was resolved by 1,2 addition with chiral lithiated sulfoximine $\mathbf{1 3 9}$ and separation of the resulting diastereomers by column chroma tography. Independent pyrolysis of each diastereomer furnished both antipodes of ketone 206 in optically pure form. After ster eoselective addition of vinylmagnesium bromide to afford alcohol 207, the stage was set for the key step of the synthesis: an anionic oxy Cope rearrangement, a signature reaction of the Paquette group. Indeed, treating alcohol 207 with KHMDS in refluxing THF triggered the formation of tricyclic anti Bredt alkene 208 in a remarkably efficient $88 \%$ yield. In preparation for annulation of the D ring, a four step sequence gave silyl ether 209, which in turn was attacked by the lithium salt of phosphine oxide 215. Following desilylation and phosphinate elimination, the resultant isomeric enol ethers $\mathbf{2 1 0}$ were transformed into allylic iodide 211, requiring seven synthetic operations. A Kno chel chain extension was used to insert a methylene unit, by reacting iodide 211 with $\mathrm{ICH}_{2} \mathrm{ZnI}$ in the presence of $\mathrm{CuI}$ and $\mathrm{LiI}$, extending the allylic iodide chain by one carbon unit to afford homoallylic iodide 212. Paquette's various published approaches to ( ) cerorubenic acid III (202) explored several attempts to<smiles>C=C(C)C(CCC(C)=O)C(=O)OC</smiles>

187

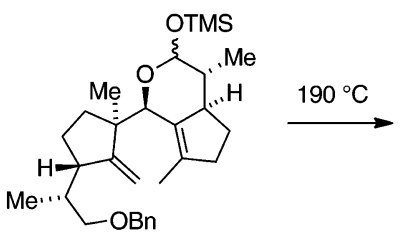

192
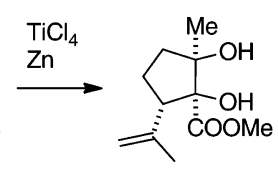

188

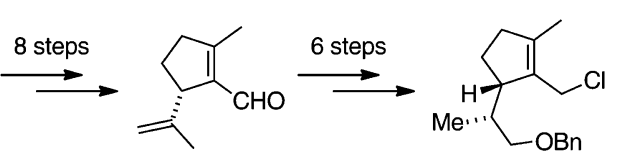

(S)-189

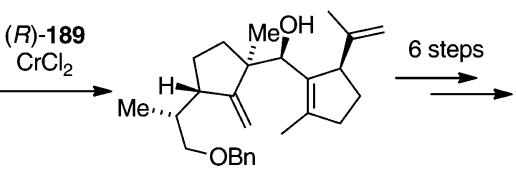

191

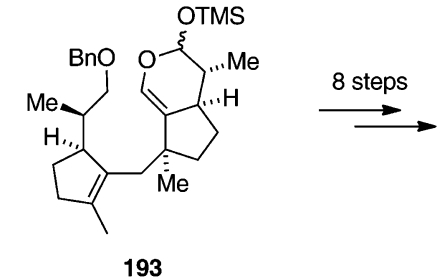

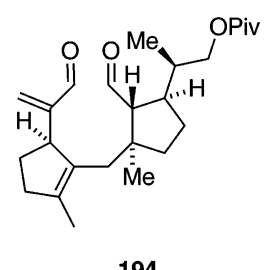

194

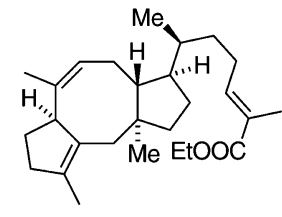

197
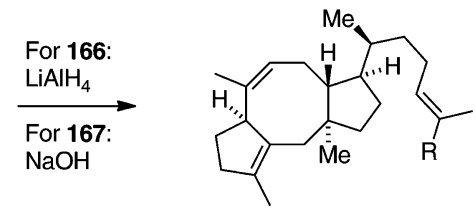

(+)-ceroplastol II (166) $\mathrm{R}=\mathrm{CH}_{2} \mathrm{OH}$ (+)-albolic acid (167) $\mathrm{R}=\mathrm{COOH}$

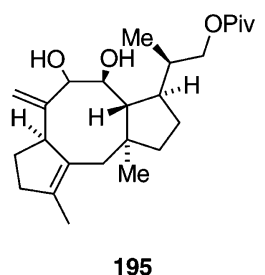

195

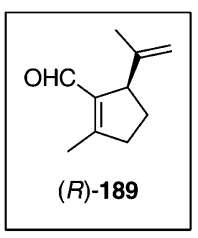

(R)-189

benzyl, TMS tri

Scheme 22 Kato's enantioselective synthesis of $(+)$ ce
methylsilyl, Piv pivaloyl, $\mathrm{Ac}_{2} \mathrm{O}$ acetic anhydride. 


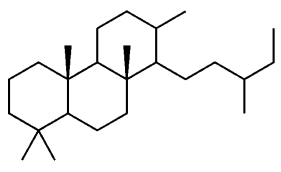

cheilanthane skeleton B

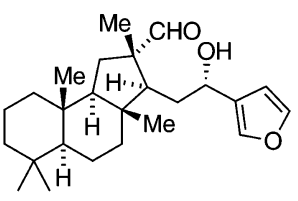

(-)-hyrtiosal (198)

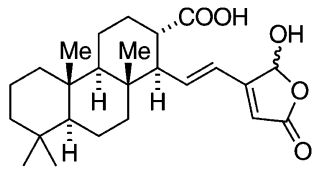

(-)-petrosaspongianolide $\mathrm{R}$ (199)

Fig. 10 Molecular structures of the cheilanthane skeleton and the two members ( ) hyrtiosal and ( ) petrosaspongianolide R.

incorporate the final six membered ring, including two different Robinson annulation strategies. ${ }^{123 c, d}$ Ultimately, only a radical 6 exo cyclization tactic proved successful. Upon subjecting homoallylic iodide $\mathbf{2 1 2}$ to free radical generating conditions ( $n \mathrm{Bu}_{3} \mathrm{SnH}, \mathrm{AIBN}$ ) the authors obtained the cyclized product, ester 213, with the desired stereochemistry at both of the newly formed stereogenic centers (single diastereomer at the ring junction, 4.9: 1 mixture of epimers at the side chain). The details concerning the stereoselectivity of this key step are discussed at length in the full paper. ${ }^{124}$ Stepwise redox/chain extension via successive Horner Wadsworth Emmons reactions delivered ( ) cerorubenic acid III methyl ester (214), that was indistin guishable from an authentic sample.

\subsection{Miscellaneous tetracarbocyclic sesterterpenoids}

Among the tetracarbocyclic sesterterpenoids, there exists a large subclass that is host to the scalarane scaffold $\mathbf{C}$ (Scheme 24). ${ }^{125}$ Owing to their range of anti microbial and cytotoxic activities, scalaranes have been targets of numerous synthetic studies, many of which are semi syntheses starting from either a structurally related sesterterpenoid, or ( ) sclareol (219) (a readily available diterpene building block). The synthesis of scalaranes has already been summarized, together with a description of isolation and biological activities, in a review from 2004. ${ }^{126}$ Since then, it has remained an active area of research, evidenced by successful syntheses of the scalaranes (+) scalarolide (218), ${ }^{\mathbf{9}, 127}$ ( ) sester statin 4 (217), ${ }^{\mathbf{1 2 8 , 1 2 9}}$ its epimer ( ) sesterstatin $5(\mathbf{2 2 0})^{\mathbf{1 2 8 , 1 2 9}}$ and (+) 16 deacetoxy 12 epi scalarafuranacetate $(\mathbf{2 2 1})^{\mathbf{1 3 0 , 1 3 1}}$ recently appearing in the literature. Notably, the latter three completed targets exhibit potent cytotoxic activity, likely stimulating further synthetic and biological studies on related natural products and structural analogs within this compound class.

One such report has been published by Kamel and Slattery in $2009 .{ }^{132}$ Therein, they accomplished the semisynthesis of 20

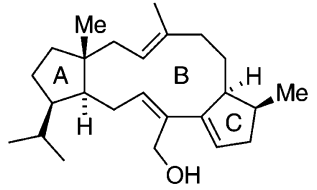

(-)-nitiol (200)
201

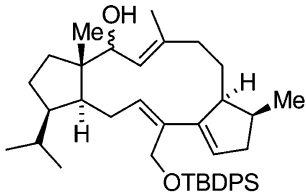

Fig. 11 Molecular structures of ( ) nitiol and Dake's advanced inter mediate 201. TBDPS tert butyldiphenylsilyl.

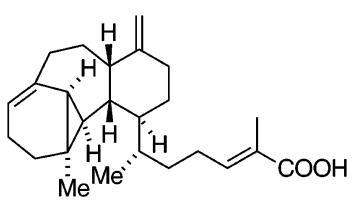

(-)-cerorubenic acid-III (202)

Fig. 12 The molecular structure of ( ) cerorubenic acid III.

natural and synthetic scalarane analogues starting from the naturally abundant metabolite heteronemin (216). ${ }^{133}$ In addition, they conducted biological tests regarding cytotoxicity against different cancer cell lines as well as anti microbial activities.

In 1997, Piers et al. ${ }^{134}$ reported a synthesis of ( ) variecolin's (222) ${ }^{\mathbf{1 3 5}}$ [ [ $\left.\begin{array}{lll}5 & 8 & 5\end{array}\right]$ core (Scheme 25). The Piers group had nearly completed its total synthesis in 2002, as described in S. D. Walk er's Ph.D. thesis. ${ }^{136}$ Unfortunately, they were unable to produce enough material to investigate the conversion of either racemic 5 deoxyvariecolin (not shown) into variecolin (222) or 5 deoxy variecolol (223) and 5 deoxyvariecolactone (224) into the corre sponding natural products. ${ }^{137}$ At around the same time, in 2001, Molander's group published an enantioselective approach to the same target. ${ }^{138}$ They planned to take advantage of a sequenced $\mathrm{SmI}_{2}$ mediated coupling, which they expected to be a viable means to produce cyclooctanoid hemiketal 225. Although their model studies demonstrated the general feasibility of the coupling step, only the asymmetric synthesis of the required building blocks 1,3 keto ester $\mathbf{2 2 6}$ and 4 chloro ketone $\mathbf{2 2 7}$ were reported, with no description of their use in the key coupling step so far.

Uemura et al. $^{139}$ developed an enantioselective route to the tetracarbocyclic core of mangicol A (228) ${ }^{\mathbf{1 4 0}}$ in 2004 (Fig. 13). They invoked a stereoselective transannular Diels Alder reac tion to access spirocycle 230, possessing the majority of the requisite carbon skeleton and functionality. In addition to Uemura et al., the Paquette group conducted initial studies aimed at establishing routes toward $(+)$ mangicol A (228). ${ }^{141}$ More recently, Sarpong et al. described a preliminary investiga tion into the synthesis of related structure $(+)$ neomangicol $\mathrm{C}$ (229), ${ }^{140}$ preparing tetracyclic ketone 231 as a racemate via intramolecular addition of an indene to an aldehyde. ${ }^{\mathbf{1 4 2}}$

The sesterterpenoid YW3699 (232), ${ }^{143}$ with its daunting [5 86 5] tetracarbocyclic core, is a potent inhibitor of GPI anchor biosynthesis, whose absolute configuration and relative config uration at the heptanoate side chain is unknown to date (Fig. 14). It drew the interest of Tori et al., who prepared an advanced intermediate en route to the natural product, tricarbocycle $\mathbf{2 3 3}$, using RCM to effectively close the central eight membered ring. ${ }^{144}$ Noteworthy, the epimeric epoxide did not undergo ring closure. Their model system, however, has not yet addressed the installation of the crucial trans hydrindane moiety found in YW3699 and related molecules. With a cis relationship between its angular methyl and iso propyl substituents, this represents a significant synthetic challenge.

\section{Pentacarbocyclic sesterterpenoids: Retigeranic acid}

Among the known members of this rare sesterterpenoid class, ( ) retigeranic acid A (234) ${ }^{145}$ remains the only one that has 


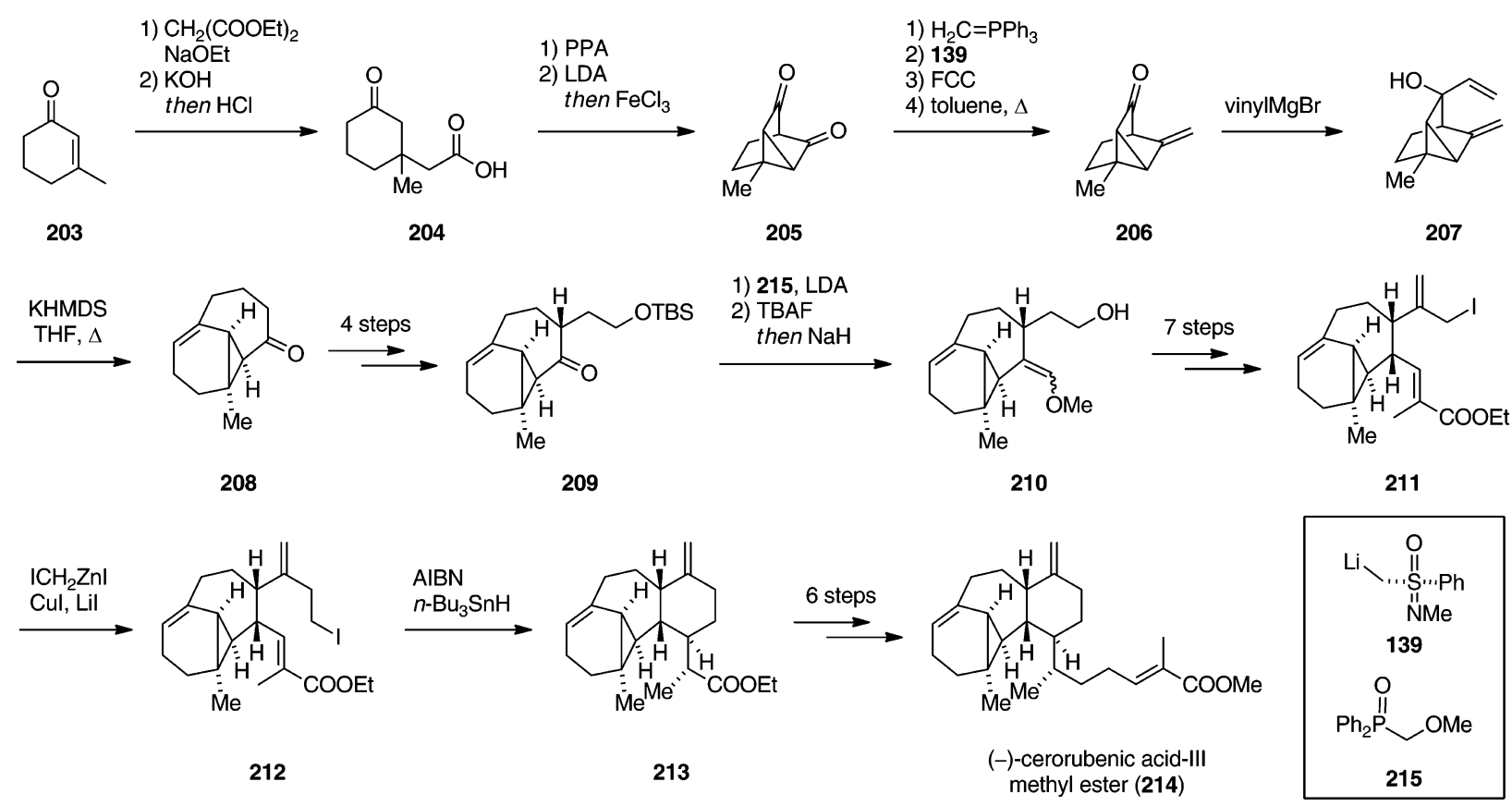

Scheme 23 Paquette's asymmetric synthesis of ( ) cerorubenic acid III methyl ester featuring an anionic oxy Cope rearrangement and a free radical cyclization. PPA polyphosphoric acid, LDA lithium diisopropylamide, FCC flash column chromatography, KHMDS potassium hexame thyldisilazide, TBAF tetrabutylammonium fluoride, AIBN $2,2^{\prime}$ azobis(2 methylpropionitrile).

succumbed to chemical synthesis (Fig. 15). First isolated in 1965 from the Himalayan lichen Lobaria retigera, ${ }^{145 a}$ the structure of acid 234 was not fully assigned until seven years later by Shibata et al., who were able to obtain an $\mathrm{X}$ ray crystal structure of its $p$ bromoanilide derivative. ${ }^{145 c}$

However, during the Corey group's pursuit of a retigeranic acid (234) total synthesis in the early 1980s (see below), ${ }^{146}$ they discovered that an authentic sample of retigeranic acid, which they obtained from Shibata, was in fact a mixture of two dia stereomers. This was learned by the esterification of natural retigeranic acid with $\mathrm{CH}_{2} \mathrm{~N}_{2}$, which enabled separation of the corresponding ester derivatives using HPLC. Furthermore, it was found that ( ) retigeranic acid A (234) ${ }^{\mathbf{1 4 7}}$ was actually the minor component of the mixture. The structure of the major component ( ) retigeranic acid B (235) was elucidated several years later using $X$ ray crystallography and finally published in 1991, again by Shibata. It turned out that acid $\mathbf{2 3 5}$ differs from its counterpart 234 only by the iso propyl substituents' relative stereochemistry (Fig. 15). ${ }^{145 d}$ As a consequence of this molecule's complicated history, all four successful total syntheses targeted the originally reported structure of ( ) retigeranic acid (234), since the synthetic work was completed prior to Shibata disclosing the identity of ( ) retigeranic acid B (235).

From a synthetic chemist's point of view, retigeranic acid (234) can be thought to possess an intimidating molecular structure, being comprised of several noteworthy features: eight stereogenic centers, two of which are quaternary, and a unique penta carbocyclic skeleton. This framework includes a trans hydrin dane and a triquinane moiety that together comprise four five membered and one six membered ring. Remarkably, the molecule has only a single oxygenated site, namely a lone carboxylic acid functionality. Often labelled as a classic target in total synthesis, ${ }^{\mathbf{1 4 8 , 1 4 9}}$ retigeranic acid (234) has provided numerous challenges for the groups of Corey, ${ }^{146}$ Paquette, ${ }^{150}$ Hudlicky ${ }^{151}$ and Wender, ${ }^{152}$ all of whom were ultimately successful undertaking its synthesis.

The Corey group was the first to complete the total synthesis of retigeranic acid (234) in 1985, ensuring its subsequent popularity as a synthetic target. ${ }^{146}$ One of the most obvious stumbling blocks they faced, the diastereoselective installation of the crucial quaternary center embedded within the triquinane system, was addressed elegantly with an intramolecular ketene/alkene [2 + 2] cycloaddition. It was anticipated that subsequent ring expan sion/ring contraction processes could be exploited to access to the required triquinane moiety. They elected to begin their synthesis from racemic hydrindenone 236, which was readily available via Robinson annulation. ${ }^{153}$ The authors chose to employ a substrate directed hydrogenation to set the trans ring junction in alcohol 237, since formation of the strained trans hydrindane ring system is usually thermodynamically unfa vored. ${ }^{154} \mathrm{~A}$ short sequence of functional group manipulations were carried out: a diastereoselective reduction of ketone 236 with $\mathrm{LiAlH}_{4}$, followed by alcohol inversion using Mitsunobu conditions. Directed hydrogenation in the presence of cationic Rh catalyst 247 under high pressure (950 psi) furnished the desired trans hydrindane 237 (Scheme 26). Subsequently, the alcohol was re oxidized to the corresponding ketone using Jones' reagent. A two step protocol commencing with vinyl Grignard addition, followed by elimination of water yielded diene $\mathbf{2 3 8}$, which in turn served as a substrate for the Diels Alder reaction with dienophile 248. The desired [4 2] cycloadduct 239 was produced in $61 \%$ yield as the major isomer, and six additional steps were needed to prepare carboxylic acid 240, the precursor for the key $[2+2]$ cycloaddition. Treatment with oxalyl chloride 
a)<smiles>CC1[C@H]2CC[C@@](C)(C(C)CCC3C2CC[C@H]2C(C)(C)CCCC32C)[C@@H]1C</smiles>

scalarane skeleton C

b)

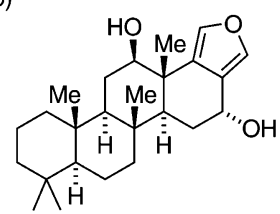

(-)-sesterstatin 4 (217)

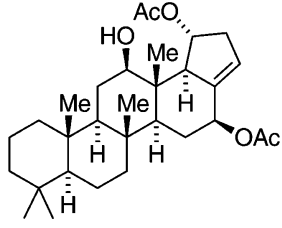

heteronemin (216)

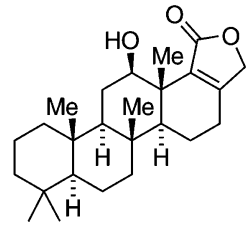

(+)-scalarolide (218)

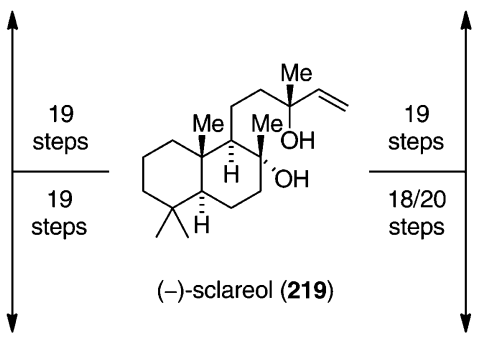

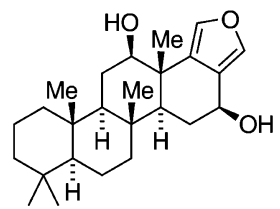

(-)-sesterstatin $5(220)$

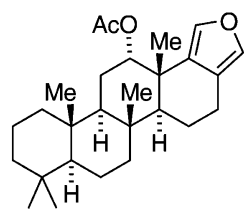

(+)-16-deacetoxy-12-episcalarafuranacetate (221)

Scheme 24 (a) Molecular structures of the scalarane skeleton $\mathbf{C}$ and the natural product heteronemin, (b) recently reported semisyntheses of biologically active scalaranes starting from ( ) sclareol.

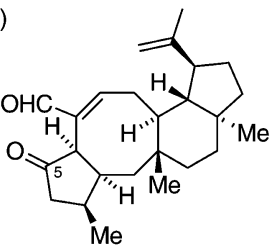

(-)-variecolin (222) b)

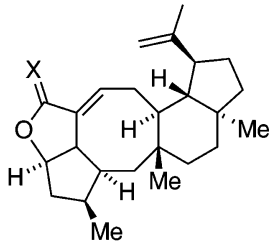

5-deoxyvariecolol (223) $\quad \mathrm{X}=\mathrm{H}_{2}$ 5-deoxyvariecolactone (224) $\mathrm{X}=\mathrm{O}$

c)

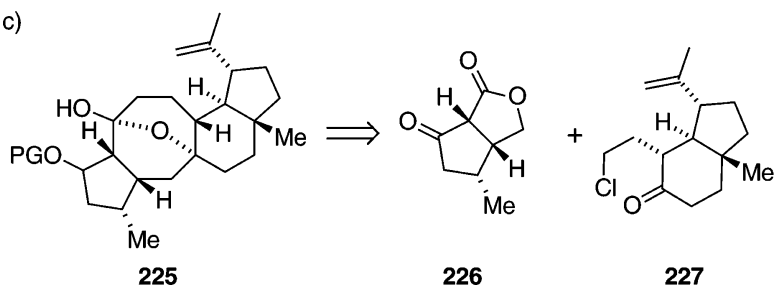

Scheme 25 (a) Molecular structure of ( ) variecolin, (b) deoxygenated natural products synthesized by Piers, (c) Molander's retrosynthetic analysis and building blocks $\mathbf{2 2 0}$ and $\mathbf{2 2 1}$ prepared in an enantioselective fashion. PG protecting group.

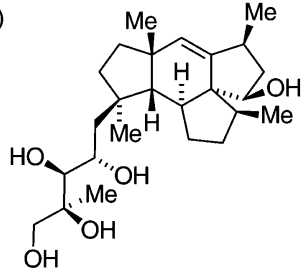

(+)-mangicol A (228)

b)

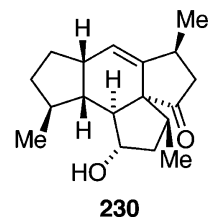

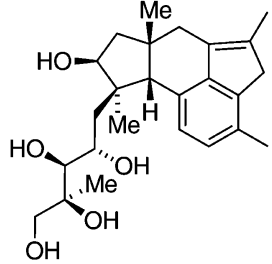

(+)-neomangicol C (229)

c)<smiles>CC1=C2C(=O)C3(C)CCC=C3c3cccc(c32)C1</smiles>

Fig. 13 (a) Molecular structures of $(+)$ mangicol A and $(+)$ neo mangicol C, (b) core structure $\mathbf{2 3 0}$ asymmetrically prepared by Uemura via a Diels Alder reaction, (c) Sarpong's racemic tetracyclic intermediate 231.

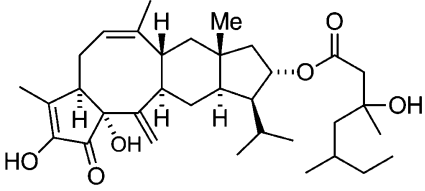

YW3699 (232)

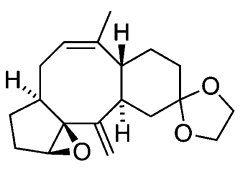

233
Fig. 14 Molecular structures of GPI anchor inhibitor YW3699 and Tori's tricarbocycle 233 prepared by RCM.

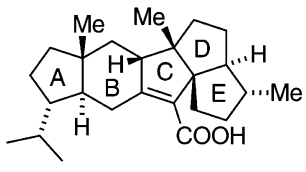

(-)-retigeranic acid A (234)

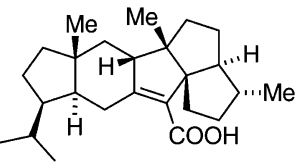

(-)-retigeranic acid B (235)
Fig. 15 Molecular structures of ( ) retigeranic acids A and B.

and $\mathrm{Et}_{3} \mathrm{~N}$ generated the corresponding ketene $\mathbf{2 4 1}$ in situ, smoothly giving rise to cyclobutanone $\mathbf{2 4 2}$ in $80 \%$ yield, thereby accomplishing diastereoselective incorporation of the all carbon quaternary center. The ring expansion of cyclobutanone $\mathbf{2 4 2}$ to the corresponding cyclopentanone was initiated by the addition of lithiated dithiane 249, giving rise to carbonyl adduct $\mathbf{2 4 3}$ in $73 \%$ yield. A subsequent CuOTf mediated thio pinacol rear rangement in the presence of $\mathrm{Et}_{3} \mathrm{~N}$ was followed by a two step desulfurization sequence: oxidation with $\mathrm{NaIO}_{4}$ and then reductive $\mathrm{C} \mathrm{S}$ bond cleavage with $\mathrm{Al} / \mathrm{Hg}$. The resulting cyclo pentanone $\mathbf{2 4 4}$, obtained in $65 \%$ overall yield, was later trans formed into alkene $\mathbf{2 4 5}$ over a five step sequence that included olefin hydrogenation, methyl group epimerization and deoxy genation via modified Wolff Kishner reduction. The final remaining hurdle was to introduce the triquinane motif via ring contraction. This was made possible in four steps, starting with $\mathrm{OsO}_{4}$ promoted dihydroxylation, followed by glycol cleavage with $\mathrm{Pb}(\mathrm{OAc})_{4}$ yielding dialdehyde $\mathbf{2 4 6}$ that was surrendered to $\mathrm{Al}_{2} \mathrm{O}_{3}$, which affected aldol ring closure. At long last, a Pinnick oxidation concluded the synthesis, providing access to racemic retigeranic acid (234) in 32 steps (longest linear sequence). 
In contrast to Corey's linear synthesis, Paquette et al. adopted a more convergent strategy in their enantioselective route to ( ) retigeranic acid (234), reported in $1987 . .^{150}$ They intended to attach the A ring via 1,4 addition to a triquinane fragment then close the $\mathrm{B}$ ring late in the synthesis using an intramolecular aldol condensation. The required triquinane building block 259 was synthesized starting from (+) pulegone (250). ${ }^{155}$ The latter was brominated, then treated with $\mathrm{NaOMe}$ to trigger a Favorskii rearrangement with concomitant elimination of bromide. Subsequent ozonolysis yielded cyclopentanone $251,{ }^{156}$ that was alkylated with tosylate $\mathbf{2 5 3}$ under basic conditions (Scheme 27). A ketone functionality was then unmasked by ozonolysis, enabling ring closure by aldol condensation. Subsequent heating of the product in the presence of LiI affected decarboxylation of the ester, yielding bicyclic enone $\mathbf{2 5 2}$ as a separable 2: 1 mixture of diastereomers. The remaining two stereogenic centers in triquinane 259 were set in two steps: a diastereoselective Michael addition of the cuprate derived from Grignard reagent 254, followed by $\mathrm{HCl}$ mediated acetal hydrolysis that resulted in spontaneous aldol cyclization and furnished triquinane 257 as a mixture of epimers. Next, thiocarbonate formation and subsequent Chugaev type elimination yielded alkene $\mathbf{2 5 8}$. Finally, Wolff Kishner reduction and a chromium mediated allylic oxidation of the corresponding hydrocarbon gave access to the desired triquinane building block 259. It is worth noting that formation of enone $\mathbf{2 5 9}$ was accompanied by significant amounts $(\mathrm{ca} .30 \%)$ of the undesired 1,3 transposed enone. This certainly represented a drawback, since separation from the desired product was only possible upon reduction to the alcohol stage, thus an extra re oxidation step was added to the sequence employed to obtain pure tricyclic ketone 259.

Paquette et al. once again turned to the chiral pool for the synthesis of the second fragment, choosing to start from ( ) limonene (260). ${ }^{157}$ It was possible to access allylic alcohol 261 in six steps, which in turn was converted into ketone 262 via Wittig Still rearrangement (utilizing stannane 256) followed by ozonolysis and TBS protection. Formation of cylcopentenone $\mathbf{2 6 3}$ from ketone $\mathbf{2 6 2}$ required adjustment of both functionality and relative stereochemistry. This net conversion was achieved using a four step protocol that involved 1,3 ketone transposition/ enone formation, followed by the 1,4 addition of vinyl cuprate (dr $77: 23$ ). Completion of the second fragment was accom plished by Wolff Kishner reduction with simultaneous desily lation, and conversion of the primary alcohol to bromide $\mathbf{2 6 4}$ with $\mathrm{ZnBr}_{2} / \mathrm{DEAD} / \mathrm{PPh}_{3}$. The authors commented that the latter transformation was exceptionally difficult due to the alcohol being neopentylic and only Mitsunobu type conditions proved effective. Having established viable routes to both fragments, Paquette and co workers explored the key coupling step, discovering that the Grignard reagent derived from alkyl bromide 264 underwent exclusive 1,4 addition to sterically hindered enone 259. Unfortunately, however, after ozonolysis of the addition product, aldehyde $\mathbf{2 6 5}$ was obtained as the minor diastereoisomer ( $\mathrm{dr} 1: 3$ ), indicating that the 1,4 addition was unselective. Closing the $\mathrm{B}$ ring via aldol condensation required quite harsh conditions, namely piperidine and HOAc in hot toluene for $48 \mathrm{~h}$. These conditions led to partial epimeriza tion of the aldehyde at the $\alpha$ position, producing the desired trans configured product as the minor diastereomer (dr 1:4, separated at the end of the synthesis by HPLC) and in modest combined yield. The resulting enone system was hydrogenated in the presence of $\mathrm{PtO}_{2}$ under elevated pressure (80 psi), giving rise to an epimeric mixture of ketones 266. Paquette et al. were able to finish the synthesis in four additional steps. First, ketone $\mathbf{2 6 6}$ was homologated via high pressure (100000 psi) cyanohydrin formation in the presence of $\mathrm{KCN}$ and 18 crown 6, then dehy drated with $\mathrm{POCl}_{3}$ and $\mathrm{DBU}$ in boiling pyridine to give the corresponding $\alpha, \beta$ unsaturated nitrile. Finally, DIBAL $\mathrm{H}$ reduction and Pinnick oxidation provided ( ) retigeranic acid (234), constituting its first asymmetric preparation.

Despite the convergent nature of Paquette's synthesis, it nevertheless required a large number of steps (26 steps, longest linear sequence), and suffered from modest yields, especially due to the low stereoselectivities obtained in late stage trans formations. One year after Paquette's work was published, Hudlicky and co workers reported a shorter asymmetric synthesis of ( ) retigeranic acid (234) with a longest linear sequence of only 18 steps. ${ }^{151}$ Their strategy hinged on generating the pentacyclic framework by forming the C ring via a $[2+3]$ annulation, involving the thermolysis of a vinyl cyclopropane (vide infra). Hudlicky et al. selected (+) menthene (267) as a starting material, carrying out its ozonolysis in the presence of $p \mathrm{TsOH} / \mathrm{MeOH}$ to protect the in situ formed aldehyde as its dimethyl acetal. Regeneration of the aldehyde under mild acidic conditions was followed by direct conversion to enamine $\mathbf{2 6 8}$ (Scheme 28). The latter was ozonolyzed, excising one carbon unit to reveal an aldehyde. A subsequent HWE reaction with phos phonate $\mathbf{2 7 5}$ was used to install a diene. Wittig methylenation of the remaining methyl ketone then gave triene $\mathbf{2 6 9}$ setting the stage for an intramolecular Diels Alder reaction to produce the indane skeleton in ester 270. This transformation proceeded diastereoselectively, but produced an inconsequential mixture of double bond isomers in modest yield. Enol ether hydrolysis and Krapcho decarboxylation finally yielded enantiomerically pure hydrindane $\mathbf{2 7 1},{ }^{158}$ which incidentally, also served as an inter mediate in Corey's retigeranic acid synthesis, albeit as a race mate. In preparation for the key step, hydrindane 271 was condensed with ethyl trimethylsilylacetate (276), and after sequential bromination/monodehydro bromination, ester $\mathbf{2 7 2}$ was obtained. With this compound in hand, Hudlicky et al. were poised to explore their annulation strategy. Adding the LDA derived dienolate of ester 272 to enone 252 ( $c f$. Scheme 27), at $100{ }^{\circ} \mathrm{C}$ resulted in 1,4 addition and subsequent nucleophilic substitution, forming vinylcyclopropane 273 as an $1: 1$ mixture of stereoisomers. Subsequently, flash vacuum pyrolysis of each isomeric vinylcyclopropane $\mathbf{2 7 3}$ gave rise to ketone $\mathbf{2 7 4}$ with good diastereoselectivitiy ( $4: 1$ to $2: 1$, depending on the isomer used). ${ }^{151 a}$ From this point, erasure of the ketone was accom plished in three steps by ketone reduction and Barton McCombie deoxygenation. Finally, saponification of the ethyl ester that followed concluded their elegant total synthesis of ( ) retiger anic acid (234).

The most recent synthesis of retigeranic acid (234) reported thus far came from the Wender group in $1990 .{ }^{152}$ Intending to close the B ring at a late stage via an intramolecular Diels Alder reaction, their plan was contingent on construction of the tri quinane portion by employing a photochemical arene alkene cycloaddition, a methodology previously developed in their 


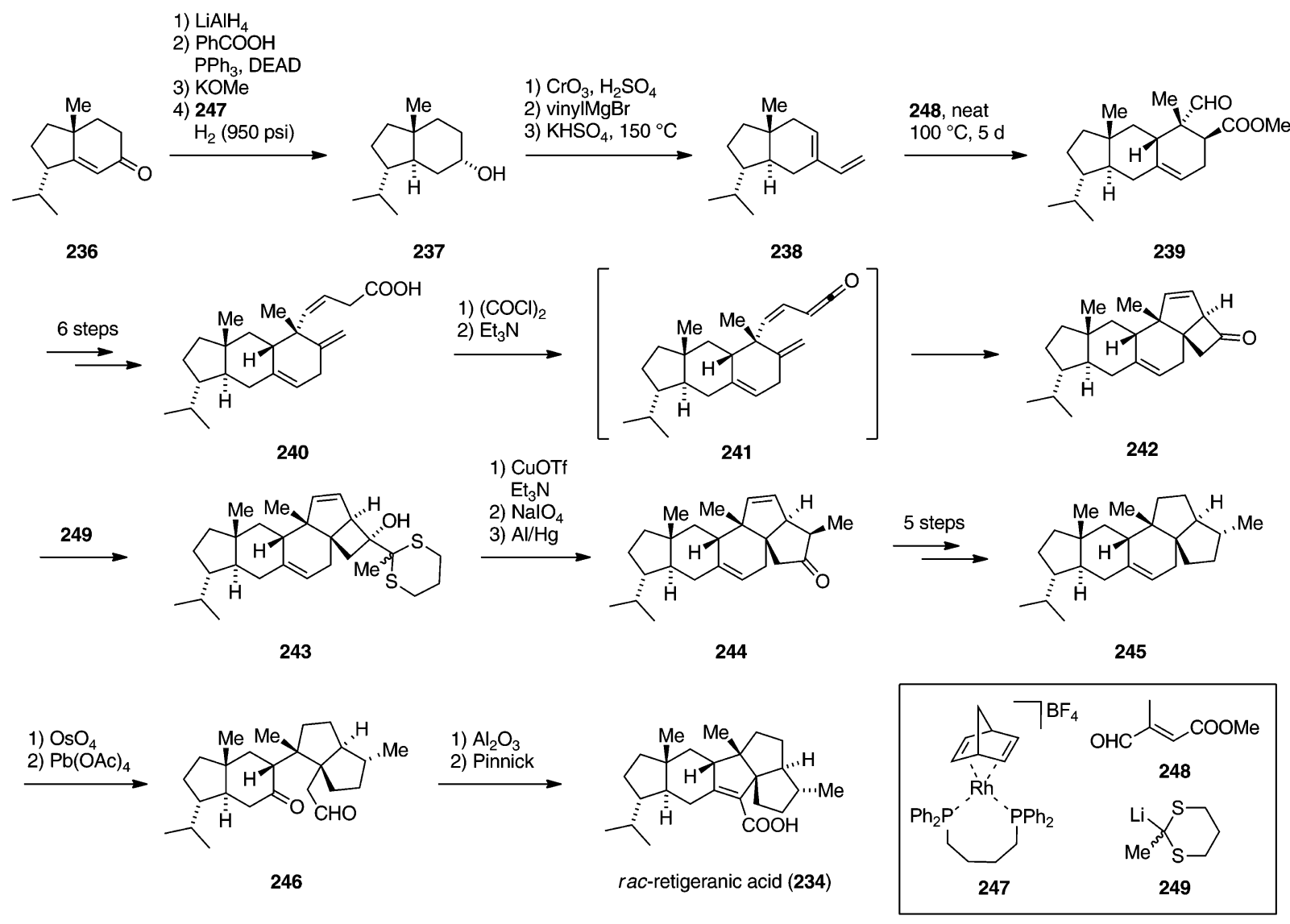

Scheme 26 Corey's racemic synthesis of retigeranic acid employing a ring expansion/contraction strategy to install the quaternary center of the tri quinane subunit. DEAD diethyl azodicarboxylate, Pinnick $\mathrm{NaClO}_{2}, \mathrm{NaH}_{2} \mathrm{PO}_{4}, t \mathrm{BuOH}$.

laboratories. Starting from half ester 277 (readily available in $99 \%$ ee by enzymatic resolution of 3 methyl glutaric dimethyl ester), six steps were required to furnish arene $\mathbf{2 7 8}$ (Scheme 29). The pivotal photochemical cycloaddition proceeded efficiently, but unfortunately furnished the desired tetracycle 279 as the minor isomer (1:2 selectivity). It is noteworthy however, that this transformation rapidly builds complexity and was suitable for preparing multi gram quantities of tetracycle 279. Cyclopropane ring opening and installation of the correct functionality was accomplished by exposure to an acyl radical, generated photochemically from formamide, resulting in addi tion to the alkene and fragmentation of the intermediate cyclo propylcarbinyl radical. The resulting amide product $\mathbf{2 8 0}$ was then methylated, yielding triquinane $\mathbf{2 8 1}$, followed by allylic oxidation with $\mathrm{SeO}_{2}$ to deliver aldehyde 282. Condensation of the latter with the dianion of acid $\mathbf{2 8 7}$ (available in four steps from $(R)$ ( ) carvone) and subsequent decarboxylative dehy dration afforded triene 283. Heating this Diels Alder precursor (toluene, $250{ }^{\circ} \mathrm{C}$ ) yielded cycloadduct 284 as the major isomer along with two isomers (one diastereomer, one double bond regioisomer). Unfortunately, however, further isomerization of the double bond into conjugation with the amide was problem atic, and the authors instead opted for an indirect method by epoxidation, base mediated ring opening and dehydration to yield diene 285. Poor selectivity was observed for the following high pressure hydrogenation step, furnishing the desired stereoisomer of pentacyclic amide $\mathbf{2 8 6}$ in only $25 \%$ yield. It was possible however, to recycle the other isomeric products obtained from this reaction. With simply oxidation state adjustment required for completion of the synthesis, amide $\mathbf{2 8 6}$ was reduced with $\mathrm{LiAlH}_{4}$, followed by stepwise oxidation using PDC and Pinnick conditions, yielding ( ) retigeranic acid (234) after 20 steps (longest linear sequence). Similar to Paquette, Wender's approach was plagued by late stage selectivity problems that were detrimental to the overall efficiency of the synthesis, leaving room for improvement from future generations of synthetic chemists. Since the 1990s however, no additional data toward the synthesis of either ( ) retigeranic acid (234) or its diastereomer, ( ) retigeranic acid B (235) (Fig. 15), have surfaced in the liter ature. Furthermore, to the best of our knowledge, no synthetic groups have reported progress toward any other members of this rare and beautiful class of sesterterpenoids.

\section{Conclusions}

Herein, we have presented a few dozen total syntheses that have yielded sesterterpenoids of varying complexity, ranging from simple linear molecules to highly complex polycyclic systems. These syntheses have featured much of the repertoire of modern chemistry, including transition metal catalyzed $\mathrm{C} \mathrm{C}$ bond formations and macrocyclizations, cycloadditions, and rear rangements. The rather lengthy sequences needed in many cases, 


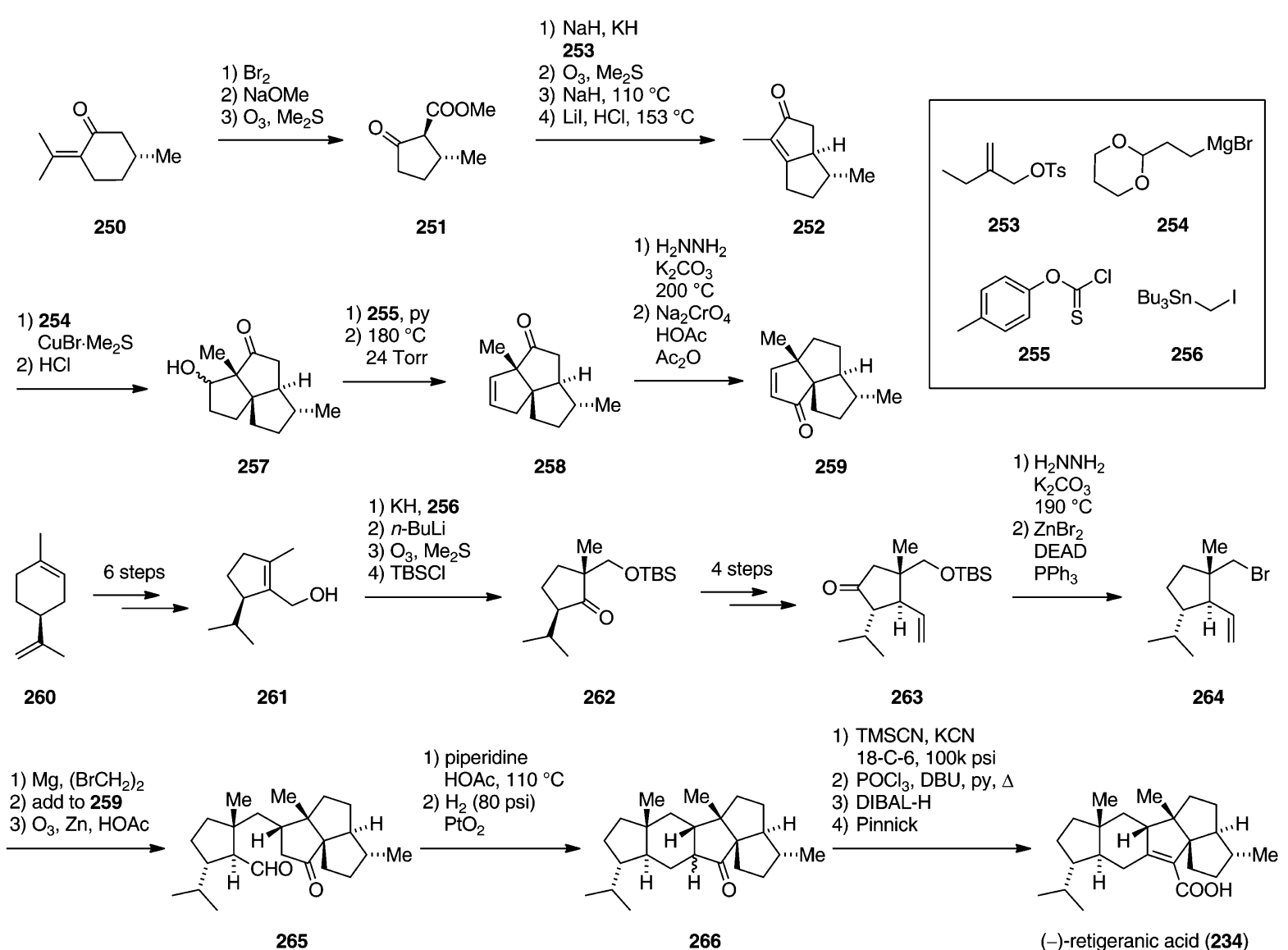

Scheme 27 Paquette's asymmetric synthesis of ( ) retigeranic acid featuring a Grignard reagent 1,4 addition and an aldol condensation to close the B ring at last. py pyridine, $\mathrm{HOAc}$ acetic acid, $\mathrm{Ac}_{2} \mathrm{O}$ acetic anhydride, TBS tert butyldimethylsilyl, DEAD diethyl azodicarboxylate, TMS trimetylsilyl, DBU 1,8 diazabicyclo[5.4.0]undec 7 ene, 18 C $6 \quad 1,4,7,10,13,16$ hexaoxacyclooctadecane, DIBAL H diisobutylaluminum hydride, Pinnick $\quad \mathrm{NaClO}_{2}, \mathrm{NaH}_{2} \mathrm{PO}_{4}, 2$ methyl 2 butene, $t \mathrm{BuOH}$.

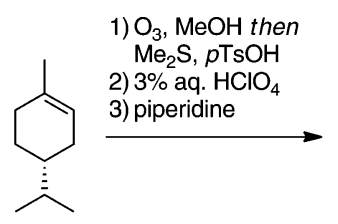

267

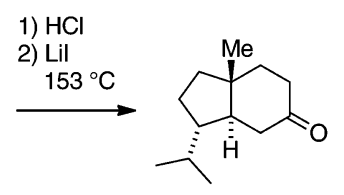

271

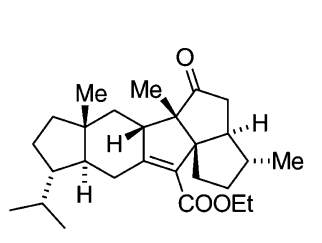

274

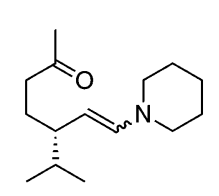

268

1) LDA, 276

2) $\mathrm{Br}_{2}$

3) $\mathrm{DBU}$
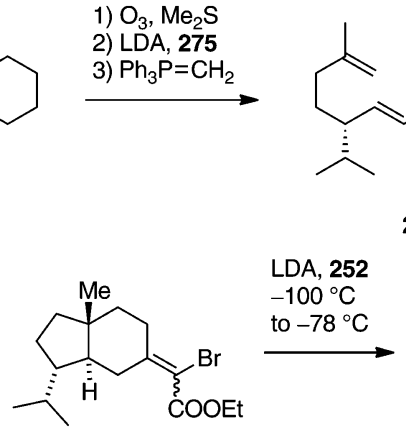

272

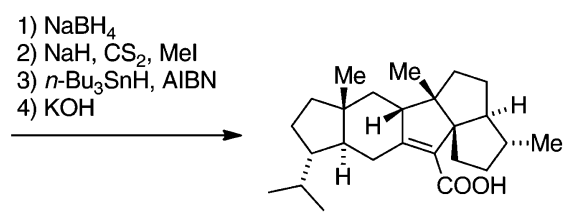

(-)-retigeranic acid (234)

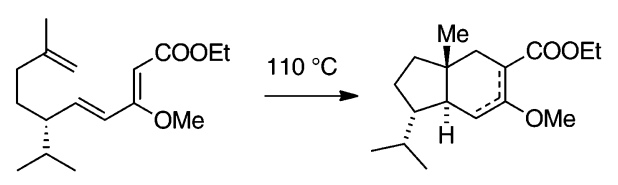

269

270

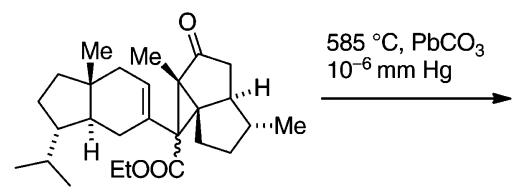

273

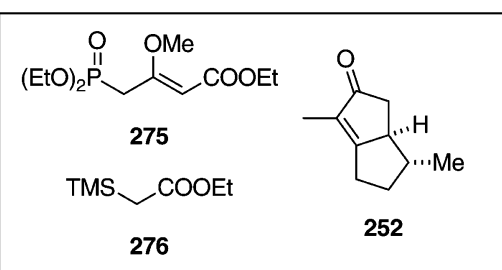

Scheme 28 Hudlicky's enantioselective synthesis of ( ) retigeranic acid utilizing a vinylcyclopropane rearrangement. $p$ TsOH para toluenesulfonic acid, LDA lithium diisopropylamide, DBU 1,8 diazabicyclo[5.4.0]undec 7 ene, AIBN 2,2' azobis(2 methylpropionitrile), TMS trimethylsilyl. 


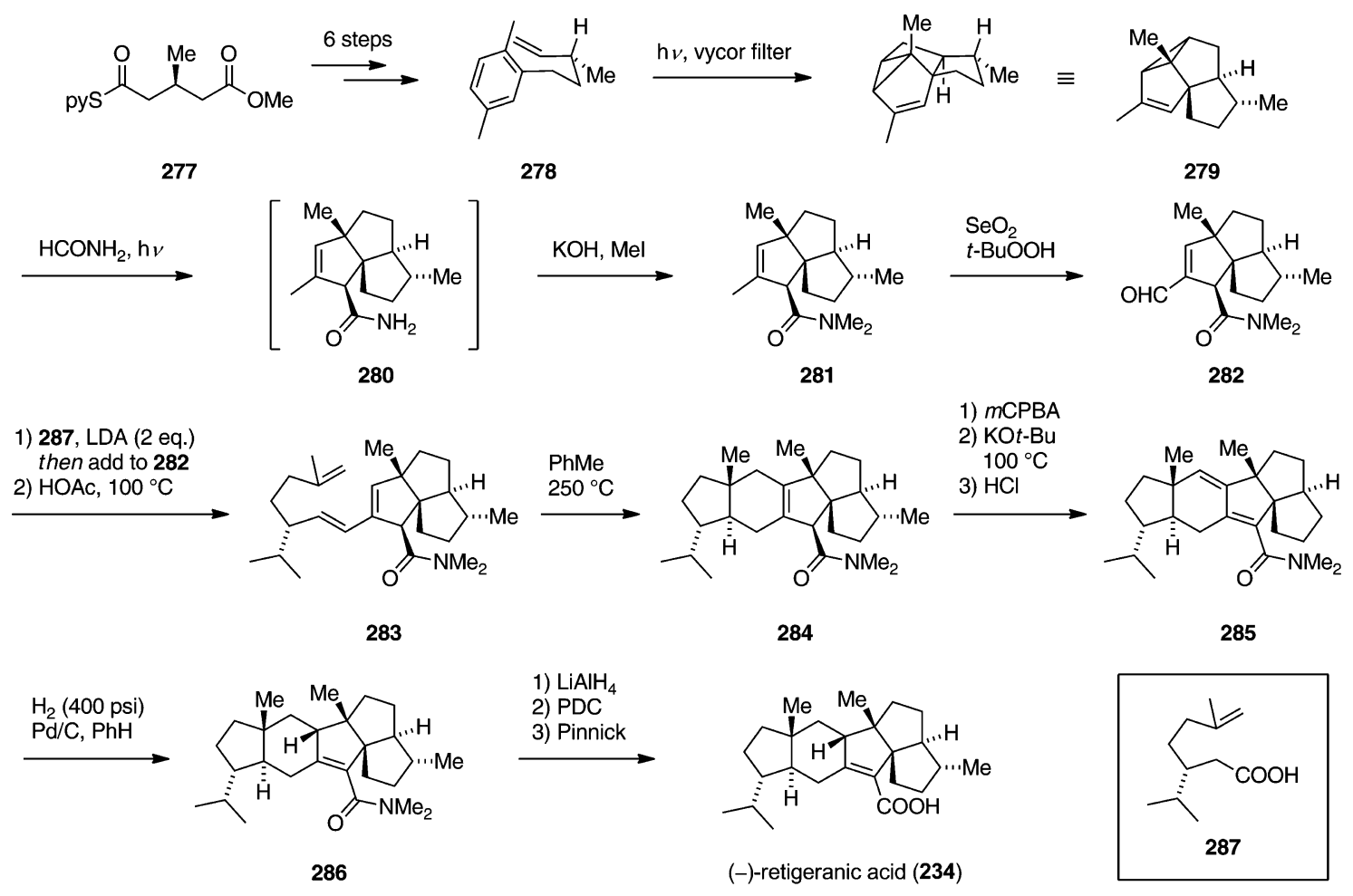

Scheme 29 Wender's asymmetric synthesis of ( ) retigeranic acid generating the triquinane subunit via a photochemical arene alkene cycloaddition. py 2 pyridyl, LDA lithium diisopropylamide, $m$ CPBA $m$ chloroperbenzoic acid, $\mathrm{PDC}$ pyridinium dichromate, $\mathrm{Pinnick}^{\mathrm{NaClO}} \mathrm{NaH}_{2} \mathrm{PO}_{4}, t$ $\mathrm{BuOH}$.

e.g. in the synthesis of ophiobolin A (140) or retigeranic acid A (234), reflect the structural complexity of sesterterpenoids but also suggest that there is some room for improvement. It may be worth revisiting some of the classic targets armed with a new set of reagents and growing confidence that reactions can be carried out with high chemoselectivity, thus avoiding protecting group operations. As new members of the sesterterpenoid family are discovered, and largely forgotten ones are unearthed, modern synthetic methods will continue to be developed and refined using this fascinating class of natural products.

\section{Acknowledgements}

The authors are grateful to the Fonds der Chemischen Industrie e. V. (Ph.D. Scholarship to D.T.H) and the Alexander von Hum boldt Stiftung (Post doctoral fellowship to R. W.) for financial support. We thank Sebastian Strych for proofreading the manuscript.

\section{References and notes}

1 For early examples of Komppa's work on camphor, see:: $(a)$ G. Komppa, Ber. Dtsch. Chem. Ges., 1903, 36, 4332 4335; (b) G. Komppa, Chem. Ber., 1909, 41, 44704474.

2 For reviews on the isolation of sesterterpenoids, see e.g.: (a) Y. Liu, L. Wang, J. H. Jung and S. Zhang, Nat. Prod. Rep., 2007, 24, 1401 1429; (b) J. R. Hanson, Nat. Prod. Rep., 1996, 13, 529 535; (c) J. R. Hanson, Nat. Prod. Rep., 1992, 9, 481 489; (d) J. R. Hanson, Nat. Prod. Rep., 1986, 3, 123 132; (e) J. R. Hanson, in Terpenoids and Steroids, ed. K. H. Orton, The Chemical Society, London, 1974, vol. 4, p. 171; (f) G. A. Cordell, Phytochemistry, 1974, 13, 23432364 .
3 For reviews on marine natural products, see e.g.: (a) J. W. Blunt, B. R. Copp, R. A. Keyzers, M. H. G. Munro and M. R. Prinsep, Nat. Prod. Rep., 2012, 29, 144 222; (b) J. W. Blunt, B. R. Copp, M. H. G. Munro, P. T. Northcope and M. R. Prinsep, Nat. Prod. Rep., 2011, 28, 196 268; (c) J. W. Blunt, B. R. Copp, M. H. G. Munro, P. T. Northcope and M. R. Prinsep, Nat. Prod. Rep., 2010, 27, 165 237; (d) J. W. Blunt, B. R. Copp, W. P. Hu, M. H. G. Munro, P. T. Northcote and M. R. Prinsep, Nat. Prod. Rep., 2009, 26, 170 244; (e) J. W. Blunt, B. R. Copp, W. P. Hu, M. H. G. Munro, P. T. Northcote and M. R. Prinsep, Nat. Prod. Rep., 2008, 25, 35 94; (f) J. W. Blunt, B. R. Copp, W. P. Hu, M. H. G. Munro and P. T. Northcope, Nat. Prod. Rep., 2007, 24, 31 86; (g) D. J. Faulkner, Nat. Prod. Rep., 2002, 19, 149 and further reviews in this series.

4 For a review on terpenes from marine derived fungi, see: R. Ebel, Mar. Drugs, 2010, 8, 23402368.

5 For a review on bioactive sester and triterpenes from marine sponges, see: S. S. Ebada, W. Lin and P. Proksch, Mar. Drugs, $2010,8,313346$.

6 For the isolation of okinonellin B, see: Y. Kato, N. Fusetani, S. Matsugaga and K. Hashimoto, Experientia, 1986, 42, 12991300.

7 For the synthesis of okinenollin B, see: W. D. Schmitz, N. B. Messerschmidt and D. Romo, J. Org. Chem., 1998, 63, 20582059.

8 Y. Noda, H. Hashimoto and T. Norizuki, Heterocycles, 2001, 55, 18391841.

9 For the isolation of idiadione and scalarolide, see: R. P. Walker, J. E. Thompson and D. J. Faulkner, J. Org. Chem., 1980, 45, 49764979.

10 (a) D. J. Faulkner, Tetrahedron Lett., 1973, 14, 3821 3822; (b) C. J. Barrow, J. W. Blunt, M. H. G. Munro and N. B. Perry, J. Nat. Prod., 1988, 51, 275281.

11 K. Takabe, H. Hashimoto, H. Sugimoto, M. Nomoto and H. Yoda, Tetrahedron: Asymmetry, 2004, 15, 909912.

12 For isolation and biological properties of palinurin, see: (a) G. Alfano, G. Cimino and S. De Stefano, Experientia, 1979, 35, 11361137 ; (b) K. A. El Sayed, A. M. S. Mayer, M. Kelly and T. Hamann, J. Org. Chem., 1999, 64, 92589260. 
13 For the synthesis of palinurin, see: M. Pérez, D. I. Pérez, A. Martínez, A. Castro, G. Gómez and Y. Fall, Chem. Commun., 2009,32523254

14 (a) R. Tschesche, F. X. Brock and I. Duphorn, Tetrahedron Lett., 1968, 9, 2905 2909; (b) R. Tschesche, F. X. Brock and I. Duphorn, Justus Liebigs Ann. Chem., 1968, 720, 58 70; (c) W. A. Slusarchyk and F. L. Weisenborn, Tetrahedron Lett., 1969, 10, 659662 .

15 For a mini review on the antibiotic function of moenomycin A, see: J. van Heijenoort, Glycobiology, 2001, 11, 25R 36R and references therein.

16 For the first total synthesis of moenomycin A, see: J. G. Taylor, Y. X. Li, M. Oberthur, W. Zhu and D. E. Kahne, J. Am. Chem. Soc., 2006, 128, 1508415085.

17 For a review on syntheses around the transglycosylation step in peptidoglycan biosynthesis including a detailed discussion on the syntheses of moenocinol and diumycinol, see: P. Welzel, Chem. Rev., 2005, 105, 46104660.

18 R. Tschesche and J. Reden, Justus Liebigs Ann. Chem., 1974, 1974, 853863.

19 P. A. Grieco, Y. Masaki and D. Boxler, J. Am. Chem. Soc., 1975, 97, 15971599.

20 (a) P. J. Kocienski, J. Org. Chem., 1980, 45, 2037 2039; (b) P. J. Kocienski and M. Todd, J. Chem. Soc., Perkin Trans. 1, 1983, 17771781.

21 R. M. Coates and M. W. Johnson, J. Org. Chem., 1980, 45, 2685 2697.

22 (a) D. Bottger and P. Welzel, Tetrahedron Lett., 1983, 24, 52015204 ; (b) U. Schuricht, L. Hennig, M. Findeisen, P. Welzel and D. Arigoni, Tetrahedron Lett., 2001, 42, 38353837.

23 M. C. Stumpp and R. R. Schmidt, Tetrahedron, 1986, 42, 59415948.

24 H. J. Huang and W. B. Yang, Tetrahedron Lett., 2007, 48, 1429 1433.

25 G. Hilt and J. Treutwein, Chem. Commun., 2009, 1395.

26 E. D. de Silva and P. J. Scheuer, Tetrahedron Lett., 1980, 21, 1611.

27 For an overview on the biochemistry of manoalide with related natural and unnatural structures, see: A. Soriente, M. De Rosa, A. Scettri, G. Sodano, M. Terencio, M. Payá and M. J. Alcaraz, Curr. Med. Chem., 1999, 6, 415431.

28 S. Katsumura, S. Fujiwara and S. Isoe, Tetrahedron Lett., 1985, 26, 58275830.

29 M. E. Garst, E. A. Tallman, J. N. Bonfiglo, D. Harcourt, E. B. Ljungwe and A. Tran, Tetrahedron Lett., 1986, 27, 45334536.

30 S. Katsamura, S. Fujiwara and S. Isoe, Tetrahedron Lett., 1988, 29, 11731176.

31 (a) P. Bury, G. Hareau, P. J. Kocienski and D. Dhanak, Tetrahedron, 1994, 50, 8793 8808; (b) A. Pommier and P. J. Kocienski, Chem. Commun., 1997, 11391140.

32 J. Coombs, E. Lattman and H. M. R. Hoffmann, Synthesis, 1998, 13671371

33 A. Soriente, M. De Rosa, A. Acipella, A. Scettri and G. Sodano, Tetrahedron: Asymmetry, 1999, 10, 44814484.

34 A. Pommier, V. Stepanenko, K. Jarowicki and P. J. Kocienski, J. Org. Chem., 2003, 68, 40084013.

35 For the isolation of luffariolide E, see: M. Tsuda, H. Shigemori, M. Ishibashi, T. Sasaki and J. Kobayashi, J. Org. Chem., 1993, 57, 35033507.

36 For the synthesis and structural reassignment of luffariolide E, see: G. Hareau Vittini, P. J. Kocienski and G. Reid, Synthesis, 1995, 10071013.

37 G. Hareau Vittini and P. J. Kocienski, Synlett, 1995, 893894.

38 (a) W. A. Slusarchyk, J. A. Osband and F. L. Weisenborn, J. Am. Chem. Soc., 1970, 92, 4486 4488; (b) W. A. Slusarchyk, J. A. Osband and F. L. Weisenborn, Tetrahedron, 1973, 29, 1465 1472.

39 See ref. 17 and references cited therein.

40 P. A. Grieco, Y. Masaki and D. Boxler, J. Org. Chem., 1975, 40, 22612263.

41 (a) P. J. Kocienski and M. Todd, J. Chem. Soc., Chem. Commun., 1982, 1078 1079; (b) P. J. Kocienski and M. Todd, J. Chem. Soc., Perkin Trans. 1, 1983, 17831789.

42 For the isolation of ceriferol and related sesterterpenoids, see: $(a)$ F. Miyamoto, H. Naoki, T. Takemoto and Y. Naya, Tetrahedron, 1979, 35, 1913 1917; (b) T. Kusumi, T. Kinoshita, K. Fujita and H. Kakisawa, Chem. Lett., 1979, 1129 1132; (c) F. Miyamoto,
H. Naoki, Y. Naya and K. Nakanishi, Tetrahedron, 1980, 36, 3481 3487; (d) Y. Naya, F. Miyamoto, K. Kinoshita, T. Kusumi, H. Kakisawa and K. Nakanishi, Chem. Lett., 1980, 883 886; (e) P. K. Pawlak, M. S. Tempest, T. Iwashita, K. Nakanishi and Y. Naya, Chem. Lett., 1983, 10691072.

43 S. Fujiwara, M. Aoki, T. Uyehara and T. Kato, Tetrahedron Lett., 1984, 25, 30033006.

44 (a) M. Kodama, Y. Shiobara, H. Sumimoto, K. Fukuzumi, H. Minami and Y. Miyamoto, Tetrahedron Lett., 1986, 27, 2157 2160; (b) M. Kodama, Y. Shiobara, H. Sumitomo, K. Fukuzumi, H. Minami and Y. Miyamoto, J. Org. Chem., 1988, 53, 14371441.

45 Y. Ikeda, M. Aoki, T. Uyehara, T. Kato and T. Yokoyoma, Chem. Lett., 1983, 10731076.

46 For the isolation and biological properties of terpestacin, see: $(a)$ M. Oka, S. Iimura, O. Tenmyo, S. Yosuke, M. Sugawara, N. Okhusa, H. Yamamoto, K. Kawano, S. L. Hu, Y. Fukagawa and T. Oki, J. Antibiot., 1993, 46, 367 373; (b) S. Iimura, M. Osa, Y. Narita, M. Konishi, H. Kakisawa, Q. Gao and T. Oki, Tetrahedron Lett., 1993, 34, 493 496; (c) M. Oka, S. Iimura, Y. Narita, T. Furumai, M. Konishi, T. Oki, Q. Gao and H. Kakisawa, J. Org. Chem., 1993, 58, 18751881.

47 For synthetic studies toward terpestacin, see: (a) K. Takeda, A. Nakajima and E. Yoshii, Synlett, 1995, 249 250; (b) M. P. Mermet Mouttet, K. Gabriel and D. Heissler, Tetrahedron Lett., 1999, 40, 843846.

48 T. J. Maimone and P. S. Baran, Nat. Chem. Biol., 2007, 3, 396407.

49 K. Tatsuta, N. Masuda and H. Nishida, Tetrahedron Lett., 1998, 39, 8386.

50 K. Tatsuta and N. Masuda, J. Antibiot., 1998, 51, 602606.

51 A. G. Myers, M. Siu and F. Ren, J. Am. Chem. Soc., 2002, 124, 42304232.

52 (a) J. Chan and T. F. Jamison, J. Am. Chem. Soc., 2003, 125, 11514 11515; (b) J. Chan and T. F. Jamison, J. Am. Chem. Soc., 2004, 126, 1068210691.

53 (a) B. M. Trost, G. Dong and J. A. Vance, J. Am. Chem. Soc., 2007, 129, 4540 4541; (b) B. M. Trost, G. Dong and J. A. Vance, Chem. Eur. J., 2010, 16, 62656277.

54 (a) G. O. Berger and M. A. Tius, J. Org. Chem., 2007, 72, 6473 6480; (b) for a previous communication dealing with the stereocontrolled synthesis of the cyclopentenone core structure of terpestacin, see: G. O. Berger and M. A. Tius, Org. Lett., 2005, 7, 50115013.

55 For the isolation and structural assignment of fusaproliferin, see: $(a)$ G. Randazzo, V. Fogliano, A. Ritieni, L. Mannina, E. Rossi, A. Scarallo and A. L. Segre, Tetrahedron, 1993, 49, 10883 10896; (b) C. Manetti, V. Fogliano, A. Ritieni, A. Santini, G. Randazzo, A. Logrieco, L. Mannina and A. L. Segre, Struct. Chem., 1995, 6, 183 189; (c) A. Santini, A. Ritieni, V. Fogliano, G. Randazzo, L. Mannina, A. Logrieco and E. Benedetti, J. Nat. Prod., 1996, 59, 109112.

56 For the isolation and first biological activity tests of dysidiolide, see: G. P. Gunasekera, P. J. McCarthy, M. Kelly Borges, E. Lobkovsky and J. Clardy, J. Am. Chem. Soc., 1996, 118, 87598760.

57 For further biological studies on dysidiolide and structural analogues, see e.g.: (a) J. L. Blanchard, D. M. Espstein, M. D. Boisclair, J. Rudolph and K. Pal, Bioorg. Med. Chem. Lett., 1999, 9, 2537 2538; (b) M. Takahasi, K. Dodo, Y. Sugimoto, Y. Aoyagi, Y. Yamada, Y. Hashimoto and R. Shirai, Bioorg. Med. Chem. Lett., 2000, 10, 2571 2574; (c) R. Shimazawa, T. Suzuki, K. Dodo and R. Shirai, Bioorg. Med. Chem. Lett., 2004, 14, 3291 3294; (d) R. Shimazawa, M. Gochomori and R. Shirai, Bioorg. Med. Chem. Lett., 2004, 14, 43394342.

58 E. J. Corey and B. E. Roberts, J. Am. Chem. Soc., 1997, 119, 12425 12431.

59 S. R. Magnuson, L. Sepp Lorenzino, N. Rosen and S. J. Danishefsky, J. Am. Chem. Soc., 1998, 120, 16151616.

60 D. Memeke and C. J. Forsyth, Org. Lett., 2000, 2, 31773179.

61 J. d'Angelo, D. Desmaele, F. Dumas and A. Guingant, Tetrahedron: Asymmetry, 1992, 3, 459505.

62 J. Boukouvalas, Y. X. Cheng and J. Robichaud, J. Org. Chem., 1998, 63, 228229.

63 M. Takahashi, K. Dodo, Y. Hashimoto and R. Shirai, Tetrahedron Lett., 2000, 41, 21112114.

64 M. E. Jung and N. Nishimura, Org. Lett., 2001, 3, 21132115.

65 D. Brohm and H. Waldmann, Tetrahedron Lett., 1998, 39, 3995 3998 . 
66 (a) D. Brohm, S. Metzger, A. Bhargava, O. Muller, F. Lieb and H. Waldmann, Angew. Chem., Int. Ed., 2002, 41, 307 311; (b) D. Brohm, N. Philippe, S. Metzger, A. Bhargava, O. Muller, F. Lieb and H. Waldmann, J. Am. Chem. Soc., 2002, 124, 13171 13178.

67 H. Miyaoka, Y. Kajiwara and Y. Yamada, Tetrahedron Lett., 2000, 41, 911914 .

68 H. Miyaoka, Y. Kajiwara, Y. Hara and Y. Yamada, J. Org. Chem., 2001, 66, 14291435.

69 K. P. Kaliappan and P. Gowrisankar, Tetrahedron Lett., 2004, 45, 82078209.

70 E. Piers, S. Caillé and G. Chen, Org. Lett., 2000, 2, 24832486.

71 R. Paczkowski, C. Maichle Mossmer and M. E. Maier, Org. Lett., 2000, 2, 39673969.

72 A. Fontana, M. L. Ciavatta and G. Cimino, J. Org. Chem., 1998, 63, 28452849

73 (a) I. S. Marcos, A. B. Pedrero, M. J. Sexmero, D. Díez, P. Basabe, F. A. Hernández, H. B. Broughton and J. G. Urones, Synlett, 2002, 105 109; (b) I. S. Marcos, A. B. Pedrero, M. J. Sexmero, D. Diez, P. Basabe, N. García, R. F. Moro, H. B. Broughton, F. Mollinedo and J. G. Urones, J. Org. Chem., 2003, 68, 74967504.

74 H. Miyaoka, M. Yamanishi and Y. Yamada, J. Org. Chem., 2003, 68, 34763479.

75 M. Nakagawa, Y. Ishihama, Y. Hamamoto and M. Endo, Chem. Abstr., 1987, 106, 96126b.

76 H. Hagiwara and H. Uda, J. Chem. Soc., Perkin Trans. 1, 1991, 18031807.

77 E. Piers and J. S. M. Wai, J. Chem. Soc., Chem. Commun., 1987, 13421343.

78 B. Sullivan and D. J. Faulkner, Tetrahedron Lett., 1982, 23, 907910.

79 A. K. Cheung and M. L. Snapper, J. Am. Chem. Soc., 2002, 124, 1158411585.

80 (a) S. De Rosa, A. Crispino, A. De Giulio, C. Iodice, R. Pronzato and V. Zabodnik, J. Nat. Prod., 1995, 58, 1776 1780; (b) A. Soriente, A. Crispino, M. De Rosa, S. De Rosa, A. Scettri, G. Scognamiglio, R. Villano and G. Sodano, Eur. J. Org. Chem., 2000, 2000, 947953 .

81 P. Basabe, O. Boderam, I. S. Marcos, D. Díez, A. Blanco, M. De Román and J. C. Urones, J. Org. Chem., 2009, 74, 77507754.

82 B. C. M. Potes, R. J. Capon and D. J. Faulkner, J. Org. Chem., 1992, 57, 29652967.

83 W. Hofheinz and P. Schonholzer, Helv. Chim. Acta, 1977, 60, 1367 1370.

84 R. P. Gregson and D. Ouvrier, J. Nat. Prod., 1982, 45, 412414.

85 For a more detailed discussion on the synthesis of ircinianin as part of a review on synthetic strategies toward naturally occurring tetronic acids, see: A. L. Zografos and D. Georgiadis, Synthesis, 2006, 31573188

86 K. Takeda, M. a. Sato and E. Yoshii, Tetrahedron Lett., 1986, 27, 39033906.

87 J. Uenishi, R. Kawahama and O. Yonemitsu, J. Org. Chem., 1997, 62, 16911701

88 A. Fontana, I. Fakhr, E. Mollo and G. Cimino, Tetrahedron: Asymmetry, 1999, 10, 38693872

89 (a) S. H. Luo, Q. Luo, X. M. Niu, M. J. Xie, X. Zhao, B. Schneider, J. Gershenzon and S. H. Li, Angew. Chem., Int. Ed., 2010, 49, 4471 4475; (b) S. H. Luo, L. H. Weng, M. J. Xie, X. N. Li, J. Hua, X. Zhao and S. H. Li, Org. Lett., 2011, 13, 18641867.

90 J. Xie, Y. Ma and D. A. Horne, J. Org. Chem., 2011, 76, 6169 6176.

91 G. Brochere Ferreol and J. Polonsky, Bull. Soc. Chim. Fr., 1960 , 963967.

92 For further structural assignment of gascardic acid, see: R. Scartazzini, Ph.D. Thesis, ETH Zurich, 1966.

93 For further synthetic approaches to install the carbon skeleton of gascardic acid, see: (a) U. Sanyal, P. K. Ghosal and P. C. Dutta, Tetrahedron Lett., 1978, 19, 2187 2190; (b) G. Bérubé and A. G. Fallis, Tetrahedron Lett., 1989, 30, 4045 4048; (c) G. Bérubé and A. G. Fallis, Can. J. Chem., 1991, 69, 7783.

94 R. K. Boeckman, Jr., D. M. Blum and S. D. Arthur, J. Am. Chem. Soc., 1979, 101, 50605062.

95 R. K. Boeckman, Jr., D. M. Blum, E. V. Arnold and J. Clardy, Tetrahedron Lett., 1979, 20, 46094612.

96 For the isolation and structure determination of ophiobolin A, see: (a) K. Ishibashi and R. Nakamura, J. Agric. Chem. Soc. Jpn.,
1958, 32, 739 744; (b) S. Nozoe, M. Morisaki, K. Tsuda, Y. Iitaka, N. Tokahashi, S. Tamura, K. Ishibashi and M. Shirasaka, J. Am. Chem. Soc., 1965, 87, 49684970.

97 For a review on the biology of ophiobolins, see: T. K. Au, W. S. H. Chick and P. C. Leung, Life Sci., 2000, 67, 733742.

98 For synthetic studies toward the common carbon skeleton of the ophiobolins and ceroplastins, see: (a) W. G. Dauben and D. J. Hart, J. Org. Chem., 1977, 42, 922 923; (b) T. K. Das, P. C. Dutta, G. Kartha and J. M. Bernassau, J. Chem. Soc., Perkin Trans. 1, 1977, 1287 1295; (c) R. K. Boeckman, Jr., J. P. Bershas, J. Clardy and B. Solheim, J. Org. Chem., 1977, 42, 3630 3633; (d) L. A. Paquette, J. A. Colabret and D. R. Andrews, J. Org. Chem., 1983, 48, 1147 1149; (e) L. A. Paquette, J. A. Colabret and D. R. Andrews, J. Org. Chem., 1985, 50, 201 205; $(f)$ R. M. Coates, J. W. Muskopf and P. A. Senter, J. Org. Chem., 1985, 50, 3541 3557; $(g)$ G. Mehta and N. Krishnamurthy, J. Chem. Soc., Chem. Commun., 1986, 1319 1321; (h) M. Umehara, S. Hishida, S. Okumoto, S. Ohba, M. Ito and S. Saito, Bull. Chem. Soc. Jpn., 1987, 60, 4474 4476; (i) J. H. Rigby and C. Senanayake, J. Org. Chem., 1987, 52, 4634 4635; (j) W. G. Dauben and A. M. Warshawsky, J. Org. Chem., 1990, 55, 3075 3087; (k) L. A. Paquette, S. Liang and P. Galatsis, Synlett, 1990, 663 665; (l) B. B. Snider and K. Yang, J. Org. Chem., 1992, 57, 3615 3626; (m) J. H. Rigby, T. McGuire, C. Senanayake and K. Khemani, J. Chem. Soc., Perkin Trans. 1, 1994, 3449 3457; (n) L. A. Paquette, S. Liang and H. L. Wang, $J$. Org. Chem., 1996, 61, 3268 3279; (o) A. J. Blake, A. J. Highton, T. N. Majid and N. S. Simpkins, Org. Lett., 1999, 1, 1787 1789; (p) K. F. McGee, Jr., T. H. Al Tel and S. M. Sieburth, Synthesis, 2001, 1185 1196; $(q)$ P. C. K. Lo and M. L. Snapper, Org. Lett., 2001, 3, 2819 2821; (r) P. K. Ruprah, J. P. Cros, J. E. Pease, W. G. Whittingham and J. M. J. Williams, Eur. J. Org. Chem., 2002, 2002, 3145 3152; (s) B. Salem and J. Suffert, Angew. Chem., Int. Ed., 2004, 43, 2826 2830; $(t)$ K. Michalak, M. Michalak and J. Wicha, Molecules, 2005, 10, 1084 1100; (u) K. Michalak, M. Michalak and J. Wicha, Tetrahedron Lett., 2005, 46, 1149 1153; (v) C. Bour, G. Blond, B. Salem and J. Suffert, Tetrahedron, 2006, 62, 10567 10581; (w) M. Michalak, K. Michalak, Z. Urbanczyk Lipkowska and J. Wicha, J. Org. Chem., 2011, 76, 74977509 .

99 S. Nozoe, K. Hirai and K. Tsuda, Tetrahedron Lett., 1966, 7, 2211 2216.

100 M. Rowley, M. Tsukamoto and Y. Kishi, J. Am. Chem. Soc., 1989, 111, 27352737.

101 K. Tsuna, N. Noguchi and M. Nakada, Angew. Chem., Int. Ed., 2011, 50, 94529455.

102 For reviews on the synthesis of cyclooctanoid systems including discussions of the methods used within the synthesis of ophiobolin C, ceroplastol I and ceroplastol II as well as of some approaches toward the ophiobolin/ceroplastin skeleton, ref. 98, see: (a) G. Mehta and V. Singh, Chem. Rev., 1999, 99, 881 930; (b) N. A. Petasis and M. A. Patane, Tetrahedron, 1992, 48, 5757 5821.

103 Kishi installed the two stereogenic centers within the first four steps of this sequence following a procedure described previously, see: J. H. Hutchinson, T. Money and S. E. Piper, Can. J. Chem., 1986, 64, 854860 .

104 For Kishi's successful synthesis of the building block $\mathbf{1 5 3}$ as well as the ophionbolin core lacking the side chain, see: M. Rowley and Y. Kishi, Tetrahedron Lett., 1988, 29, 49094912.

105 Nakada's asymmetric synthesis of the spirocyclic portion of ophiobolin A has been communicated previously, see: N. Noguchi and M. Nakada, Org. Lett., 2006, 8, 20392042.

106 In the communication of the disclosed synthesis, ref. 101, Nakada noted that carefully optimized, but not further specified reaction conditions increased the yield of this cyclization to $68 \%$.

107 (a) T. Ríos and F. Colunga, Chem. Ind. (London), 1965, 1184 1185; (b) Y. Itake, I. Watanabe, I. T. Harrison and S. Harrison, J. Am. Chem. Soc., 1968, 90, 10921093.

108 T. Ríos and L. Quijano, Tetrahedron Lett., 1969, 10, 13171318.

109 T. Ríos and F. Gómez, Tetrahedron Lett., 1969, 10, 29292930.

110 R. K. Boeckman, Jr., A. Arvantis and M. E. Voss, J. Am. Chem. Soc., 1989, 111, 27372739.

111 L. A. Paquette, T. Z. Wang and N. H. Vo, J. Am. Chem. Soc., 1993, 115,16761683 . 
112 For Piers' useful protocol to conduct a methylenecyclopentane annulation by a cuprate addition/alkylation sequence, see: E. Piers and V. Karunaratne, J. Chem. Soc., Chem. Commun., 1983, 935 936.

113 (a) N. Kato, H. Kataoka, S. Ohbuchi, S. Tanaka and H. Takeshita, J. Chem. Soc., Chem. Commun., 1988, 354 356; (b) N. Kato, H. Takeshita, H. Kataoka, S. Ohbuchi and S. Tanaka, J. Chem. Soc., Perkin Trans. 1, 1989, 165174

114 For the preparation of building blocks as well as Kato's synthesis of the carbon skeleton of ceroplastol II, see: (a) H. Takeshita, T. Hatsui, N. Kato, T. Madsuda and T. Tagoshi, Chem. Lett., 1982, 1153 1156; (b) N. Kato, S. Tanka and H. Takeshita, Chem. Lett., 1986, 1989 1992; (c) N. Kato, K. Nakanishi and H. Takeshita, Bull. Chem. Soc. Jpn., 1986, 59, 11091123.

115 N. Ungur and V. Kulciţki, Tetrahedron, 2009, 65, 38153828.

116 For the isolation of hyrtiosal, see: K. Iguchi, Y. Shimada and Y. Yamada, J. Org. Chem., 1992, 57, 522524.

117 For syntheses of hyrtiosal, see: (a) P. Basabe, A. Diego, D. Díez, I. S. Marcos and J. G. Urones, Synlett, 2000, 1807 1809; (b) I. Lunardi, G. M. P. Santiago and P. Imamura, Tetrahedron Lett., 2002, 43, 36093611.

118 L. Ferreiro Mederos, S. Lanners, H. Henchiri, A. Fekih and G. Hanquet, Nat. Prod. Res., 2009, 23, 256263.

119 A. Randazzo, C. Debitus, L. Minale, P. García Pastor, M. J. Alcaraz, M. Payá and L. Gomez Paloma, J. Nat. Prod., 1998, 61, 571575 .

120 N. Kawahara, M. Nozawa, A. Kurata, T. Hakamatsuka, S. Sekita and M. Satake, Chem. Pharm. Bull., 1999, 47, 13441345.

121 (a) M. S. Wilson and G. R. Dake, Org. Lett., 2001, 3, 2041 2044; (b) M. S. Wilson, J. C. S. Woo and G. R. Dake, J. Org. Chem., 2006, 71, 42374245.

122 M. S. Tempesta, Z. Iwashita, F. Miyamoto, K. Yoshihara and Y. Naya, J. Chem. Soc., Chem. Commun., 1983, 11821183.

123 (a) M. A. Poupart and L. A. Paquette, Tetrahedron Lett., 1988, 29, 269 272; (b) L. A. Paquette and M. A. Poupart, J. Org. Chem., 1993, 58, 4245 4253; (c) L. A. Paquette, G. Y. Lasalle and C. J. Lovely, J. Org. Chem., 1993, 58, 4254 4261; (d) L. A. Paquette, D. N. Deaton, Y. Endo and M. A. Poupart, $J$ Org. Chem., 1993, 58, 4262 4273; (e) L. A. Paquette, S. Hormuth and C. J. Lovely, J. Org. Chem., 1995, 60, 48134821.

124 L. A. Paquette and B. Y. Dyck, J. Am. Chem. Soc., 1998, 120, 5953 5960.

125 For a recent review on isolated structures and biological properties of scalaranes, see: M. A. González, Curr. Bioact. Compd., 2010, 6 , 178206.

126 N. Ungur and V. Kulciţki, Phytochem. Rev., 2004, 3, 401415.

127 For the synthesis of scalarolide, see: (a) X. J. Meng, Y. Liu, W. Y. Fan, B. Hu, W. Du and W. D. Deng, Tetrahedron Lett., 2009, 50, 4983 4985; (b) W. Y. Fan, Z. L. Wang, Z. G. Zhang, H. C. Li and W. P. Deng, Tetrahedron, 2011, 67, 55965603.

128 For the isolation and biological properties of sestertatins, see: $(a)$ G. R. Pettit, R. Tan, N. Melody, Z. A. Cichacz, D. L. Herald, M. S. Hoard, R. K. Pettit and J. C. Chapuis, Bioorg. Med. Chem. Lett., 1998, 8, 2093 2098; (b) G. R. Pettit, R. Tan and Z. A. Cichacz, J. Nat. Prod., 2005, 68, 12531255.

129 For the synthesis of sestertatins 4 and 5, see: W. Y. Fan, Z. L. Wang, H. C. Li, J. S. Fossey and W. P. Deng, Chem. Commun., 2011, 47, 29612963.

130 For the isolation of 16 deacetoxy 12 epi scalarafuran acetate, see: A. De Giulio, S. De Rosa, G. Di Vincenzo and N. Zavodnik, J. Nat. Prod., 1989, 52, 12581262.

131 For syntheses of 16 deacetoxy 12 epi scalarafuran acetate, see: $(a)$ X. B. Chen, Q. J. Yuan, J. Wang, S. K. Hua, J. Ren and B. B. Zeng, J. Org. Chem., 2011, 76, 7216 7221; (b) Z. L. Wang, Z. G. Zhang, H. C. Li and W. P. Deng, Tetrahedron, 2011, 67, 69396964.

132 H. N. Kamel, Y. B. Kim, J. M. Rimoldi, F. R. Fronczek, D. Ferreira and M. Slattery, J. Nat. Prod., 2009, 72, 14921496.

133 (a) R. Kazlauskas, P. T. Murphy, R. Q. Quinn and R. J. Wells, Tetrahedron Lett., 1976, 17, 2631 2634; (b) Y. Kashman and A. Rudi, Tetrahedron, 1977, 33, 2997 2998; (c) A. D. Patil, J. W. Westley, P. W. Baures and D. S. Eggleston, Acta Crystallogr., Sect. C: Cryst. Struct. Commun., 1991, C47, 1250 $1253 ;(d)$ the absolute configuration of heteronemin as depicted in
Scheme 24 is thus far only assigned tentatively as $(\mathrm{)}$ ) based on stereospecificity of biosynthetic pathways and comparison with related natural products, see: J. Anderson Clement, Ph.D. Thesis, Virginia Polytechnic Institute and State University, 2005.

134 E. Piers and S. L. Boulet, Tetrahedron Lett., 1997, 38, 88158818.

135 (a) O. D. Hensens, D. Zink, J. M. Williamson, V. J. Lotti, R. S. L. Chang and M. A. Goetz, J. Org. Chem., 1991, 56, 3399 3403; (b) H. Fujimoto, E. Nakamura, E. Okuyama and M. Ishibashi, Chem. Pharm. Bull., 2000, 48, 14361441.

136 S. D. Walker, Ph.D. thesis, University of British Columbia, 2002.

137 For the isolation of variecolol and variecolactone, see: H. Takahashi, T. Hosoe, K. Nozawa and K. Kawai, J. Nat. Prod., 1999, 62, 1712 1713.

138 G. A. Molander, M. S. Quirmbach, L. F. Silva, Jr., K. C. Spencer and J. Balsells, Org. Lett., 2001, 3, 22572260.

139 K. Araki, K. Saito, H. Arimoto and D. Uemura, Angew. Chem., Int. $E d$, 2004, 43, 8184 .

140 For the isolation and biological properties of mangicols and neomangicols, see: (a) M. K. Renner, P. R. Jensen and W. Fenical, J. Org. Chem., 1998, 63, 8346 8354; (b) M. K. Renner, P. R. Jensen and W. Fenical, J. Org. Chem., 2000, 65, 48434852.

141 (a) S. Pichlmair, M. de Lera Ruiz, K. Basu and L. A. Paquette, Tetrahedron, 2006, 62, 5178 5194; (b) S. Pichlmair, M. de Lera Ruiz, I. Vilotijevic and L. A. Paquette, Tetrahedron, 2006, 62, 57915802

142 J. L. Wood, B. G. Pujanauski and R. Sarpong, Org. Lett., 2009, 11, 31283131 .

143 Y. Wang, M. Dreyfuss, M. Ponelle, L. Oberer and H. Riezman, Tetrahedron, 1998, 54, 64156426

144 R. Mizutani, K. Nakashima, Y. Saito, M. Sono and M. Tori, Tetrahedron Lett., 2009, 50, 22252227.

145 For isolation and structure determination of retigeranic acids, see: (a) P. S. Rao, K. G. Sarma and T. R. Seshadri, Curr. Sci., 1965, 34, 9 11; (b) M. Kaneda, R. Takahashi, Y. Iiataka and S. Shibata, Tetrahedron Lett., 1972, 13, 4609 4611; (c) M. Kaneda, R. Takahashi and S. Shibata, Acta Crystallogr., Sect. B: Struct. Crystallogr. Cryst. Chem., 1974, B30, 358 364; (d) H. Sugawara, A. Kasuya, Y. Iitaka and S. Shibata, Chem. Pharm. Bull., 1991, 39, 30513054

146 E. J. Corey, M. C. Desai and T. A. Engler, J. Am. Chem. Soc., 1985, 107, 43394341.

147 From here on we refer to retigeranic acid A as retigeranic acid.

148 For an excellent, detailed discussion on the syntheses of retigeranic acid, see: T. Hudlicky and J. W. Reed, The Way of Synthesis: Evolution of Design and Methods for Natural Products, Wiley VCH, Weinheim, 1st edn, 2007, page 392.

149 For a brief discussion on the syntheses of retigeranic acid as part of a review on polyquinanes, see: G. Mehta and A. Srikrishna, Chem. Rev., 1997, 97, 671720 .

150 (a) L. A. Paquette, J. Wright, G. J. Drtina and R. A. Roberts, J. Org. Chem., 1987, 52, 2960 2962; (b) J. Wright, G. J. Drtina, R. A. Roberts and L. A. Paquette, J. Am. Chem. Soc., 1988, 110, 58065817.

151 (a) T. Hudlicky, L. Radesca Kwart, L. q. Li and T. Bryant, Tetrahedron Lett., 1988, 29, 3283 3286; (b) T. Hudlicky, A. Fleming and L. Radesca, J. Am. Chem. Soc., 1989, 111, 66916707.

152 P. A. Wender and S. K. Singh, Tetrahedron Lett., 1990, 31, 2517 2520.

153 (a) B. B. Snider, D. J. Rodini and J. van Straten, J. Am. Chem. Soc., 1980, 102, 5872 5880; (b) E. J. Corey and T. A. Engler, Tetrahedron Lett., 1984, 25, 149152.

154 For a review on the synthesis of trans hydrindane systems, see: P. Jankowski, S. Marzak and J. Wicha, Tetrahedron, 1998, 54, 1207112150

155 For Paquette's previous communication on the synthesis of the triquinane portion, see: L. A. Paquette, R. A. Roberts and G. J. Drtina, J. Am. Chem. Soc., 1984, 106, 66906693.

156 This ring contraction has been described previously, see e.g.: J. N. Marx and L. R. Norman, J. Org. Chem., 1975, 40, 16021606.

157 Paquette's synthesis of alcohol 261 was optimized from a procedure reported by Newhall, see: W. R. Newhall, J. Org. Chem., 1958, 23, 12741276.

158 Hudlicky optimized a previously reported racemic synthesis of trans hydrindane 271, see: S. K. Attah Paku, F. Chau, V. K. Yadav and A. G. Fallis, J. Org. Chem., 1985, 50, 34183419. 